\title{
MAPPING POTENTIAL BLANDING'S TURTLE HABITAT USING AERIAL ORTHOPHOTOGRAPHIC IMAGERY AND OBJECT BASED CLASSIFICATION
}

\author{
By \\ Rebecca Barker, B.A (Hons.)
}

\begin{abstract}
A thesis submitted to
the Faculty of Graduate Studies and Research

in partial fulfillment of the requirements

for the degree of Master of Science
\end{abstract}

Department of Geography and Environmental Studies

Carleton University

Ottawa, Ontario, Canada

May 2010

(C) 2010 


\section{Library and Archives}

Canada

Published Heritage

Branch

395 Wellington Street Ottawa ON K1A ON4

Canada
Bibliothèque et

Archives Canada

Direction du

Patrimoine de l'édition

395 , rue Wellington

Ottawa ON K1A ON4

Canada
Your file Votre référence

ISBN: 978-0-494-68739-0

Our file Notre référence

ISBN: 978-0-494-68739-0
NOTICE:

The author has granted a nonexclusive license allowing Library and Archives Canada to reproduce, publish, archive, preserve, conserve, communicate to the public by telecommunication or on the Internet, loan, distribute and sell theses worldwide, for commercial or noncommercial purposes, in microform, paper, electronic and/or any other formats.

The author retains copyright ownership and moral rights in this thesis. Neither the thesis nor substantial extracts from it may be printed or otherwise reproduced without the author's permission.

\begin{abstract}
AVIS:
L'auteur a accordé une licence non exclusive permettant à la Bibliothèque et Archives Canada de reproduire, publier, archiver, sauvegarder, conserver, transmettre au public par télécommunication ou par l'Internet, prêter, distribuer et vendre des thèses partout dans le monde, à des fins commerciales ou autres, sur support microforme, papier, électronique et/ou autres formats.
\end{abstract}

L'auteur conserve la propriété du droit d'auteur et des droits moraux qui protège cette thèse. $\mathrm{Ni}$ la thèse ni des extraits substantiels de celle-ci ne doivent être imprimés ou autrement reproduits sans son autorisation.
In compliance with the Canadian Privacy Act some supporting forms may have been removed from this thesis.

While these forms may be included in the document page count, their removal does not represent any loss of content from the thesis.
Conformément à la loi canadienne sur la protection de la vie privée, quelques formulaires secondaires ont été enlevés de cette thèse.

Bien que ces formulaires aient inclus dans la pagination, il n'y aura aucun contenu manquant. 


\begin{abstract}
Blanding's turtle (Emydoidea blandingii) is a threatened species in southern Québec that is being inventoried to determine abundance and potential habitat by the Québec Ministry of Natural Resources and Wildlife. In collaboration with that program and using spring leaf-off aerial orthophotos of Gatineau Park, attributes associated with known habitat criteria were analyzed: wetlands with open water, vegetation mounds for camouflage and thermoregulation, and logs for spring sun-basking. Pixel-based classification to separate wetlands from other land cover types was followed by object-based segmentation and rule-based classification of within-wetland vegetation and logs. Classifications integrated several image characteristics including texture, context, shape, area and spectral attributes. Field data and visual interpretation showed the accuracies of wetland and within wetland habitat feature classifications to be over $82.5 \%$. The wetland classification results were used to develop a ranked potential habitat suitability map for Blanding's turtle that can be employed in conservation planning and management.
\end{abstract}




\section{ACKNOWLEDGMENTS}

Thank you to all who encouraged me to follow through with my original degree and onto my Masters.

Many warm thanks to Mom (Pat Barker) and Dad (Jim Barker-post humous) for always supporting me and who I think gave me my passion for the environment. Thanks to my brother Matt Barker, who encouraged me from a younger age to follow through with university and always follow my interests. Thanks Adam for always bringing a smile to my face and being supportive. A world of thanks to Matt Boyer, my fiancé, for putting up with years of my distraction to this research, yet always remaining supportive.

Many thanks to Doug King for his advice, guidance and encouragement throughout this research and for his compassion during my times of illness and patience during discouraging processing problems. The research funding necessary to accomplish this research was provided by an NSERC Discovery grant to D. King.

Field support was provided by the Carleton University Geomatics and Landscape Ecology Research Laboratory through the Canada Foundation for Innovation and other funding. Thanks to Dan Bert for assisting in computer issues. A huge thank you to Valerie Torontow for assisting me in field work. That summer will always be memorable and I hope we get to enjoy the outdoors together in the future.

The National Capital Commission provided access to the Gatineau Park aerial orthophotos and other support that was vital to this research.

Laura Dingle Robertson was very appreciated for her introduction to the 'sometimes' wonderful Definiens software and conversations discussing concepts and testing.

Thank you Dave Hackett for your long time assistance and support. 


\section{TABLE OF CONTENTS}

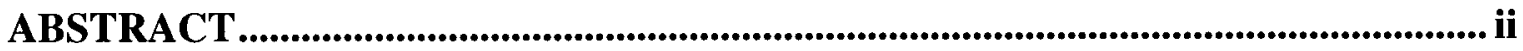

ACKNOWLEDGMENTS ..................................................................................................... iii

TABLE OF CONTENTS …...................................................................................................... iv

LIST OF TABLES ..................................................................................................................... vi

LIST OF FIGURES ........................................................................................................... vii

1.0 INTRODUCTION.................................................................................................................. 1

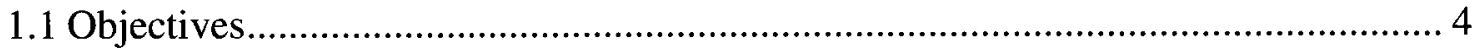

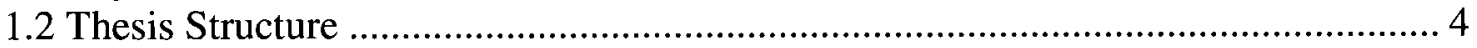

2.0 BACKGROUND ................................................................................................................ 6

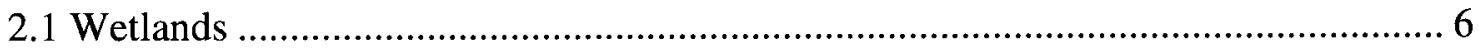

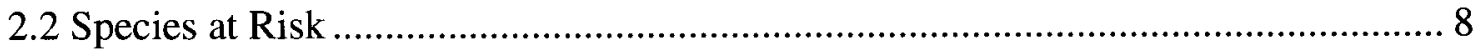

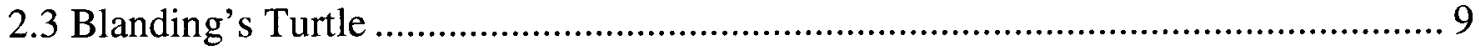

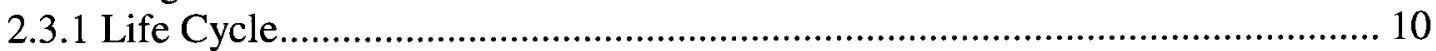

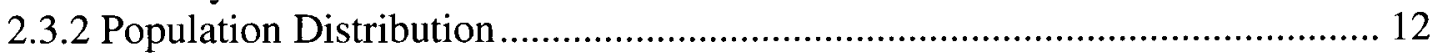

2.3.2 Threats to Blanding's Turtles....................................................................... 21

2.4 Habitat Suitability Modelling and Mapping ............................................................ 22

2.4.1 Common Approaches to Habitat Modelling and Mapping.............................. 22

2.4.2 Previous Research using Remote Sensing and Habitat Suitability Modelling

Relevant to this Research...................................................................................... 25

2.4.2.1 Wetland Mapping using Remote Sensing ................................................. 27

2.4.2.2 Habitat Mapping for Specific Species ........................................................ 31

2.4.3 Blanding's Turtle Habitat Suitability Mapping ………........................................... 33

2.5 Aspects of Remote Sensing Relevant to this Research........................................... 36

2.5.1 Object-based Segmentation and Classification................................................ 36

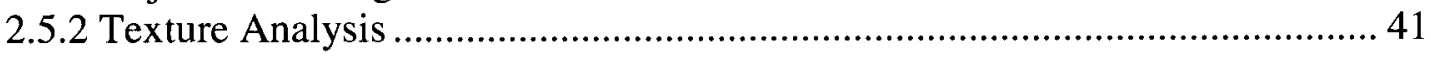

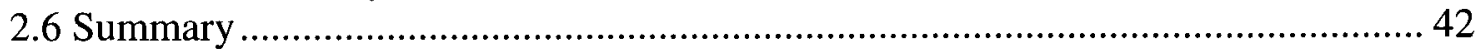

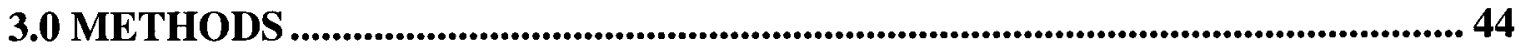

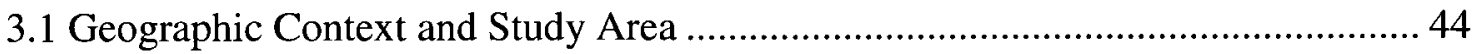

3.1.2 Selection of Study Area ............................................................................... 44

3.2 Field Site Selection and Data Acquisition ........................................................... 46

3.3 Acquisition, Processing and Classification of High Resolution Digital

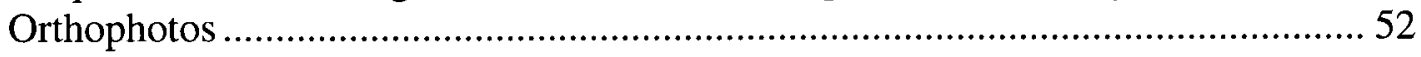

3.3.1 Image Acquisition and Mosaicking ……...................................................... 52

3.3.2 Selecting a Suitable Classification Approach ................................................ 53

3.3.3 Extraction of Spectral Information ............................................................. 55

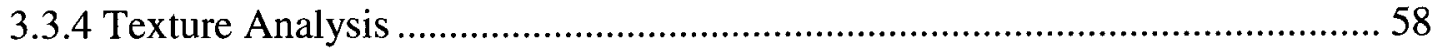

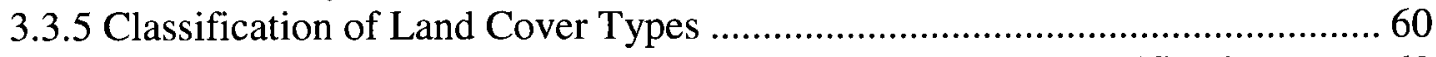

3.3.5.1 Supervised Classification (MLC) and Object-based Classification........... 60

3.4 Object-Based Segmentation and Classification of Wetlands and Wetland

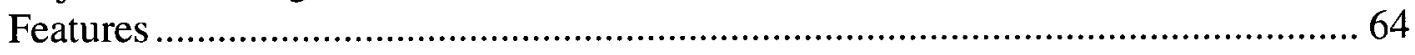

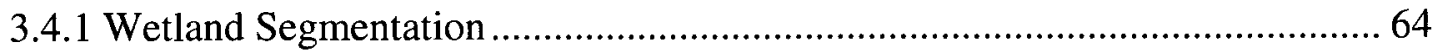


3.4.2 Within Wetland Log and Vegetation Segmentation .................................. 68

3.4.3 Classification of Wetlands and Within Wetland Objects ............................ 72

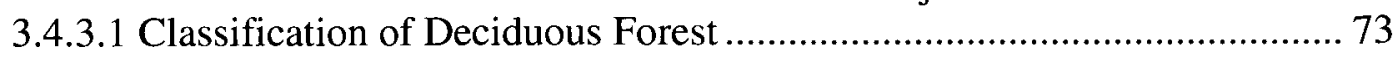

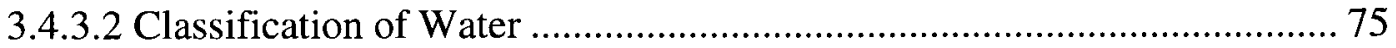

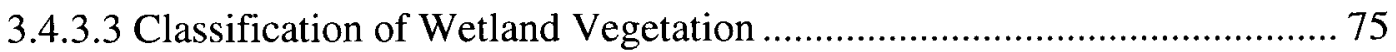

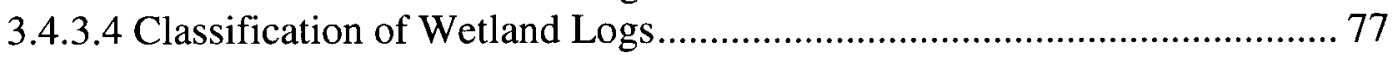

3.4.3.5 Classification of Linear, Road and Hydroline ................................... 77

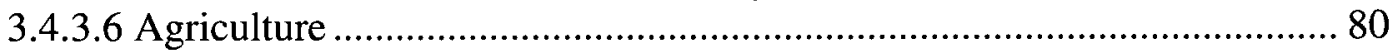

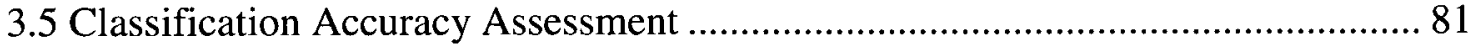

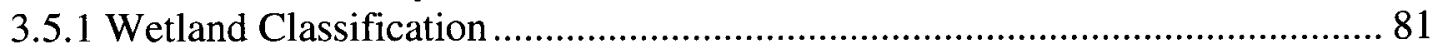

3.5.2 Wetland Attribute Classification Accuracy ............................................... 81

3.5.2.1 Classification of Wetland Vegetation, Logs and Water....................... 82

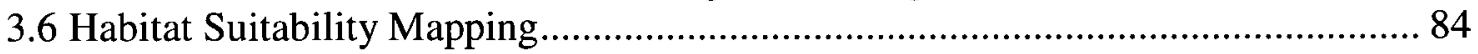

3.6.1 Merging Wetland Fragments, Associating Wetland Features to Individual Wetlands, and Extraction of Wetland Feature Metrics......................................... 84

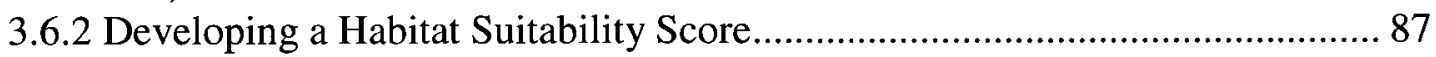

4.0 RESULTS

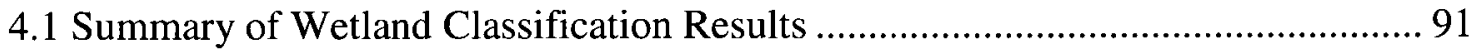

4.2 Wetland and Within Wetland Feature Classification........................................ 94

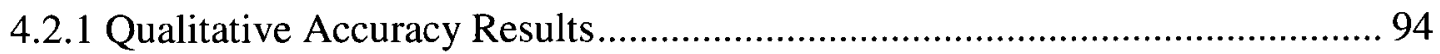

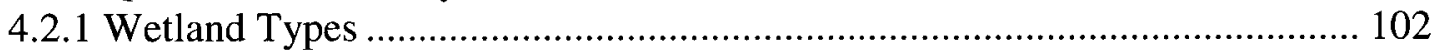

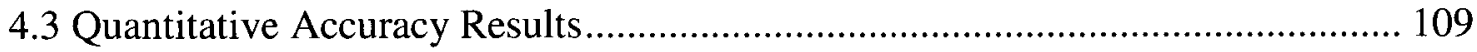

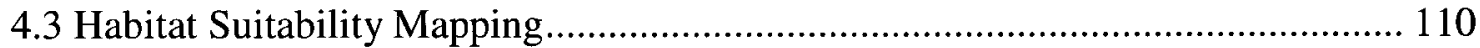

4.3.1 Habitat Suitability Score Distribution.................................................. 110

4.3.2 Wetland Suitability and Blanding's Turtle Observations ......................... 111

5.0 DISCUSSION ........................................................................................................................ 118

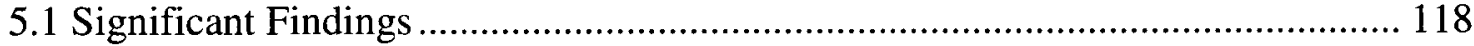

5.2 Research Limitations and Recommendations ........................................ 122

6.0 THESIS SUMMARY AND CONCLUSIONS ............................................ 129

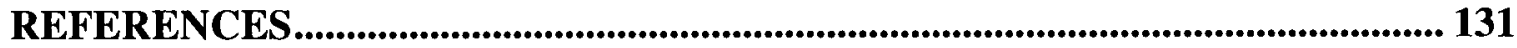

Appendix 1 Data Forms used during Field Surveying of Wetlands............................. 141

Appendix 2 Field Survey Records .......................................................................................... 142 


\section{LIST OF TABLES}

Table 1. Description of texture measures that were evaluated for suitability in wetland mapping (Sources for descriptions: Definiens AG, 2007 and PCI Geomatics, 2008)

Table 2. Polygons that outlined potential wetland survey locations (Figure 10) were manually created and categorized based on characteristics that were visually interpreted in orthophotos

Table 3. Overview of main steps used in this research.

Table 4. Manual extraction of spectral signatures (DN) from targeted landcover types and attributes yielded the Minimum (Min.) and Maximum (Max.) spectral range... 57

Table 5. Overlap of land cover types in their spectral signature range. The box insets outline grouped land cover types and patterns of confirmed overlap ("yes") or separation ("no"). The light grey box outlines consistent overlap with wetland vegetation (high $\mathrm{DN}$ ), the medium grey identifies a cover type that has some overlap with the wetland vegetation group and the shadow/water group (medium $\mathrm{DN}$ ). The darkest grey denotes the dark classes, with very little overlap (low DN).

Table 6 . Illustration of the digital number range (min-max) for each land cover type using GLCM textures (except for GLDV ASM) on the red band.

Table 7. Example of a wetland evaluated for its three class components: A) Wetland Vegetation; B) Logs C) Water. (this example is from Wetland ID 230).......... 84

Table 8 .Wetland size classes and Wetland Vegetation classes associated with scores used in Habitat Suitability Analysis.

Table 9. Habitat suitability score related to ordinal scale habitat suitability level.

Table 10. Potential combinations of wetland attributes (Log and Wetland Vegetation) and their affiliated score totals (bold numbers) and suitability level (colour). .........99 90

Table 11. Error matrix for landcover object classification. 109

Table 12. Error matrix for Wetland feature classification. 


\section{LIST OF FIGURES}

Figure 1. A Blanding's turtle on a log. Observation made during 2008 population inventory in Québec. Source: Giguère, 2008.

Figure 2. Sedge tussock in wetland, considered important as a Blanding's turtle habitat indicator. Photograph taken in Gatineau Park by the Author (2008).

Figure 3. Blanding's turtle range in the United States, Ontario and south-western Québec. Source: Center for Reptile and Amphibian conservation and management, 2008

Figure 4. Range of Blanding's turtles in Ontario and Québec. Source: SARA. 2004. Species at risk, Species Profile of Blanding's turtle. Online March 10, 2008. URL: http://www.sararegistry.gc.ca/species/speciesDetails e.cfm?sid=846 .. 14

Figure 5. The study region is shown within Canada and the province of Québec. Gatineau Park (green area) in southern Québec is the regional study area. The aerial orthophoto imagery coverage is shown (red outline), indicating the local study area. The La Pêche Lake sector is outlined in the lower left corner. Pontiac is the name of the region around the associated marker.

Figure 6a. Study area (outlined in red) in relation to potential ecological corridor for Blanding's turtles movement. 40 Blanding's turtles found in study area. Inset boxes are illustrated in Figures $6 \mathrm{~b}$ (yellow) and 6c (purple). Source: NRCan, 2007c; Dubois, 2009; St-Hilaire et al., 2008

Figure 6b: A larger scale inset of the yellow boxed-area in Figure 6, illustrating Blanding's turtle observation points in the conservation area near the town of Bristol, QC. This population is potentially using an ecological corridor to access habitat to the north-east, in Gatineau Park. Source: Ducks Unlimited Canada, 2008; NRCan, 2007c: St-Hilaire et al., 2008.

Figure 6c. A zoomed in inset of purple box in Figure 6a, illustrating Blanding's turtle observations around the Eardley-Masham road between the years 1996-2009. Source: Ducks Unlimited Canada, 2008; NRCan, 2007c; St-Hilaire et al., 2008; Parc de la Gatineau, 2007.

Figure 7. Image object levels consist of a layer of image objects that are linked to their neighbours (superobjects, subobjects). Source: Definiens AG, 2007.

Figure 8. Weighted components of the homogeneity criterion. Source: Adapted from Definiens AG, 2007 
Figure 9: Existing water classified in the study area, including: wetland layers from Ducks Unlimited and Wetlands of Eastern Ontario and water bodies. White signifies urban or agricultural areas. Note that during this research many more small wetlands were identified than are shown on this map. Source: NRCan, 2007c; Ducks Unlimited Canada, 2008

Figure 10. Example subarea showing potential survey wetlands. Green: large open water; Light purple: continuous wetland vegetation, dry; Orange: almost dried up, very little water with lots of wetland vegetation; Pink: very small wetland or shadow; Red: wetland vegetation, trees, logs. Orthophoto source: NCC (2007).

Figure 11. Orthophoto examples of continuous wetland vegetation (Left) and (leaf-off) deciduous forest (right).

Figure 12. Example orthophoto (left), GLDV ASM texture (middle) and MLC classification (right) (Right: Water=blue; Other=green).

Figure 13. Example of shadows in forest that were erroneously classified as Water (Lakes/wetlands) and subsequently removed. Water=blue; Other=green

Figure 14. Example of Water class objects (blue) that would have been removed if a size threshold of $500 \mathrm{~m}^{2}$ was applied. Potentially important hydrological features in a wetland could be removed if a size threshold is utilized to address removal of misclassified shadow (Figure 13). Wetland vegetation is green. 63

Figure 15. Orthophoto (left) used to conduct texture (GLDV ASM) (centre) analysis that was a component in producing the wetland mask (right).

Figure 16. The original red band air photo image is shown within each masked object. Some errors still present in the mask include the electricity line corridor (lower right), agriculture (top right) and deciduous forest (near centre), usually illustrated by dark grey.

Figure 17. An example of a process tree used to classify wetlands and within wetland attributes (Logs, Wetland Vegetation and Water). The symbol is 'Assign class' and $\$$ is 'multi-resolution segmentation' and is 'merge region' .. 69

Figure 18. A translation of the processing tree in Figure 17, to illustrate an example of the processing steps (listed on the left) used to classify wetlands and within wetland attributes in one orthophoto mosaic. Text in bold signifies output classes and text in brackets indicates the object filter used.

Figure 19. Example segmentation of a portion of a wetland in the red band to determine the optimal scale parameter level for the target wetland classes of $\log$ and Wetland Vegetation. Top left: Scale $=100$; Top right: Scale $=50$; Bottom: Scale 20 
Figure 20. Within wetland segmentation of the blue band (left) and red band (right). The red band produced more detailed segments with better delineation of the boundaries of Logs and Wetland Vegetation.

Figure 21. Within the image object hierarchy, each image object is linked to its neighbours, its super-object and its sub-object.

Figure 22. A simplified illustration of the classes used in the image object hierarchy (boxes). Text inside of circles refers to rules used in classification; bold text refers to final classes that were mapped within the wetland mask; arrows refer to connections to classes or object levels; the dashed line represents the class that was segmented at a second object level. 73

Figure 23. Orthophoto of part of a wetland (top)* compared to the same image segmented (centre with orange outlined objects) and the final classification result (bottom). A log is outlined in red in the orthophoto (top) and remains in red in the segmented image (centre) and classification result (bottom). Blue is Water and green symbolizes Wetland Vegetation. *Source: NCC, 2007..... 79

Figure 24. Example of Logs (brown) partially enclosed or bordering Wetland Vegetation (green). Water is blue. Orthophoto source: NCC, 2007.

Figure 25. Random sample of 550 points interpreted as wetland (yellow), non-wetland (Other) (pink), and Lake (orange).

Figure 26. Example of classified wetlands that were removed (red) because they were less than the defined water area threshold of $100 \mathrm{~m}^{2}$. Blue wetlands were retained for habitat suitability analysis.

Figure 27. Wetlands and water bodies mapped previous to this research and wetland and water body classification results from this research. Source: QMNRF, 2008; NRCan, 2007b; Belanger and Grenier, 2003

Figure 28. The number of wetlands mapped based on wetland size. The wetlands that contained more than $100 \mathrm{~m}^{2}$ of Water (grey bars) were retained for habitat suitability analysis.

Figure 29. Percent Wetland Vegetation cover in all wetlands (all sizes).

Figure 30. The number of wetlands related to the quantity of Logs, for all wetlands and wetlands with over $100 \mathrm{~m}^{2}$ of Water surface area.

Figure 31. Orthophoto of a wetland (from wetland mask) compared to classification results of three wetland attribute classes critical to Blanding's turtle habitat mapping: Water, Logs and Wetland Vegetation. 
Figure 32. The legend used for all figures showing examples of classification results.... 96

Figure 33. Orthophoto (top) and wetland classification (bottom). The shadows cast from the conifer trees onto continuous vegetation (upper image red arrows) are misclassified as Water (lower image black arrows; two blue polygons).......96 96

Figure 34. Orthophoto (left) and wetland classification (right). Sections of wetland were not included in the wetland mask (red arrow compared to black) and there are missing narrow water sections (Red box compared to black). 98

Figure 35. Spring Orthophoto (I)* and wetland classification (II). Satellite image of the same wetland in summer (III)**, exhibiting increased wetland vegetation compared to spring orthophoto. Photograph taken in summer of the wetland at location B (IV)***, also illustrates the abundance of floating aquatic vegetation that is present in summer but not apparent in spring.

Sources: *NCC, 2007; **Google Earth, 2009.*** Author, 2008 100

Figure 36. Spring orthophoto (I)* and wetland classification (II). Satellite image of the same wetland in summer (III)**, exhibiting increased wetland vegetation compared to spring orthophoto. Photograph taken in summer of the wetland at location A (IV)** also illustrates the abundance of vegetation (mostly emergent grasses) that is present in summer but not apparent in spring. A Blanding's turtle was at this wetland in 2009 , as recorded in a telemetry study by the QMNRF. Sources: *NCC, 2007; **Google Earth, 2009. ***Author, 2008 .

Figure 37. Orthophoto (left)* and wetland classification (right). Wetland boundary estimated to be $>90 \%$ classified when compared to orthophoto. $*$ Source: NCC, 2007.

Figure 38a. Orthophoto (top)* and wetland classification (bottom). An example of a wetland characterized by abundant Logs and Wetland Vegetation.

* Source: NCC, 2007.

Figure 38b. Photograph of a wetland. Corresponding orthophoto and classification are shown in Figure 38a. Source: Author, 2008.

Figure 40. Two open Water wetland examples. Orthophoto (I)* and wetland classification (II), photograph of smaller wetland in left of orthophoto (III)** and the larger wetland (IV)**. Both of these wetlands have low vegetative cover and over 5 Logs. Sources: *NCC, 2007; **Author, 2008. 105 
Figure 41. An example of a wetland with very abundant Logs and low Wetland Vegetation cover $(<25 \%)$. This wetland has characteristics that could be potentially suitable for overwintering or spring Blanding's turtle habitat. Orthophoto source: NCC, 2007.

Figure 42. An example of a wetland with plenty of open Water, a high abundance of Logs and medium $(25-50 \%)$ Wetland Vegetation cover. Orthophoto source: NCC, 2007.

Figure 43. Orthophoto (left) and wetland classification (right). The wetland has over $50 \%$ Wetland Vegetation cover and only 1 classified Log. Orthophoto source: NCC, 2007. 108

Figure 44. Orthophoto (top) and wetland classification (bottom). One section of this wetland is characterized by open Water and Logs while the other section has more is dominated more by Wetland Vegetation. Orthophoto source: NCC, 2007

Figure 45. Blanding's turtle potential habitat suitability map. Habitat suitability levels were created from habitat scores.

Figure 46. Habitat suitability score distribution for all available wetlands (minimum 100 $\mathrm{m}^{2}$ Water; Black) and the habitat suitability score of Wetlands within $500 \mathrm{~m}$ of a Blanding's turtle observation (Grey).

Figure 47. Habitat Suitability level related to the number of wetlands and the number of wetlands within $500 \mathrm{~m}$ of a Blanding's turtle observation.

Figure 48. Habitat suitability level of wetlands within $500 \mathrm{~m}$ of Blanding's turtle observations, located near the vicinity of Eardley-Masham Road, where most observations have been documented.

Figure 48b. Photograph of wetland taken at location B (Figure 48a) by Author (2008).

Figure 48c. Photograph of a wetland at location C (Figure 48a) and of a turtle basking on a $\log$ in the sun (arrow). Source: Author, 2008

Figure 49a. Orthophoto (top) and wetland classification (bottom). The habitat suitability level was 'very high'. The wetland photos were taken from locations A, B, and C. Orthophoto source: NCC, 2007

Figure 49b. Photograph of wetland at location A (Figure 49a). This area is characterized by a variety of vegetation types (including sedge tussocks).

Source: Author, 2008. 
Figure 49c. Photograph of wetland at location B (Figure 49a). This area is characterized by open water, floating aquatic vegetation and bank vegetation. Source:

Author, 2008 .

Figure 49d. Photograph of wetland at location C (Figure 49a). This area is characterized by large clusters of vegetation tussocks, trees, logs and open

water.

Figure 50. Orthophoto (left)* and wetland classification (right). This wetland was rated as 'High' suitability. Photograph of wetland in Figures 48b-48d. *Source: NCC, 2007

Figure 51a. Example of wetlands that have not been previously mapped and have had recorded Blanding's turtle occurrences (triangles) (QMNRF, 2009;

Blanding's turtle recovery team telemetry study in 2009). The wetland in the top right window is an isolated pool in a bog.

Figure 51b. Photograph of the wetland in Figure 5la. Blanding's turtle observations have been made in multiple years, including this one by the author (photo source: Author, 2008). This wetland was categorized as having high suitability.

Figure 52a. Orthophoto of three wetlands (top)* and their associated classification (bottom). These wetlands have never been mapped before and the middle wetland had a Blanding's turtle observation by the author (2008) (Figure $52 \mathrm{~b}$ ). The other two wetlands were also validated in a field survey and have Blanding's turtle observations within $500 \mathrm{~m}$. *Source: NCC, 2007.

Figure 52b. Photograph of a wetland never mapped before (middle wetland in Figure 52a) and a Blanding's turtle basking in the sun on a log. Source: Author, 2008 


\section{CHAPTER ONE}

\section{INTRODUCTION}

The issue of wetland loss and species at risk protection are two important topics of concern in Canada and globally (Fournier et al., 2007; Davidson and Finlayson, 2007). Conversion and alteration of wetlands and surrounding terrestrial habitat have resulted in wetland losses exceeding $75 \%$ in Southern Ontario since European settlement (Whitefield Gibbons et al., 2000; Ontario Ministry of Natural Resources, 2008). In Québec, amphibians and reptiles are the categories most in decline, with more than half of their species appearing on the list to be designated as threatened or of special concern (Developpement durable, Environnement et Parcs, 2008).

A species' population can decline based on loss of habitat, which makes it extremely important to identify the amount and location of critical habitat in the species' range. This thesis examines remote sensing methods for mapping of wetlands and within wetland features that are primary habitat attributes for the Blanding's turtle (Emydoidea blandingii).

Wetlands are highly productive ecosystems that provide several important services to humans and many essential functions to flora and fauna. There are over 200 bird species and over 50 species of mammals that depend on wetlands for food and habitat in Canada (Natural Resources Canada (NRCan), 2009). Many fish spend part of their life cycle in wetlands, as well as frogs, salamanders, turtles, insects and shellfish (Karakker and 
Gibbs, 2009; SARA, 2005; NRCan, 2009). Plants are a very significant part of the food chain in wetlands and provide energy flow into the system.

Agricultural expansion has caused $85 \%$ of Canada's wetland losses; since European settlement began (1800s) it is estimated that over 20 million hectares have been lost to agriculture (NRCan, 2009). The cumulative loss of many small wetlands can represent a large proportion of the total wetland area in a landscape and their loss can greatly increase the isolation of remaining wetlands (Joyal et al., 2001). There is an escalating concern for global wetland resources and consequently a rising need for automated and reproducible wetland maps (Baker, 2006).

The Blanding's turtle (Figure 1) is a medium-sized reptile (up to $27 \mathrm{~cm}$ length) with a rounded black carapace (shell) that is speckled with yellow dots. The Plastron (belly of the shell) is yellow with square black blotches and its long neck, throat and chin are bright yellow (Committee on the Status of Endangered Wildlife in Canada (COSEWIC), 2005). It is a freshwater turtle that inhabits palustrine and riverine habitats. Palustrine wetlands include "marshes, bogs, fens, wet meadows, swamps and seasonally wet woods." (Tiner, 1999). Riverine wetland types are characterized as stream beds and emergent wetlands.

The global range of the Blanding's turtle spans parts of North America with $20 \%$ of the population in Canada and the rest in the United States (COSEWIC, 2005). Blanding's turtle is listed in the U.S. as Special Concern, Threatened or Endangered (Grgurovic and Sievert, 2005). Canada's populations are listed as Threatened (Nova Scotia) and Endangered (Great Lakes/St. Lawrence) (COSEWIC, 2005). Threatened 
status infers that the species is expected to become endangered if limiting factors are not reversed (COSEWIC, 2005).

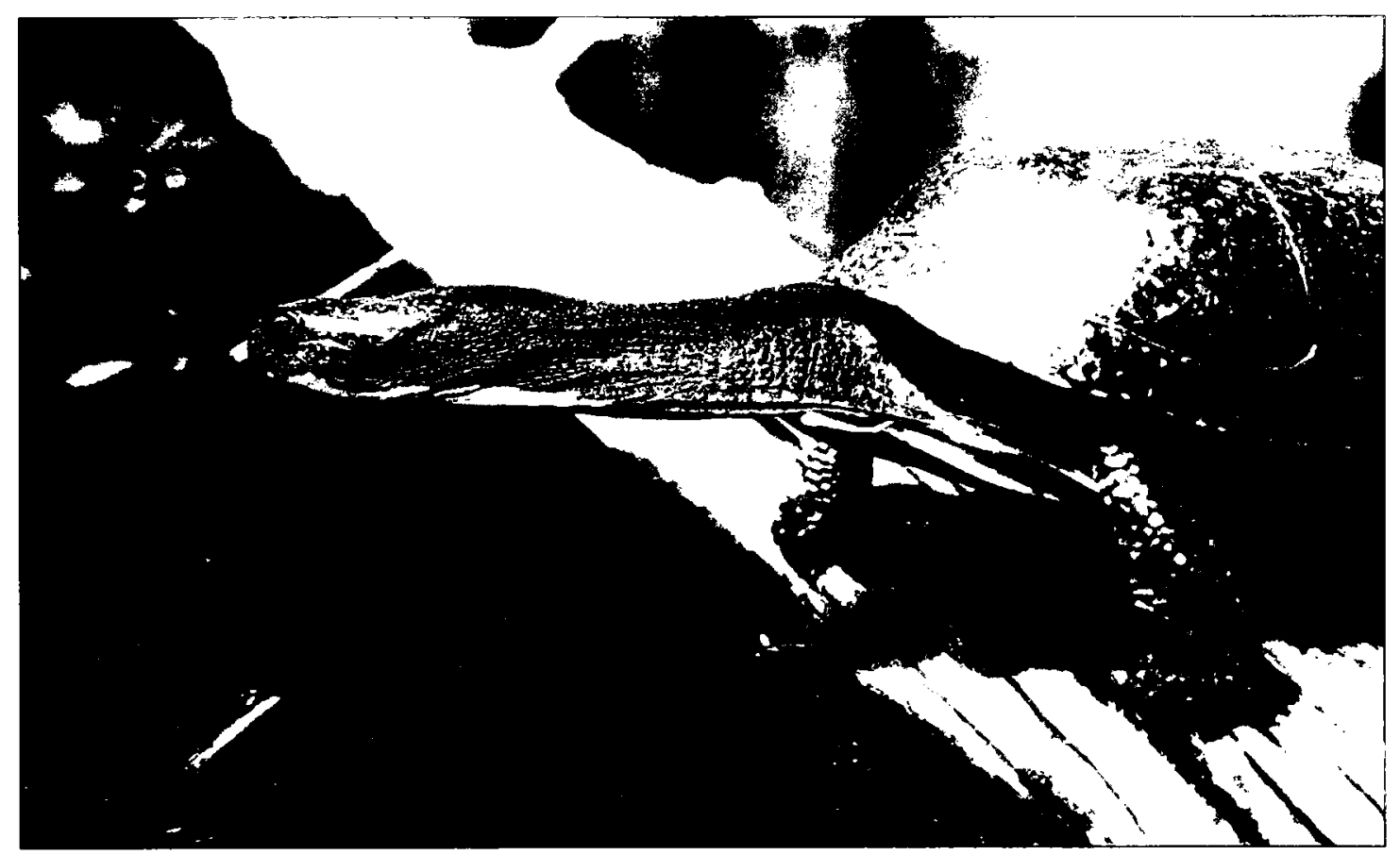

Figure 1. A Blanding's turtle on a log. Observation made during 2008 population inventory in Québec. Source: Giguère, 2008

This thesis is part of a larger research initiative to study the Great Lakes/ St. Lawrence population of Blanding's turtle in southern Québec, including within Gatineau Park and its periphery. The National Capital Commission (NCC) and Ministère des Ressources Naturelles et de la Faune du Québec (Québec Ministry of Natural Resources and Wildlife (QMNRF)) are both interested in habitat suitability mapping and modelling for this turtle species in Gatineau Park. For three years the NCC and QMNRF have conducted several studies related to Blanding's turtles in this focal region, including 2007 and 2008 population inventories and a 2009 telemetry study. The telemetry study is planned to expand and continue in 2010 into other areas of the Gatineau Park and near the town of Bristol. The QMNRF anticipates utilizing the wetland map and Blanding's turtle habitat 
suitability map produced from this thesis research as part of the continuing Blanding's turtle recovery program to aid in selection of wetlands for potential field observation of the turtles and to aid in understanding of the spatial distribution of potential habitat for conservation management planning.

\subsection{Objectives}

The objectives of this research were to:

- Classify and map wetlands and wetland habitat attributes of the Blanding's turtle within the area of Gatineau Park that is proximal to known populations.

- From the wetland and within wetland features maps, create a habitat suitability map that ranks wetlands based on their potential as habitat for Blanding's turtle.

\subsection{Thesis Structure}

This thesis is organized into 5 chapters. The first chapter introduces the research topic, objectives, the importance of habitat mapping for species at risk, and the focal species, Blanding's turtle. The second chapter provides more detailed background on wetlands and Blanding's turtles. Habitat suitability modelling and mapping is defined and several approaches and studies are presented. The final section of Chapter Two provides an overview of remote sensing with a focus on wetland mapping, texture analysis and object-based classification, all pertinent to this research. The third chapter describes the methods used in this thesis, including study area selection, field work, image acquisition, processing and analysis, and development of a habitat suitability map. The fourth chapter summarizes qualitative and quantitative results of the wetland classification and habitat 
mapping. The fifth chapter discusses important findings of this research as well as limitations met and recommendations for future research. 


\section{CHAPTER TWO}

\section{BACKGROUND}

\subsection{Wetlands}

In Canada wetlands are formally defined as "land that is saturated with water long enough to promote wetland or aquatic processes as indicated by poorly drained soils, hydrophytic vegetation which is periodically deficient in oxygen and various kinds of biological activity adapted to a wet environment" (National Wetlands Working Group Canada Committee on Ecological Land Classification, 1988, p.416). Wetlands occupy about $14 \%$ of the terrestrial surface of Canada and these wetlands account for $25 \%$ of the world's estimated wetlands, totalling approximately $1,270,000 \mathrm{~km}^{2}$ (NRCan, 2009).

The Canada Wetland Classification System (CWCS), Second Edition, (National Wetlands Working Group, 1997) is comprised of three hierarchical levels: Class, Form and Type. There are five wetland classes that are characterized by their developmental characteristics and the environment in which they occur: bog, fen, marsh, swamp and shallow water.

Bogs are peat-covered wetlands dominated by sphagnum moss. The sphagnum creates a cushioned carpet interspersed with heath shrubs and sometimes stunted trees (NRCan, 2007a; Zoltai and Vitt, 1995). Fens similar to bogs, dominated by peatland cover, but they support more marshy vegetation and greater diversity of plant species than bogs and are characterized by a fluctuating, non-stagnant water table. (NRCan, 2007a; Zoltai and Vitt, 1995). 
Marshes are treeless wetlands that have seasonal water fluctuations, sometimes being inundated with standing or slowly moving water. Water or saturated soils remain during the growing season; marshes are characterized by emergent vegetation, including: reeds, rushes and sedges (NRCan, 2007a; Zoltai and Vitt, 1995). Swamps have standing or gently moving water that is present seasonally or for long periods. Coniferous and deciduous forests, often with dead standing trees, as well as tall shrub thickets dominate swamps (NRCan, 2007a; Zoltai and Vitt, 1995).

Shallow water bodies are often associated with ponds or sloughs and are small, non fluvial bodies of standing water. They are often in the transition zone between lakes and marshes and the surface waters are usually open and absent of emergent vegetation but can have other vegetation (NRCan, 2007a; Zoltai and Vitt, 1995).

Wetland plants are defined by Cronk and Siobhan $(2001 ;$ p.6) as plants commonly found growing "in or on the water or where soils are flooded or saturated long enough for anaerobic conditions to develop in the root zone."

Freshwater resources are abundant in the Mixedwood plain ecozone of the Great Lakes-St. Lawrence basin (Environment Canada, 2004). NRCan (2009) has estimated that Québec has 12,151,000 hectares of wetlands that account for $9 \%$ of the total area of the province and $10 \%$ of the total wetlands in Canada.

Wetlands provide a multitude of social, economic and environmental benefits (NRCan, 2009; Environment Canada, 2004; Warner and Rubec, 1997), including: flood reduction and control, watershed and shoreline protection, water purification and sinks for pollutants, carbon sequestration, retention of sediments and nutrients, and other services related to resource use. 
Amongst these, in the context of this thesis research, provision of habitat, most importantly for species at risk, is a critical function of wetlands, particularly in areas where wetland losses have been significant.

\subsection{Species at Risk}

Habitat loss and degradation are primary threats to amphibian and reptile populations (Whitefield Gibbons et al., 2000). The Canada Species at Risk Act (SARA) provides legislative power for protection, conservation, and recovery or rehabilitation of species populations and habitat. At the national level the assessment is conducted to classify the degree of risk for wildlife species by the Committee on the Status of Endangered Wildlife in Canada (COSEWIC). This committee, through scientific evaluation, categorizes species at risk as extirpated, endangered, threatened or of special concern. These risk categories are respectively ranked from high to low.

As part of the Species at Risk Act, it is important to understand the various attributes associated with the habitat of each species, particularly in order to map out currently used habitat, as well as map and model potential habitat (SARA, 2005). The ability to develop explicit relations between species and habitat that are quantifiable and testable makes habitat models useful for attempting to predict species presence (Garcia and Armbruster, 1997).

To successfully identify and protect critical habitats for species at risk it is essential to know the factors affecting habitat suitability and selection. SARA (p. 4, 2003) defines critical habitat as "the habitat that is necessary for the survival or recovery of a listed wildlife species and that is identified as the species' critical habitat in the recovery 
strategy or in an action plan for the species". Habitat is defined by SARA in respect to aquatic species as "spawning grounds and nursery, rearing, food supply, migration and any other areas on which aquatic species depend directly or indirectly in order to carry out their life processes, or areas where aquatic species formerly occurred and have the potential to be reintroduced".

Taking a landscape ecology approach to planning the recovery of a species has been recently adopted by conservationists. Studies in habitat supply modeling use abiotic and biotic spatial variables such as topography and vegetation type to determine suitable habitat for a specific species (McDermid et al., 2005). Land cover can be transformed to inferences about habitat through implied relationships or through the explicit integration of other spatially referenced information (e.g., data points representing species presence) or environmental factors (Store and Kangas, 2001).

\subsection{Blanding's Turtle}

Blanding's turtles prefer the following types of aquatic habitats: permanent and temporary ponds, streams and wetlands, including: vernal pools, bogs, marshes, swamps and fens (See section 2.1 for Class descriptions) (Pappas and Brecke, 1992; Ross and Anderson, 1990; Herman et al., 1994; Edge, 2008). They spend the majority of their lives in aquatic habitats (e.g., over 90\%; Hamernick, 2001), but they are not usually associated with open, deep sections of lakes, preferring instead to frequent vegetated areas near the edges of lakes and throughout shallow lakes (Natural Heritage and Endangered Species Program, 2007). 
Blanding's turtles are mainly aquatic predators that feed on insect larvae and nymphs, snails, leaches, crayfish, small fish, frogs and frog eggs, plant material and seeds from aquatic plants (Blanding's turtle recovery team, 2006). On land, Blanding's turtles eat vegetation, grasses, earthworms and slugs (Natural Heritage and Endangered Species Program, 2007).

\subsubsection{Life Cycle}

After emerging from hibernacula (place of dormancy over the winter) in mid-April, and until the end of May, Blanding's turtles often bask in the sun by sitting on sedge clumps, matted stick piles, logs, cattail debris or the wetland bank to thermoregulate and increase their metabolism (Rowe and Moll, 1991; Edge, 2008). Peak mating usually occurs before spring dispersal at overwintering wetland locations (usually open water or pond sites) or at the wetland visited after the hibernacula site (potentially ephemeral) (Natural Heritage and Endangered Species Program, 2007).

Beginning in early June and lasting until July, the pregnant (gravid) females move to suitable nesting locations (Grgurovic and Sievert, 2005) in open areas with access to sunlight to thermoregulate the incubating eggs. Nesting sites are usually near ephemeral wetlands or are located in anthropogenic habitats such as road sides, trails, sandy gravel roads, and power line right-of-ways (Joyal et al., 2001; Parc de la Gatineau, 2007; Power et al., 1994; Edge, 2008). Nest sites have been found over 400m from the nearest wetland and Blanding's turtles have been observed to travel $100 \mathrm{~m}-1620 \mathrm{~m}$ (avg. 633 m) for several days to nest (Joyal et al., 2001; Innes et al., 2008). In early spring (June), 
non-nesting Blanding's turtles often travel to ephemeral wetlands or wetlands with abundant vegetation (Grgurovic and Sievert, 2005).

In July they move away from the nesting areas to wetlands with vegetation (Grgurovic and Sievert, 2005). In the summer most research has found that Blanding's turtles often use marshes and highly productive ponds (Kofron and Schreiber, 1985; Ross and Anderson, 1990; Pappas and Brecke; 1992; Power et al., 1994; Bury and Germano, 2003). However, they would not use ponds without aquatic vegetation or wetlands covered by cattail mats that are without open water (Ross and Anderson, 1990); this illustrates the importance of aquatic habitats with at least some vegetation present.

Habitats with emergent vegetation are related to food resources and thermoregulation for all stages of the Blanding's turtle life cycle (Hamernick, 2001; Edge, 2008). Marshes and small water habitats characterized by abundant vegetation are important for juveniles for refuge from predators as they are often found or captured in emergent sedges or the sedge-water interface (Kofron and Schreiber, 1985; Pappas and Brecke, 1992; Bury and Germano, 2002; Hamernick, 2001; Edge, 2008). Sedges often grow in tussocks, unlike grass, and can provide a low umbrella-like cover that maintains low temperatures in the summer and protection and are used for movement when they are located along the shoreline or within wetlands (Bourque, 2006; Edge, 2008) (Figure 2).

In a study by Pappas and Brecke (1992), larger individuals were caught in the sedgewater interface and open water. There was at least $50 \%$ cover of grasses and sedges at all nest sites found by Ross and Anderson (1990), indicating the further importance of these types of vegetation forms. 
In late August until late October they move to a wetland to hibernate (November April) and mate (Innes et al., 2008). During these migration movements or other sojourns where they may be crossing land, they require vernal pools or temporary wetlands (Natural Heritage and Endangered Species Program, 2007; Joyal et al., 2001). In late fall (September to October) Blanding's turtles move to deeper ponds where they use the soft substrate to bury themselves and hibernate over the winter (Kofron and Schreiber, 1985). The deeper ponds provide warmer water temperatures in early fall and stable water levels that are critical for overwintering (Ross and Anderson, 1990; Carroll and Ultsch, 2007).

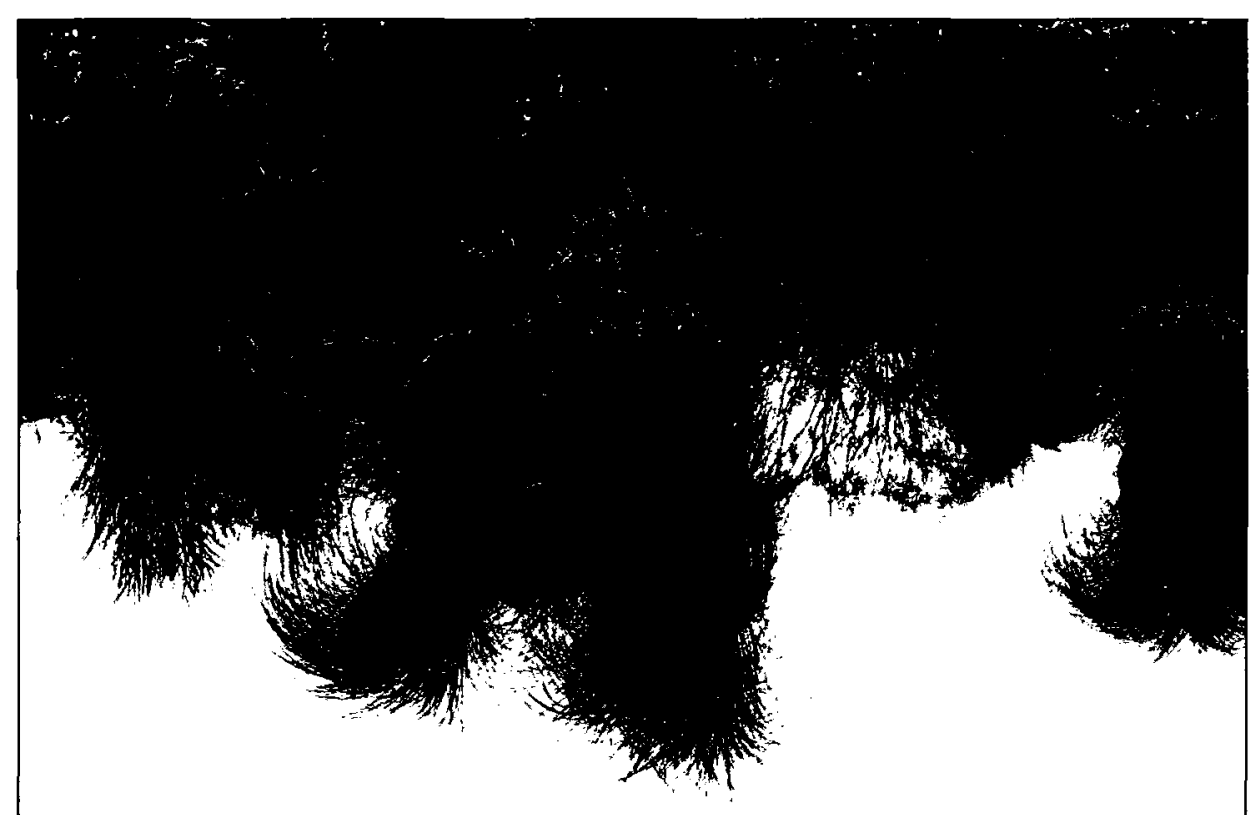

Figure 2. Sedge tussock in wetland, considered important as a Blanding's turtle habitat indicator. Photograph taken in Gatineau Park by the Author (2008).

\subsubsection{Population Distribution}

The Blanding's turtle population range in the United States extends from Nebraska eastward through the central and northern prairies into eastern states such as Ohio and 
Pennsylvania (Figure 3; COSEWIC, 2005). There are also small local populations in New York, Massachusetts, New Hampshire, and Maine (COSEWIC, 2005).

Several reasons for Blanding's turtle's at risk status include: habitat loss and degradation contributing to population declines and extirpations (Standing et al., 1999; NatureServe, 2007); their susceptibility to road and predatory kill because they often nest in exposed sand and gravel, including on roads or road shoulders (Parc de la Gatineau, 2007); multiple biological traits that make this species more vulnerable to decline (outlined in section 2.3.2).

In Ontario and Québec the species' range is in proximity to the Great Lakes Basin (Figure 4). The Great Lakes/St. Lawrence range spans from southern and south-central Ontario, eastward into the extreme south-western portion of Québec in and near Gatineau Park (COSEWIC, 2007; St-Hilaire, 2003).

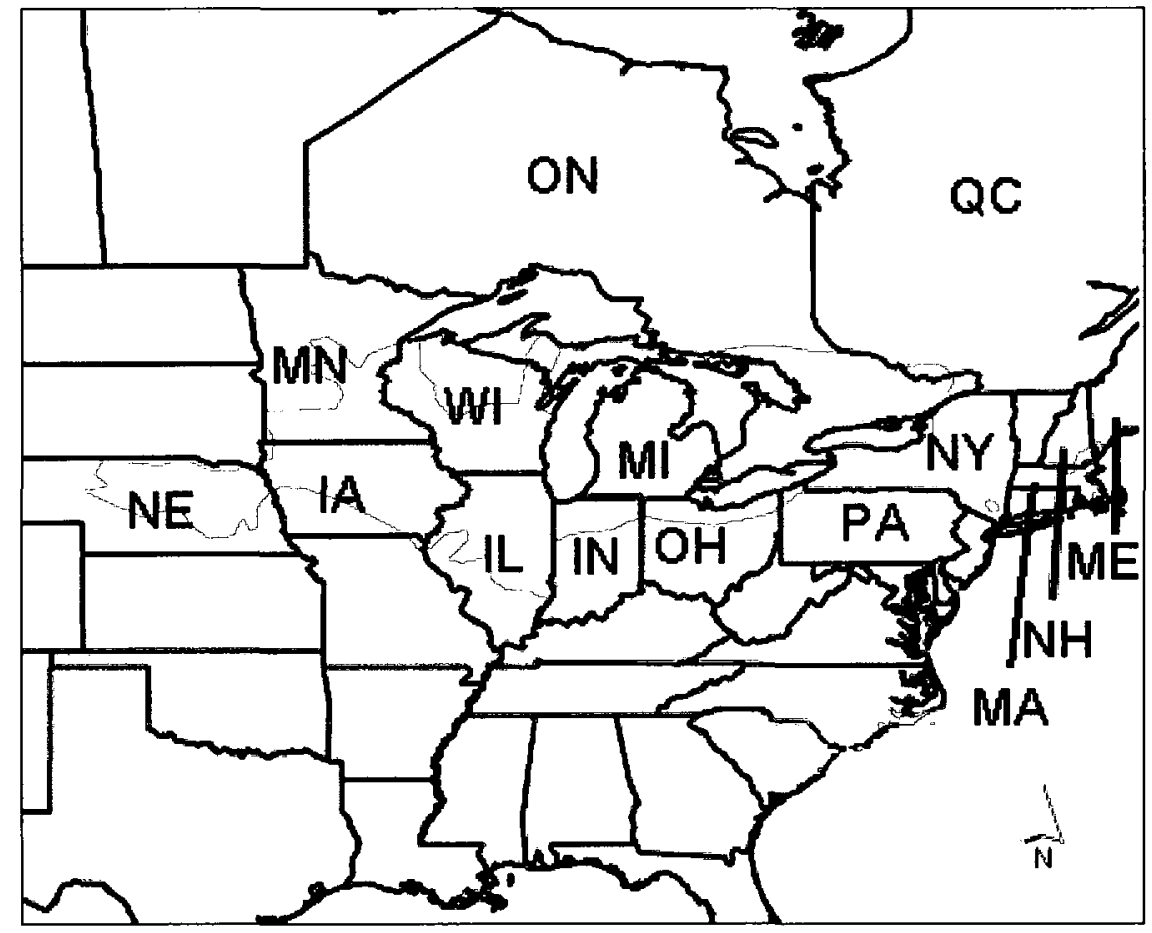

Figure 3. Blanding's turtle range in the United States, Ontario and south-western Québec. Source: Center for Reptile and Amphibian conservation and management, 2008. 
Gatineau Park, the study area location for this research, is $361 \mathrm{~km}^{2}$ (NCC, 2007) of mostly unmanaged forest and wetlands (Figure 5). The park is managed by the NCC and part of the Gatineau Park Natural Resources Management Program is to protect species at risk by finalizing and implementing the 'Species at Risk Protection Plan' and participating in the federal program for species at risk recovery (NCC, 2007).

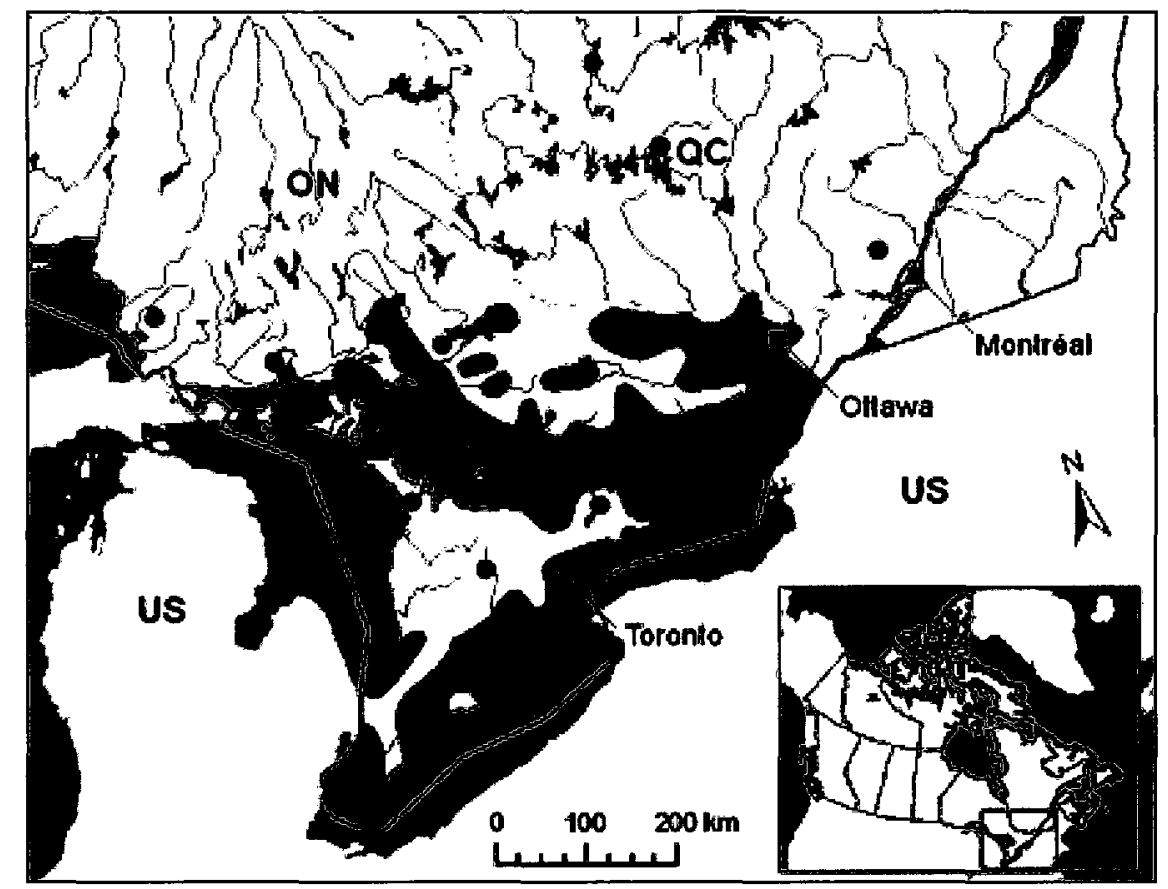

Figure 4. Range of Blanding's turtles in Ontario and Québec. Source: SARA. 2004. Species at risk, Species Profile of Blanding's turtle. Online March 10, 2008 . URL: http://www.sararegistry.gc.ca/species/speciesDetails e.cfm?sid=846

When the Blanding's turtle was designated as threatened in 2005 there was little known about the size and distribution of the Québec population (St-Hilaire, 2003; COSEWIC, 2005) except for a population inventory conducted between 1996-1999, mainly in the Bristol area in a conservation wetland area near the Ottawa river that was known to have Blanding's observations (Figures 6a and 6b) (St-Hilaire et al., 2008).

Blanding's turtles have been observed between the years 1996 and 2009, in Gatineau Park (Figure 5a). Observations were recorded between 1996 and 1999 (St-Hilaire et al., 
2008) and population inventory data were collected in 2007 in the limited vicinity around Chemin Eardley-Masham (Purple box inset in Figure 6) (Parc de la Gatineau, 2007). In the spring and summer of 2008 , six Blanding's turtle observations were recorded. The studies between 1996-2008 had totalled 49 Blanding's turtle observations (Figures 5a and $5 b$ and 6).

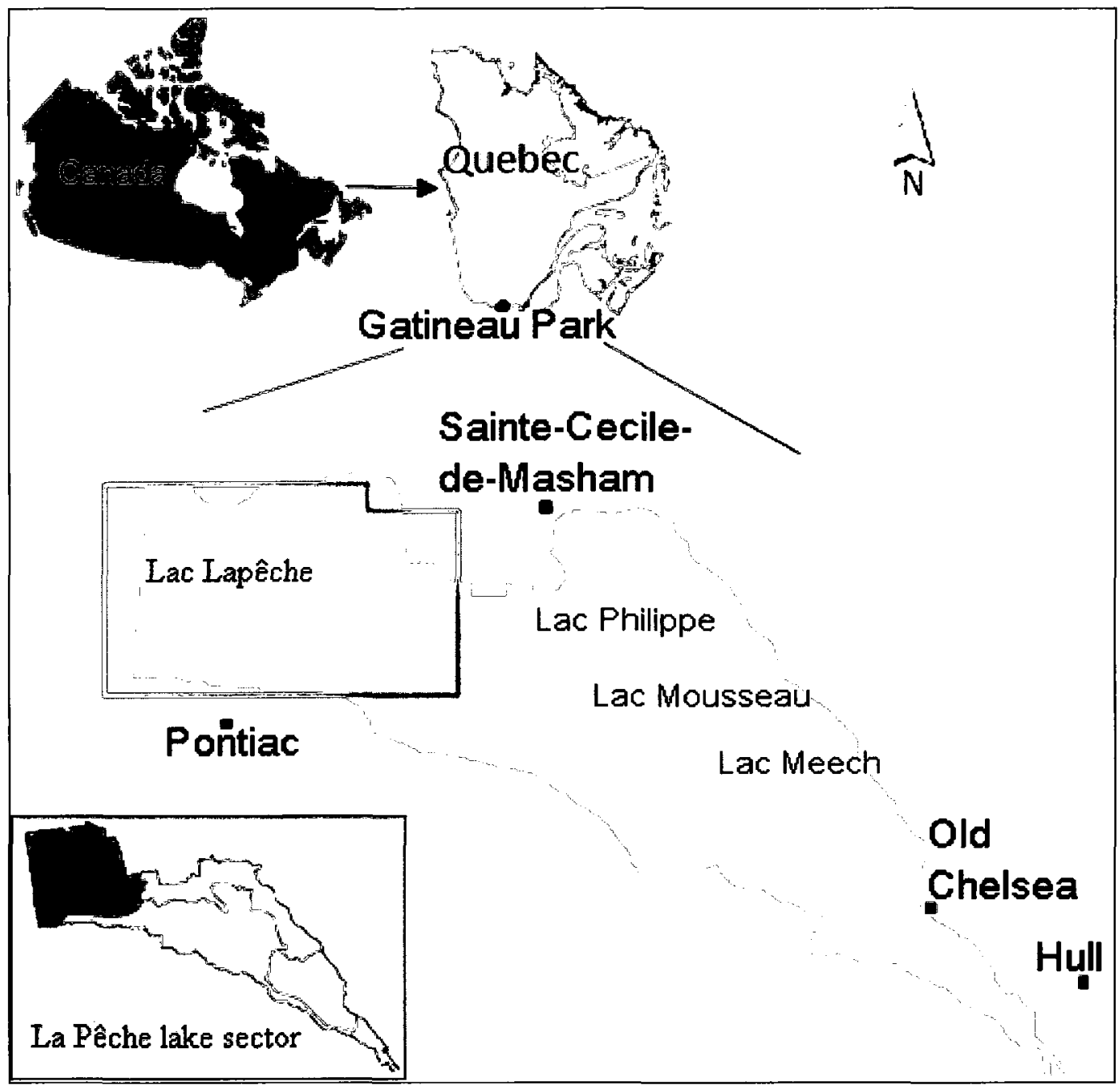

Figure 5. The study region is shown within Canada and the province of Québec. Gatineau Park (green area) in southern Québec is the regional study area. The aerial orthophoto imagery coverage is shown (red outline), indicating the local study area. The La Pêche Lake sector is outlined in the lower left corner. Pontiac is the name of the region around the associated marker.

Source: NRCan (2007b) Google maps data (2009); NCC, 2005. 
The density of Blanding's turtle observations to the southwest of the study area located near Bristol and the Ottawa River is much higher than has been recorded thus far in Gatineau Park (St-Hilaire, 2008; QMNRF, 2008). The QMNRF and the NCC hypothesize that an ecological corridor (Figure 6, red arrow) exists between the two areas. In May 2008, the Blanding's turtle Recovery Team (sponsored by the QMNRF and including the author as an additional member) conducted a population distribution inventory in Southern Québec near the towns of Clarendon, Bristol, and elsewhere in the municipalities of Pontiac and La Pêche as well as in the northwest section of Gatineau Park (including the four observations mentioned above).

To determine which wetlands to survey for Blanding's turtles in 2008 and 2009, the team used a wetland compilation map created by Ducks Unlimited Canada (2008) that included seven wetland classes. Many wetlands in the NW section of Gatineau Park were labelled unclassified and were consequently not useful in selecting wetlands to survey. Wetland size and distance to road (logistical reasons) were also used to prioritize which wetlands to visit. Results from this inventory showed Blanding's turtles preferred marsh (32\%), swamps (24\%), non-classified land (27\%) and ponds (15\%) (Dubois, 2009). .

The Blanding's turtle Great Lakes/St. Lawrence population is included in the Québec Turtle Recovery Strategy that involves research, inventory and education activities in support of recovery planning (SARA, 2008). Part of the strategy is to identify critical habitat and the Blanding's turtle population size. In the summer of 2009 , radiotelemetry devices were attached to individual turtles which were tracked over a period of time, and the data were later used in a GIS to determine home ranges of individuals and critical 
habitat types used. In June and July, ten Blanding's turtles were tracked in the Gatineau Park study area for this research and preliminary results show preference for open, larger wetlands in early spring and then movement into smaller, more vegetated wetlands in summer within $1 \mathrm{~km}$ of original wetland dwelling for some turtles (approx. 4 turtles) (Dubois, Y. pers. comm., March 2010).

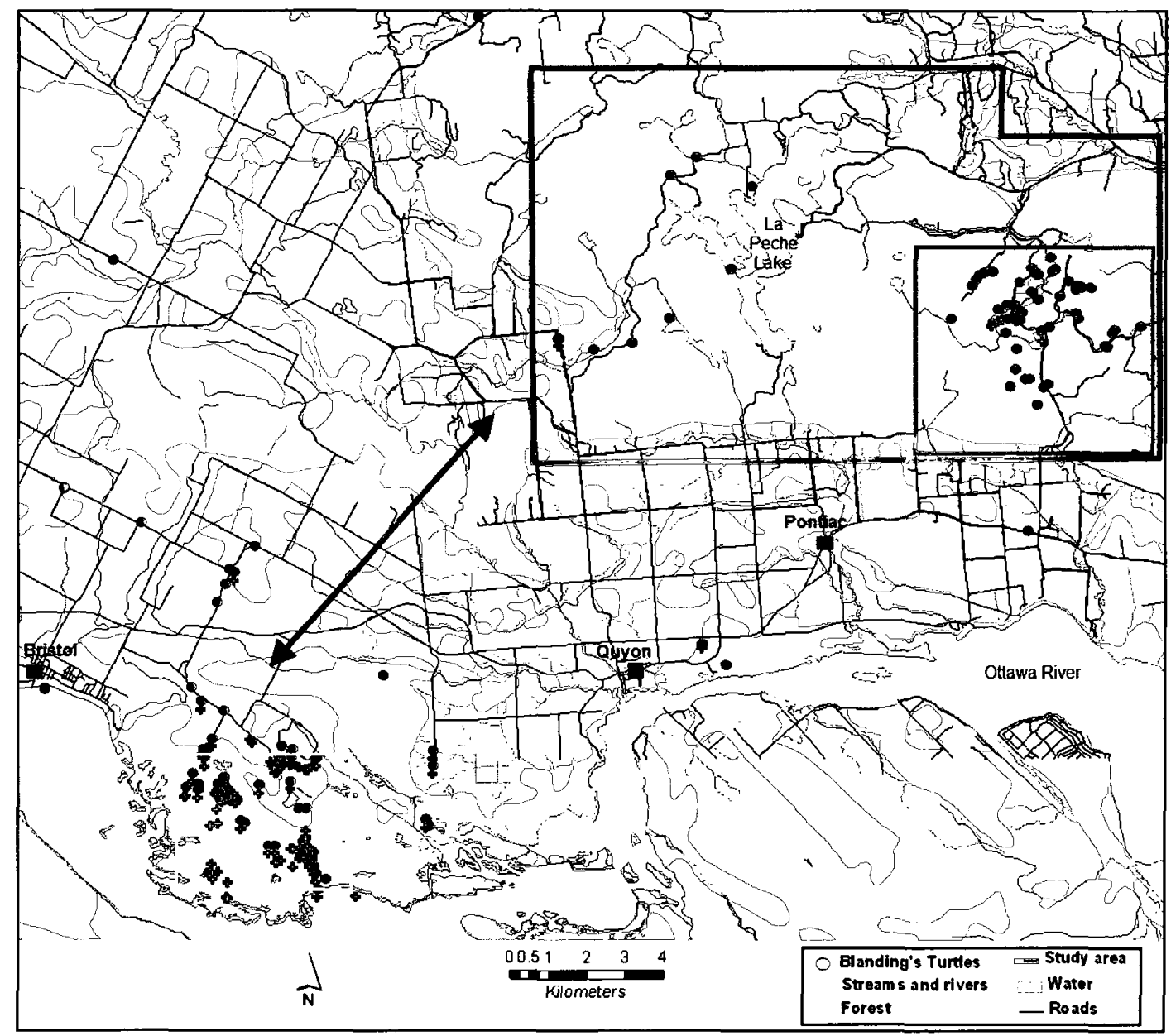

Figure 6a. Study area (outlined in red) in relation to potential ecological corridor for Blanding's turtles movement. 40 Blanding's turtles found in study area. Inset boxes are illustrated in Figures 6b (yellow) and 6c (purple). Source: NRCan, 2007c; Dubois, 2009;

St-Hilaire et al., 2008

Another ten traps were set in August and an additional ten in the Bristol area. This telemetry study is a project that will expand in 2010 and 2011 to a larger area with a larger tracking sample size (20 turtles in Gatineau Park) (Dubois, Y. pers. Comm.; 
October 2009 and March 2010). Another goal of the project is to estimate the impact of road deaths and other threats (Dubois, pers. comm. October 2009).

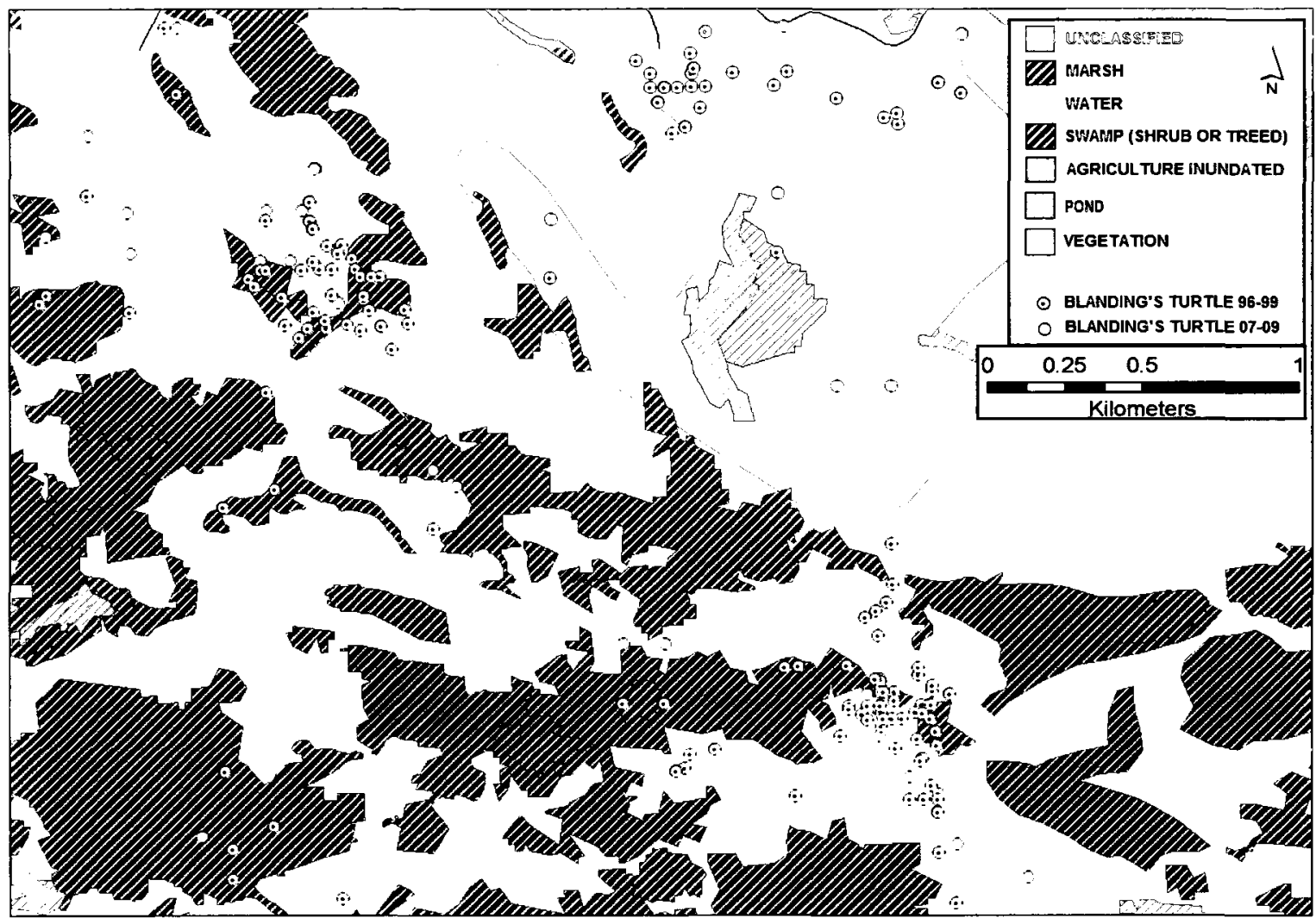

Figure 6b: A larger scale inset of the yellow boxed-area in Figure 6, illustrating Blanding's turtle observation points in the conservation area near the town of Bristol, QC. This population is potentially using an ecological corridor to access habitat to the north-east, in Gatineau Park. Source: Ducks Unlimited Canada, 2008; NRCan, 2007c: St-Hilaire et al., 2008.

Numerous studies have analyzed the Blanding's turtle habitat characteristics at the micro and macro scales (Kofron and Schreiber, 1985; Rowe and Moll, 1991; Pappas and Brecke; 1992; Joyal et al., 2001; Grgurovic and Sievert, 2005; Attum et al., 2008; Innes et al., 2008) because it is essential to their protection and population sustainability that habitat characteristics and use be understood at all scales. 


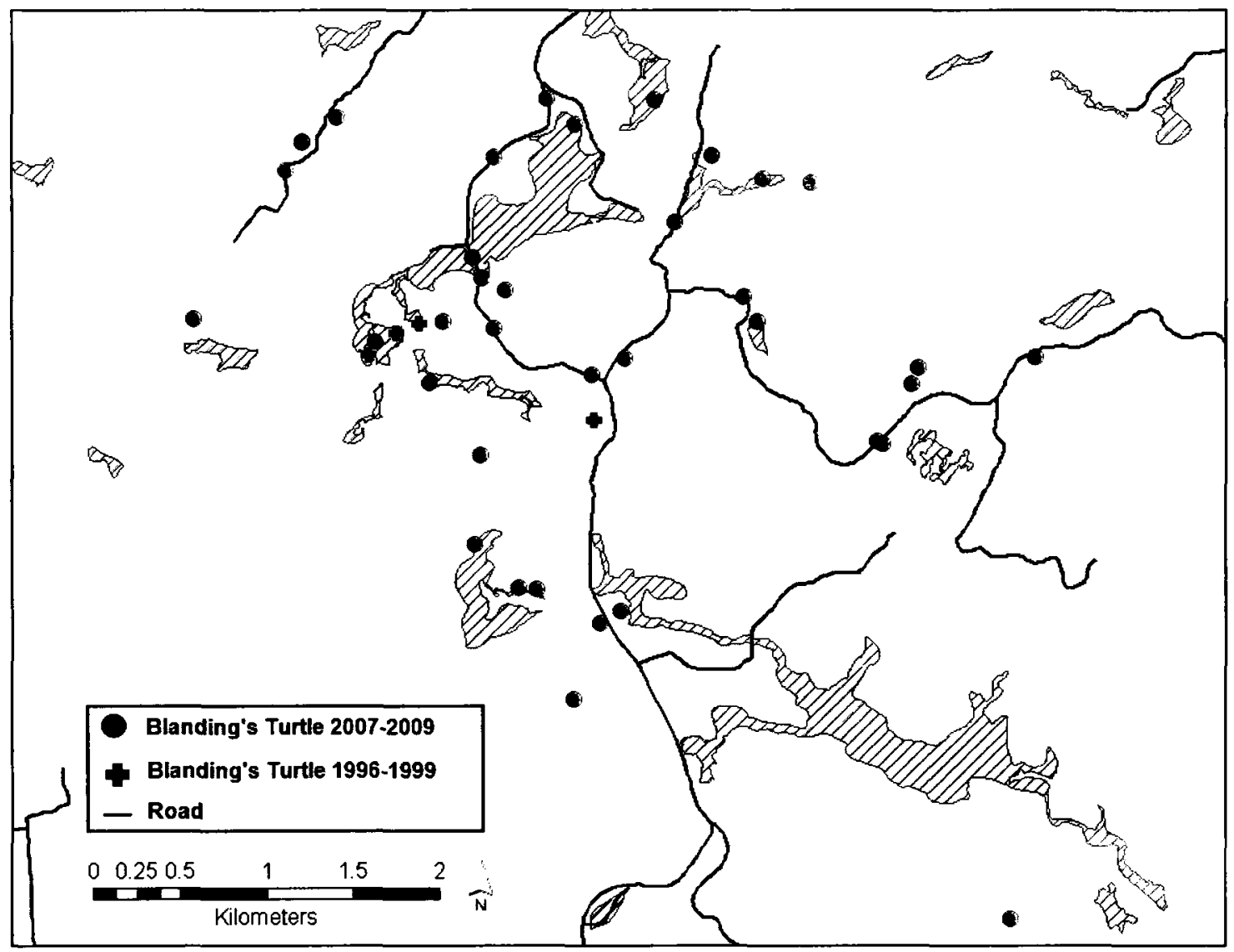

Figure 6c. A zoomed in inset of purple box in Figure 6a, illustrating Blanding's turtle observations around the Eardley-Masham road between the years 1996-2009. Source: Ducks Unlimited Canada, 2008; NRCan, 2007c; St-Hilaire et al., 2008; Parc de la Gatineau, 2007.

Numerous studies have used turtle observation points, trapping and/or tracking to determine suitable habitat and movement patterns of Blanding's turtles (Kofron and Schreiber, 1985; Ross and Anderson, 1990; Rowe and Moll, 1991; Power et al., 1994; Hamernick, 2001; Joyal et al., 2001; Grgurovic and Sievert, 2005; Innes et al., 2008; Edge, 2008). Blanding's turtles movement patterns are associated with seasonal requirements (Rowe and Moll, 1991; Joyal et al., 2001; Hamernick, 2001; Grgurovic and Sievert, 2005) that are related to food, thermoregulation, nesting, hibernation, and mating. Blanding's turtle home range size varies from 1.5 ha to 63 ha (Innes et al., 2008; Piepgras and Lang, 2000) and their mean travel distance can range from $489 \mathrm{~m}$ to $7 \mathrm{~km}$, 
but more commonly they travel up to $2 \mathrm{~km}$ (Ross and Anderson, 1990; Joyal et al., 1996; Bury and Germano, 2003; St-Hilaire, 2003; Edge, 2008). Home range size is often related to several factors including population density, carrying capacity, habitat composition, and distribution of crucial resources such as food, refugia and potential mates (Piepgras and Lang, 2000; Hamernick, 2001). Habitat quality is especially important for females that require more resources for reproduction and consequently travel long distances (>1 km) for resource acquisition (Rowe and Moll, 1991).

The connectivity of wetlands is a fundamental concept of landscape ecology that is important to vagile species such as the Blanding's turtle that travel long overland distances to reach nearby wetlands (Joyal et al., 2001). The connectivity of wetlands refers to the physical proximity to the nearest wetland as well as the corridor quality between wetlands. Barriers and unfavourable habitat that exist between wetlands create a higher risk of mortality and limited movement of individuals between populations and wetland complexes (Joyal et al., 2001). Therefore, the upland landscape surrounding wetlands is important to preserve in order to sustain a population. Blanding's turtles were found to spend up to $38 \%$ of the time in upland areas and travel up to $2 \mathrm{~km}$ between wetlands $(90 \mathrm{~m}-2050 \mathrm{~m})$ (Joyal et al., 2001).

Joyal et al. (2001) found that Blanding's turtles occupied less isolated pools, more specifically the difference in surrounding wetland area between occupied and unoccupied pools was significant within a $500 \mathrm{~m}$ radius but not within a $250 \mathrm{~m}$ radius. Blanding's turtles use several wetlands in a year but only a small number of individuals will typically occupy a single wetland (Joyal et al., 2001). 
Using backward stepwise logistic regression and Blanding's turtle observations, Attum et al. (2008) found that wetland connectivity, connectivity quality and patch (wetland) size were significant predictors of occurrence (positive correlations). Forest area within $250 \mathrm{~m}$ was a significant predictor. A longer shoreline was found to be an important predictor and could be related to important feeding areas (610 m vs. $410 \mathrm{~m})$. They found Blanding's preferred shorter distances to the nearest wetland (48 $\mathrm{m}$ vs. $60 \mathrm{~m}$ ).

\subsubsection{Threats to Blanding's Turtles}

There are several characteristics of Blanding's turtles that make them more susceptible to population decline. Delayed sexual maturity of 16 or 17 years causes low recruitment since the chance of surviving to a reproductive age is low (Hamernick, 2001; Congdon et al., 1993a). Conservation programs must recognize that protection of all life stages is necessary when dealing with a long lived (up to and past 110 years) (Congdon et al., 1993b) species such as the Blanding's turtle that can reproduce past the age of 70 (Grgurovic and Sievert, 2005).

The successful hatching of Blanding's turtles eggs and the sex are temperature dependent (COSEWIC, 2005). This narrow thermal tolerance range and a relatively high minimum thermal tolerance result in high nest failure (COSEWIC, 2005). The temperature-based sex determination can create skewed sex ratios and influence future recruitment (Grgurovic and Sievert, 2005). Roads create a high risk of mortality for gravid females who often use shoulders of roads where there is suitable substrate such as sand or gravel to lay their eggs and no canopy. They often choose open areas to allow 
the sunlight to warm the eggs. Nest predation can be very high, up to $100 \%$ (Ross and Anderson, 1990).

Blanding's turtles travel great distances to reach different wetlands and to nest, as discussed in 2.3.1. Gibbs and Shriver (2000) categorized Blanding's turtle as a semiterrestrial turtle which is at risk of road mortality . Roads can also attract females for nesting, which increase the probability of being killed on the road. Nests along the road may not present successful conditions for incubation and lower recruitment levels (Congdon et al., 2000). Blanding's turtle hatchlings show no directionality (towards water or in general) on the first day of hatching (McNeil et al., 2000) and therefore the

proximity to roads can be detrimental to their chances of survival since there is potential to go onto the roadway. Nesting in open areas can lead to increase predation by such species as: racoons (Procyon lotor), striped skunks (Mephitis mephitis) and red foxes (Vulpes vulpes), and coyote (Canis latrans) (Congdon et al., 1993a). Congdon et al. (1993a) study found nest survival between the years 1985 to 1991 had a low average $(3.3 \%)$ mainly due to nest predation.

\subsection{Habitat Suitability Modelling and Mapping}

\subsubsection{Common Approaches to Habitat Modelling and Mapping}

Habitats are the resources and conditions present in an area that produce occupancy, including survival and reproduction by a given organism, and as such, imply more than vegetation and vegetation structure. A habitat is the sum of the specific resources that are needed by an organism (McDermid et al., 2005; Bissonette and Storch, 2005). Habitat availability is the accessibility and procurability of the physical and biological 
components of a habitat; suitability refers to the ability of an area of potential habitat to sustain life and support population growth (McDermid et al., 2005). Habitat suitability modelling is often used to produce probability maps depicting the likelihood of occurrence of certain species and to determine the landscape properties of preferred habitats (Palma et al., 1999). These models statistically explore the relationship between existing occurrences of the species and the site properties (Store and Kangas, 2001).

Habitat models can be considered the current, best summaries of wildlife-habitat relationships that produce useful and often realistic representations of habitat quality (Larson et al., 2004). Models based on empirical studies can be expensive, time consuming and difficult, especially if the species is rare. Expert knowledge can be transformed into numerical form so that modelling can be conducted without empirical data (Store and Kangas, 2001; Store and Jokimaki, 2003).

To effectively manage wildlife resources, forest managers require models to guide operational changes to habitat structure, aid development of desired habitat conditions, and evaluate potential impacts to species (Kroll and Haufler, 2006). There are several approaches and techniques to modelling the wildlife habitat relationship that exists, by predicting habitat selection and use by an organism (Carver, 1991; Store and Kangas, 2001; Store and Jokimaki, 2003; Larson et al., 2004; Kroll and Haufler, 2006).

There are a variety of methods for habitat suitability modelling, common ones including: 1) Development of Habitat Suitability Indices (HSI) where scores are created from weighted input variables (Catarina et al., 2006; Brown et al., 2000), 2) Analytical Hierarchy process (AHP) and spatial AHP, that produce criteria weights and make criteria of different kinds measurable by the same standard (Store and Kangas, 2001; 
Store and Jokimaki, 2003; Ludwig and Iannuzzi, 2006), 3) Heuristic optimization (HERO) that allows evaluation of habitat related to continuous attributes by applying sub-priority functions without any classification of attribute values (Store and Kangas, 2001; Store and Jokimaki, 2003). In this research the HSI approach was taken where variables critical to habitat of the Blanding's turtle were combined to produce a map of ranked potential habitat.

To manage, produce, combine and analyze spatial data, a GIS application is commonly used. Field inventories and existing data are needed as attribute data in the suitability-evaluation process (Store and Kangas, 2001). Cartographic modelling is a technique used to determine the feasible area, standardization and transformation of raw scores for priority measurements and to calculate a suitability index as a combination of single habitat factors (Store and Kangas, 2001).

For large areas and mobile species that exploit resources from many landscape features in different and distant locations, the evaluations become more complex (Garcia and Armbruster, 1997). Larger areas need more extensive management and analysis of large amounts of data (Store and Kangas, 2003). To reduce the area requiring evaluation a feasible area is determined by applying a Boolean overlay to the study area, so that unfeasible areas can be excluded. For example, this method was used in this research by creating an initial wetlands map that masked out non habitat classes of agriculture, forest and road.

A habitat suitability index (HSI) and/or habitat suitability map (HSM) is often determined by an evaluation of life requirements supplied by landscape features, such as: water, food, and cover (thermal, security, reproduction, etc.), which enables habitat 
suitability evaluation (Store and Kangas, 2001). Evaluations of habitat related to life requirements can be efficiently conducted manually for small land units with species of limited mobility. Species specific habitat requirements can also be described as habitat factors. In this research each habitat factor was treated as its own layer and given a score (more information in Section 3.6.2).

A HSI is a unit-less value between 0 and 1 that estimates habitat condition based on characteristics of land cover types. The relationships between HSI and cover types can be described mathematically, which provides a means of quantifying the effect of habitat management (Larson et al., 2004; Garcia and Armbruster, 1997).

Landscape-scale HSI models can incorporate important landscape structure and composition variables, such as habitat patch size, edge effects, and the juxtaposition and interspersion of habitat pre-requisites. Habitat models implemented in a GIS allow researchers to view and analyze spatial and other statistical variation in HSI values across a landscape (Larson et al., 2004; Dijak et al., 2007; Manton et al., 2005).

\subsubsection{Previous Research using Remote Sensing and Habitat Suitability Modelling Relevant to this Research.}

There are many habitat suitability maps and models that utilize remote sensing (e.g. Verlinden and Masogo, 1997, Osborne et al., 2001; Bechtel, 2004; McDermid et al., 2005; Benoit et al., 2008; Pasher et al., 2007) to classify landcover and vegetation types as well as the their configuration.

The pixel-based approach provides a pixelised representation of land cover that does not allow as easy demarcation of habitat maps for conservation purposes, whereas the object-based approach to classifying land cover results in solid habitat blocks, while still 
retaining small scale information. The object-based technique provides meaningful objects that can also be integrated directly into vector-GIS for further analysis (Bock et al., 2005). The technical details of object based segmentation and classification are given in 2.5.1 using the methods for habitat mapping given here.

A study by Bock et al. (2005) emphasized the use of multiple scales to produce habitat maps at regional and local scales. An object-oriented rule network was applied to high resolution satellite (QuickBird) data to map various habitats, including: urban, geest (healthland), lowland, bog and forest with several sub classes within each. Medium resolution imagery (Landsat ETM+) was used to map habitat at the regional scale, including: soil, vegetation, non-vegetation, water, buildings. Bock et al. (2005) state that "Object oriented classification methods and knowledge-based sets of rules enable the substantial limitations of purely spectral and pixel-based methods to be overcome and raise the potential for the use of EO data in future conservation monitoring".

To map habitat in the Iberia coastal mountains, Varela Diaz et al. (2008) used Landsat imagery and compared the pixel based approach (using supervised classification with a Maximum Likelihood Classifier) and object based approach (using nearest neighbour decision rules). Ortho-rectified aerial photographs were used as reference data in the training and accuracy assessment stages of analysis. Habitat types varied greatly, including: native forests, agricultural mosaics, rocky habitats, urban areas, grasslands, several wet and dry heathland types, and bogs. Objects were created based on field perception of habitat boundaries and the parameters were adjusted based on a trial-anderror procedure. They did not find that one approach was better than the other, noting advantages to classification accuracy related to each approach (often dependent on class). 
Varela Diaz et al. (2008) postulated that object-based classification may outperform pixel-based if the spatial resolution was higher than used in their study since the elements being classified were smaller than the spatial resolution of Landsat $(30 \mathrm{~m})$.

\subsubsection{Wetland Mapping using Remote Sensing}

Traditionally, at local scales, wetlands and other land cover types were mapped using visual interpretation of aerial photographs by digitizing boundaries and labelling classes manually. However, over larger areas many air photos are required resulting in time consuming processes of acquisition and inconsistency between photos that may decrease classification accuracy (Becker et al., 2007).

Wetlands have a high diversity and inter and intra-class variability that make them a difficult land-cover type to classify accurately (Baker, 2006). Riparian zones and wetlands are mostly determined by geological, topographic and hydrological conditions that affect their size, shape and distribution (Baker, 2006) which makes them highly variable and heterogeneous. Characteristics of wetlands vary transitionally into uplands, making wetland delineation challenging and often imprecise (Chui and Couloigner, 2006). Chui and Couloigner (2006) proposed remote sensing data as a source for analysis of wetlands; however they caution that the quality of data sources and the ability of data interpretation will determine overall classification accuracy.

The benefits of high resolution imagery are that focal wetland attributes (e.g., wetland vegetation, logs, and wetlands with small open water sections or overall small boundary extent) can be captured effectively (Becker et al., 2007; Baker, 2006; Chui and Couloigner, 2006). 
Traditionally aerial photographs (or orthophotos) have been used to manually classify landcover types (e.g., forest, wetlands, roads, buildings, agriculture, lakes, rivers). Some landcover type classifications and regions with high topographic relief require orthorectification which is time and cost intensive. Medium resolution satellite imagery has been used in classification for decades, however it has limitated classification accuracy of detailed classes or small features due to spatial resolution.

An example of manual orthophoto classification is Larthrop et al. (2005) who used visual interpretation of leaf-off colour infrared digital orthophotos in a computerized GIS environment to identify and map over 13,000 potential vernal pools. Using $1 \mathrm{~m}$ pixel imagery, they determined the minimum detectable pool size to be 0.02 ha $\left(200 \mathrm{~m}^{2}\right)$ (Larthrop et al., 2005).

The New Brunswick Department of Natural Resources wetland inventory was derived from visual interpretation of colour ortho-rectified digital aerial photographs. It was compared to the continuous depth-to-water map derived from a DEM and hydrographic data (Murphy et al., 2007), and they were able to locate wetlands larger than 1 ha.

Coastal wetlands of the Great Lakes are very important habitat for the area's wetland dependent species. IKONOS imagery was used by Wei and Chow-Fraser (2007) to map coastal wetlands of Lake Huron and Georgian Bay. They manually delineated the wetlands before conducting a supervised classification (MLC). The high classification accuracy, cheaper cost and larger swath of IKONOS (over aerial photography) showed the potential of mapping the remaining coastal wetlands with these data and techniques.

Chiu and Couloigner (2004) incorporated texture features into the classification of wetlands using Landsat TM data to and found that classification accuracy increased from 
$61.5 \%$ using only spectral bands to $92.6 \%$. They found very similar spectral reflectance between wetlands and open vegetation classes and that these two classes were better discriminated using image texture (Chiu and Couloigner, 2004). Wright and Gallant (2007) mapped wetlands in Yellowstone National Park using Landsat TM imagery, DEM-derived terrain variables, texture variables and classification trees. Landsat TM was relatively accurate at separating wetland from upland but the error rated dropped as terrain and texture variables were incorporated.

The Ontario Ministry of Natural Resources and Ducks Unlimited Canada (2003) developed a methodology to create a land cover layer using satellite imagery (Landsat and Indian Remote Sensing (IRS)), aerial photography, DEM data, and quaternary geology to derive a topographic index (TI) or topographic soils index (TSI), through a program called SOLRIS (Southern Ontario Land Resource Information System). The main objectives of mapping wetlands were to map 'unevaluated wetlands' (not previously mapped) and the secondary objective was to identify small temporary ponds (ephemeral wetlands). The spectral analysis yielded poor results in classifying ephemeral wetlands, which is partially due to the coarseness of the imagery and small size of the targeted wetlands. The TI and TSI were of greater benefit than the spectral information.

Hogg and Todd (2007) also used a DEM to map wetlands; however they created terrain derivatives to map wetlands. They focused on wetland boundary delineation using methods 1) visual derivate image threshold 2) logistic regression model and 3) classification and regression tree (CART) model. The CART method is a form of statistical analysis that can be used for exploring and uncovering data structure and is conducive to creation of prediction rules, variables to be evaluated and a large number of 
variables to be summarized within one process. One of the benefits of CART is that the relationships between the dependent and predictor variables do not have to be linear. CART analysis methods were used to provide insight into the selection of optimum derivatives for wetland topography explanations that are predictors used in classification of wetlands (Hogg and Todd, 2007).

Hyperspectral data AVIRIS (Airborne Visible/Infrared imaging spectrometer) has been used to map wetland vegetation (Hirano et al., 2003) and compared to manual interpretation of colour infrared aerial photographs. Limitations were found in the coarse spatial resolution of the data and from not incorporating information on spatial/geographical context that is included in manual interpretation of aerial photographs. Their results were not generally as accurate as the manual interpretation classification method and the methods were less labour intensive and could be automated to extend to other areas. Zomer et al. (2009) used airborne hyperspectral imagery (PROBE-1) to map wetlands at the global level.

Radar has been used to detect wetlands in many studies since the late 1960's (Pietroniro and Leconte, 2000; Ozesmi and Bauer, 2002; Grenier et al., 2007; Henderson and Lewis, 2008). A couple of benefits of radar include its sensitivity to dielectric properties which varies with soil and vegetation moisture content and its ability to penetrate vegetation canopies (unlike optical imagery). Different bands of radar have been used to classify wetlands as well as different polarizations and incidence angles. In Henderson and Lewis' (2008) review of radar detection of wetland ecosystems they concluded that L-band and C-band with $\mathrm{HH}$ polarization were optimal for mapping forest or herbaceous wetland vegetation. Henderson and Lewis (2008) and Grenier et al, (2007) 
also reviewed studies that used a combination of radar and optical imagery and found benefits in using both data types.

\subsubsection{Habitat Mapping for Specific Species}

Object-based classification of Landsat-7 ETM+ images was used to identify potential habitat for the Grasshopper Sparrow in Québec (Benoit et al., 2008). Reference sites of previously detected Sparrow locations were used to derive characteristics of the habitat patches that could be interpolated in other areas. The initial segmentation step was to separate the suitable land cover type (agriculture fields) from unsuitable types (wetlands, forest, water) using a membership function. Once the potential sites (agriculture) were identified, a second level of segmentation was performed to eliminate unsuitable sites. A third level of segmentation was performed on the remaining potential sites which divided continuous fields that had different textural and spectral information. The object features used were band ratio, texture, context, brightness and shape (similar to those in this research).

Pasher et al. (2007) compared high resolution (IKONOS) to medium resolution (Landsat ETM+) imagery in classification of potential habitat for the threatened (in Ontario) species, the hooded warbler (Wilsonia citrina). Observed nesting sites were used to identify common characteristics that could be modeled using remote sensing analysis of landscape features. The nesting site (and characteristics identified) could be considered the deterministic habitat factor. The main characteristic of nesting sites was gaps in the canopy as measured by skyward hemispherical photographs. The gaps were shown to be associated with larger shadows and greater shadow variability in remotely 
sensed imagery. Image heterogeneity measures such as image texture were found to discriminate nest areas from non-nest areas in classifications using the maximum likelihood classifier and binary logistic regression. They concluded that nesting habitat could be identified using remote sensing imagery and analysis.

Woodland caribou (Rangifer tarandus caribou) habitat was mapped using classified Landsat TM scenes and woodland caribou telemetry data (Bechtel et al., 2004). A statistical analysis was performed at the sites where caribou locations intersected the classified scene to determine if there was a pattern in the spectral classes occupied or avoided. The spectral signal related to the habitat type was used as the deterministic habitat factor to map potential caribou habitat. For instance, woodland caribou were found to use the 'black spruce group' more and 'treeless fen' less.

Mladenoff et al. (1995) created a habitat model for grey wolves to determine if they have the potential to expand their territories. Telemetry was used to determine where the wolf packs inhabited the landscape as well as avoided areas (non pack areas where wolves had viable movement). Logistic regression analysis was used to determine the land use/land cover types that were correlated and not correlated with wolves.

Habitat suitability for ungulates and ostriches in Botswana was mapped using NDVI extracted from Advanced Very High Resolution Radiometer (AVHRR) data (Verlinden, 1997) to test whether sites with suitable habitats for different species have different spectral signatures compared to unsuitable habitat. They found that only some species were associated with the level of greenness and NDVI. There were significant relationships between NDVI and grass greenness and animal density increased in some instances of higher NDVI. 
Kroll and Haufler (2006) calculated mean values for HSI model variables for the dusky flycatcher (Empidonax oberholseri). They determined the correlation between site HSI values and several categories of behavioural use such as nesting success, annual reproductive success, and density of breeding territories at each site. The mean values for model variables are calculated from all transects or plots sampled within a specific territory or area of interest (Carter et al., 2006; Kroll and Haufler, 2006).

Burnett and Blaschke (2003) used multi-scale segmentation to delineate suitable habitat patches for the three-toed woodpecker that are related to different forest patch characteristics. Another project by Burnett and Blaschke (2003) monitored bush encroachment in a biosphere reserve. A mosaic of aerial photographs was ortho-rectified and used to identify single bushes and encroachment within pastures. The ability to segment small features such as shrubs was of great benefit in this type of wetland vegetation mapping.

\subsubsection{Blanding's Turtle Habitat Suitability Mapping}

While there have not been any studies of Blanding's turtles habitat using digital remote sensing, several studies have used aerial photography to identify habitat characteristics and aid in spatial mapping of turtle movement. Most studies did not report the resolution of the aerial photographs or orthophotos used.

In a study by Hamernick (2001) the positions of radio tracked Blanding's turtles were traced onto a Digital Orthophoto Quarter Quadrangle map (DOQQ) in the field and eventually incorporated in GIS as $\mathrm{x}, \mathrm{y}$ coordinates. The $\mathrm{x}, \mathrm{y}$ locations were overlaid on 
1989 USGS land cover maps with 12 classes. To determine habitat types that were either selected, avoided or neither, a statistical model created by Neu et al. (1974) was utilized.

Hamernick (2001) also calculated the home range area and home range length used by males and females. Of the 12 land cover categories, Blanding's turtles only used three: Emergent, Submergent-Rooted Floating Aquatic (SRFA) and Woody Terrestrial. The turtles found in the Woody Terrestrial habitat were usually females in transit to a nesting site or were actually in waters of flooded deciduous forest or in a small pocket of wetland within floodplain forest. The Woody Terrestrial category had problems of misclassification due to the creation, implementation and accuracy of the land cover map. The small wetlands that were misclassified as Woody Terrestrial were smaller than the minimum mapping unit ( $<1$ ha) used and were consequently misrepresented. Hamernick (2001) suggests that a habitat selection survey should be conducted at a finer scale than lha to allow more accurate results.

In a study by Joyal et al. (2001) in Maine, USA, a base map of the study area was delineated from aerial infrared photographs (1:9600) and digitized into a GIS. The perimeters of 76 wetlands were located visually, digitized and then geo-referenced. They found that Blanding's turtles used permanent pools, seasonal pools and forested swamps, with the majority of time (over 50\%) spent in permanent pools. Occupied pools were less than 0.4 ha in size with a mean of 0.176 ha. These small wetlands, especially vernal pools, escape detection and often fail to meet the size criterion to be eligible for protection. If it were not for the visual interpretation of aerial photos they would not have detected the small wetlands to survey for Blanding's turtles. These findings were 
taken into consideration in the planning of this thesis research to map small wetlands $(<1$ ha.)

Edge (2008) used spatially referenced orthophotos to visually locate wetlands in Algonquin Park (Ontario). Each wetland was also field validated with a handheld GPS to ensure classification accuracy. Habitat was evaluated at the home range scale, in which no difference in habitat selection among seasons was found. Edge (2008) also did not find "conclusive evidence of seasonal shifts in microhabitat preference". However, he did find that overwintering sites that are thermally stable at around $0^{\circ} \mathrm{C}$ were more often selected. The reason that he did not find seasonal shifts in micro or macro habitat in the study area (Algonquin Park, Ontario, Canada) was that the habitat available was not low quality or a limiting resource for Blanding's turtles. He postulated that more disturbed habitats (e.g., not a wilderness Park) are more conducive to microhabitat selection based on "important habitat features that may represent limited resources".

Bourque (2006) studied Blanding's turtle patch occupancy in Nova Scotia using interpretation of aerial photographs to characterize wetland type and subclasses, vegetation distribution and percent vegetation cover. He found that such interpretation was useful to identify coarse characteristics of wetlands but the method did "not appear to be sufficiently precise to capture habitat features key to Blanding's turtle presence". None of the above variables were found to be significant predictors of Blanding's turtle presence, whether assessed in the field or from the aerial photographs. This was thought to be due primarily to the habitat available and sampling bias. The majority of wetlands were either fens or bogs and Blanding's turtle trapping could really only occur in fens 
where there was water, creating a low sample size for any other wetland types and inhibiting identification of statistically significant trends.

In summary, most previous studies have noted that aerial photographs are valuable for identifying unsurveyed wetlands and some habitat characteristics suitable to Blanding's turtle. No previous studies have mapped wetlands for Blanding's turtles habitat or population research using classification techniques; instead all studies found used visual interpretation of aerial photos of varied scales. The approach taken in this research was to use high-resolution digital orthophotos with advanced image segmentation and classification methods that can incorporate various aspects of image spatial and spectral information in classification of critical habitat features. Background to these image processing and analysis methods is given in the next section.

\subsection{Aspects of Remote Sensing Relevant to this Research}

Aspects of remote sensing applied in this research that were more advanced than traditional pixel -based classification methods are described in this section. A rule-based classification using object-based segmentation was applied with class defining attributes related to texture, shape, area and context in addition to spectral information.

\subsubsection{Object-based Segmentation and Classification}

Single pixel-based classification often produces thematic maps with a salt-and-pepper effect due to individual pixels often being assigned a class different from their neighbours (Bock et al., 2005). To resolve this problem, some options include: 1) image preprocessing using techniques such as low-pass filters and texture analysis (Hill and Foody, 1994), 2) contextual classification (Gong et al., 1992), and 3) post-classification 
processing techniques, such as mode filtering of classified maps (Yu et al., 2006). All of these options incorporate spatial information to characterize each class using neighbourhood relationships. An object based approach was selected for the Canadian Wetland Inventory (Fournier et al., 2007) because of its "flexibility for classification rules and suitability for the spatial heterogeneity of wetlands".

There are several object-based software packages available (ENVI Feature Extraction (ENVIFx); ESRI ArcView Feature Extraction; Definiens Ecognition for Earth Sciences (Definiens AG, 2007)). Ecognition, used in this research, offers over 100 different feature expressions that can be used individually in a rule set to assign objects to a class or in conjunction with other object feature expressions.

In object-based classification, the image is split into objects through segmentation and objects are linked to their neighbours, enabling access to the context of each image object primitive. Image objects are organized into levels (Figure 7), with the option to create objects within an image object level or at the pixel level. Different object levels (image object sizes and inter-relations) can be used for subsequent classification of the same scene (Definiens AG, 2007).

The image objects are hierarchically structured, meaning that all objects on a lower level are completely contained in exactly one object of a higher level (Figure 7). There are two types of feature distance: level distance refers to distance between image objects on different object levels in the object hierarchy (processes with different scale parameters selected); spatial distance refers to distance between objects on the same object level in the hierarchy (e.g., 0 refers to bordering objects) (Definiens AG, 2007). 


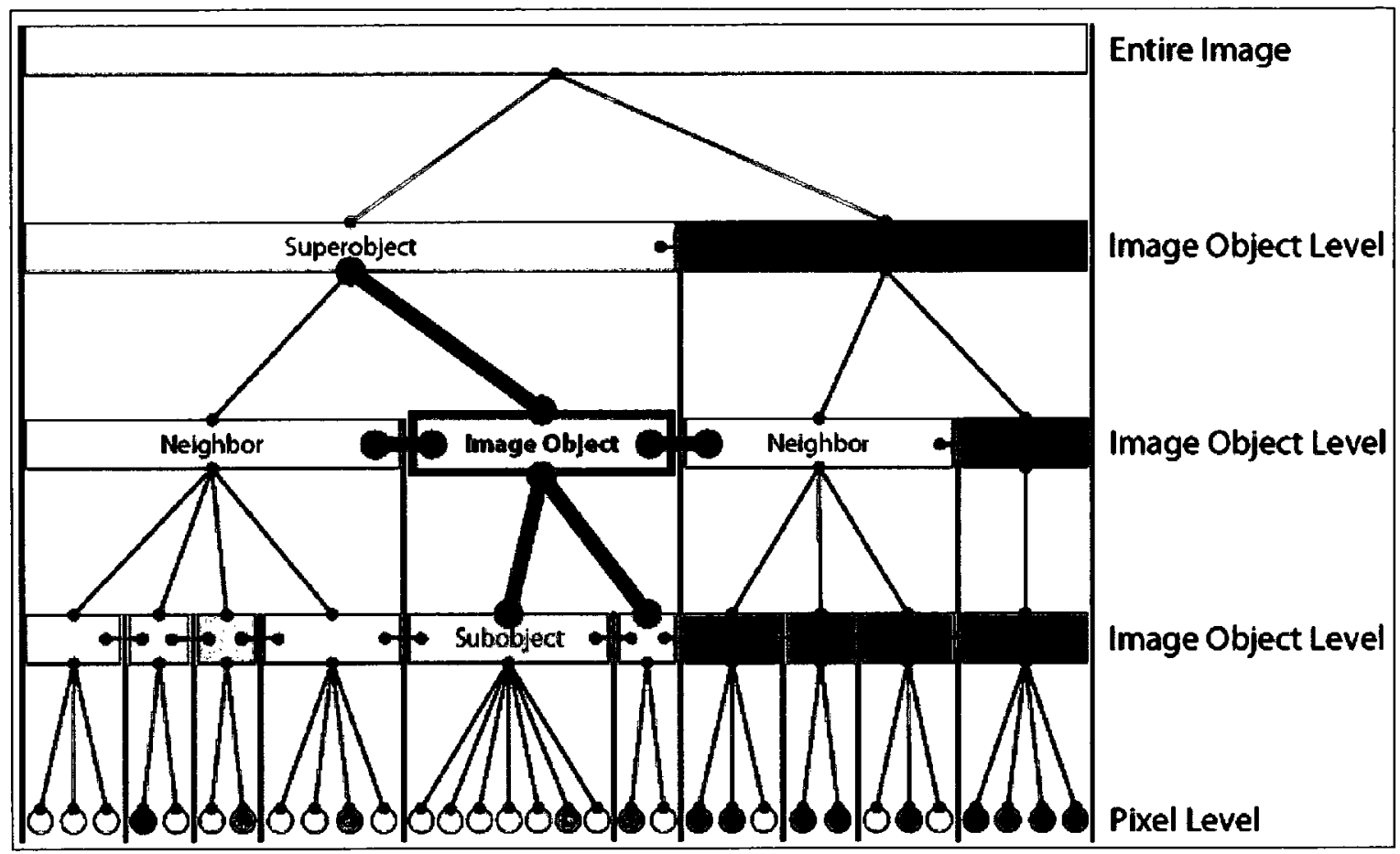

Figure 7. Image object levels consist of a layer of image objects that are linked to their neighbours (superobjects, subobjects). Source: Definiens AG, 2007.

There are several types of segmentation that can be applied at the pixel level to create new image object levels, including: chessboard segmentation (equal sized squares), quadtree segmentation (creates squares of different sizes) or multi-resolution segmentation (Definiens AG, 2007). Multi-resolution segmentation is an optimization procedure that locally minimizes the average heterogeneity of an image object for a given resolution. The algorithm used by this process can be applied at the pixel or object level. Image objects or pixels are merged into larger units as long as the upper threshold of homogeneity is not exceeded locally. The homogeneity criterion is a combination of spectral and shape homogeneity. Homogeneous data will generally result in larger objects than heterogeneous data (Definiens AG, 2007).

The size of image objects is also influenced by the user-defined scale parameter. The user defines a scale parameter that affects object size by selecting a higher scale to create 
larger objects or a smaller scale to create smaller image objects. The objective is to produce objects using the coarsest possible scale while still being fine enough to distinguish between targeted regions or classes (Definiens AG, 2007).

Four homogeneity criteria define the total relative homogeneity for the resulting image objects at the specified scale: colour, shape, smoothness and compactness (Definiens AG, 2007; Lucieer, 2008). Each criterion is weighted from 0 to 1 . The higher scale (larger) objects are typically broad landcover types that are divided into lower level (smaller) objects until all targeted classes are identified (Bock et al., 2005).

The colour parameter is synonymous with spectral reflectance or brightness, and is usually the most important criterion to create meaningful objects. The shape parameter defines the regularity of delineated object boundaries in terms of two sub-parameters, smoothness and compactness (Definiens AG, 2007). Smoothness refers to optimizing the resulting image objects in regard to smoothness of border (heterogeneous data should have a higher value). Compactness minimizes deviation from a compact form such as a square (homogeneous data should have a higher value) (Definiens AG, 2007).

The weight for the colour criteria is defined in relation to that for shape such that (e.g., shape $=0.2$; colour $=0.8$ ) (Figure 8 ). The colour criterion should be as high as possible to ensure spectral homogeneity of the resulting objects. The weighting of shape $\left(\mathbf{w}_{1}\right)$ can be set between 0.1 and 0.9. Colour and shape weighting sum to one, therefore the colour weight is automatically input based on the weight input for shape $\left(1-\mathbf{w}_{1}\right)$. The weighting of compactness $\left(\mathbf{w}_{2}\right)$ within the shape criterion is set between 0.1 and 0.9 . Weighting of smoothness $\left(1-\mathbf{w}_{2}\right)$ and compactness sum to one, therefore the weight set for compactness determines the weight for smoothness. 
Based on the weighting settings of shape and compactness, the weighting of compactness within the enclosing homogeneity criterion is $\left[\mathbf{w}_{\mathbf{1}} * \mathbf{w}_{\mathbf{2}}\right]$. For smoothness the weighting is $\left[\mathbf{w}_{1} *\left(1-\mathbf{w}_{2}\right)\right]$. Therefore, if the user inputs the shape weight value as 0.4 and compactness as 0.7 , then the weighting (within the homogeneity criterion) of compactness and smoothness is 0.28 and 0.12 , (sum to 0.4 ) respectively.

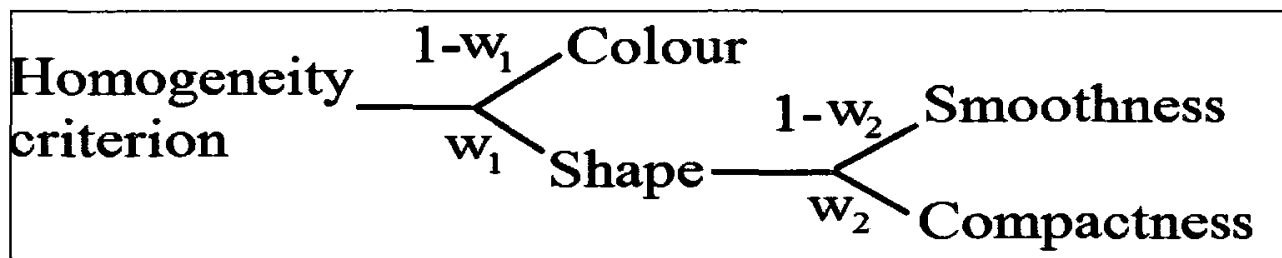

Figure 8. Weighted components of the homogeneity criterion. Source: Adapted from Definiens AG, 2007

The shape criterion should be as high as necessary to produce objects with the smoothest borders and greatest possible compactness (Definiens AG, 2007). In implementation, it is generally necessary to iteratively adjust these parameters and weights based on visual interpretation of the resulting object maps until a map is produced that best matches the desired landscape objects (Burnett and Blaschke, 2003).

In the object classification stage an object feature can be evaluated by itself or as it is embedded in in the context of the image object hierarchy, using one or a combination of the following object feature groups: texture (co-occurrence matrix by Haralik (1979)); shape (e.g., length or area), context (e.g., distance to another class), layer values (e.g., mean brightness or standard deviation), or thematic attributes (e.g., related to a thematic layer such as a landuse vector file).

The main attributes (object features) used to classify wetland types and distinguish wetlands from uplands in this research were texture (e.g., contrast), brightness and context (e.g., relative border to neighbour objects). One of the applicable conclusions 
from Grenier et al. (2008) to this research is that the user-selected attributes and membership functions were comparable in classification accuracy to those identified by logistic regression. Grenier at al. (2008) used similar methods to map 5 wetland types with SPOT-4 imagery (15m pixels). Texture, brightness, band ratios, shape, area and relation to borders were the main attributes used.

Gilmore et al. (2008) used LiDAR and QuickBird (2.44 m resolution) to map wetland vegetation in a tidal marsh. A field spectroradiometer was used to measure the reflectance spectra of the dominant vegetation communities to compare with the QuickBird reflectance patterns. A hierarchical object-oriented approach using band ratios and a Normalized Difference Vegetation Index (NDVI) was used to discriminate plant species, in addition to utilizing canopy height information from LiDAR.

\subsubsection{Texture Analysis}

Textural information is increasingly being used for class discrimination of remotely sensed images (Arzandeh and Wang, 2002; Chui and Couloigner, 2004; Bock et al., 2005; Grenier et al., 2007). Image texture quantifies the spatial variation of tone that is related to the distributions of different land cover types on the ground surface (Arzandeh and Wang, 2002). Traditional classification algorithms do not consider the potential of spatial information existing between a pixel and its neighbours when applied on a pixel by pixel basis. Chui and Couloigner (2004) found the overall accuracy of wetland classification can be improved by $5 \%$ by incorporating texture measures in the classification process. In this thesis research, due to a relative lack of spectral information in the air photos, texture information was critical. 
Grey-level co-occurrence matrix (GLCM) texture metrics are the most widely used in classification (Chiu and Couloigner, 2004; Yu et al., 2006; Pasher et al., 2007). The GLCM is derived from the relative frequencies of two neighbouring pixels separated by a distance on the image (reference and neighbour pixel). Higher frequencies are generally found along or near the diagonals of the matrix due to spatial autocorrelation as proximal pixels are more similar in brightness than distant pixels. Consequently, image brightness variations (texture) in local regions are often indicative of land cover types or conditions. Incorporation of texture measures can improve classification for different cover types by representing local variability of grey levels across the landscape.

Texture can be derived from a moving window of specified size or for a defined image object, where the texture is calculated for all pixels in the object. Texture calculations can be generated using pixel sampling in all directions or user-specified directions $\left(0^{\circ}\right.$, $45^{\circ}, 90^{\circ}$ or $135^{\circ}$ ). The texture measures evaluated for potential use in the landcover mapping (section 3.3.3) and wetland mapping stage of this research (Section 3.4.3.1 and 3.4.3.3) are described briefly in Table 1. These descriptions are generic, and testing is commonly done to determine which measures best discriminate given land cover types or targeted classes.

\subsection{Summary}

From the above literature analysis several aspects were deemed to be key considerations in development of this research, including the following. Habitat attributes that are critical to Blanding's turtle and that have potential for mapping with high resolution imagery included water bodies, wetland vegetation and logs. These attributes have potential to be represented as objects using image segmentation and classification 
algorithms. Given high resolution imagery is required, image spatial information was expected to contribute significantly to habitat feature classification.

Table 1. Description of texture measures that were evaluated for suitability in wetland mapping (Sources for descriptions: Definiens AG, 2007 and PCI Geomatics, 2008)

\begin{tabular}{|l|l|}
\hline Texture & Brief description \\
\hline Homogeneity & $\begin{array}{l}\text { High when GLCM frequencies concentrate along the diagonal } \\
\text { meaning high local homogeneity. }\end{array}$ \\
\hline Contrast & $\begin{array}{l}\text { The opposite of Homogeneity, measuring the amount of local } \\
\text { variation in the image and very responsive to edges where image } \\
\text { brightness changes significantly. It is high when the local region has } \\
\text { high contrast. }\end{array}$ \\
\hline Dissimilarity & $\begin{array}{l}\text { Similar to Contrast, it is high when the local region has a high } \\
\text { contrast. }\end{array}$ \\
\hline Mean & Average grey level in the local window. \\
\hline $\begin{array}{l}\text { Standard } \\
\text { Deviation }\end{array}$ & $\begin{array}{l}\text { Grey level standard deviation in the local window. It is high when } \\
\text { there is a large grey level standard deviation in the local region. }\end{array}$ \\
\hline Entropy & $\begin{array}{l}\text { High when the frequencies of GLCM are distributed equally meaning } \\
\text { all brightness pairs have equal probability. Low when the image is } \\
\text { uniform. }\end{array}$ \\
\hline $\begin{array}{l}\text { Angular } \\
\text { Second } \\
\text { Moment } \\
\text { (ASM) }\end{array}$ & $\begin{array}{l}\text { Opposite of Entropy. It is a measure of local homogeneity. High when } \\
\text { the pixels are similar in window. }\end{array}$ \\
\hline Correlation & Measures the linear dependency of grey levels of neighbouring pixels. \\
\hline & $\begin{array}{l}\text { Similar to Angular Second Moment, it measures the local } \\
\text { homogeneity. High when some elements are large and the remaining } \\
\text { ones are small. }\end{array}$ \\
GLDV ASM
\end{tabular}




\section{CHAPTER THREE \\ METHODS}

\subsection{Geographic Context and Study Area}

\subsubsection{Selection of Study Area}

The north-western portion of Gatineau Park was selected as the research study area for several reasons related to the recorded distribution of Blanding's turtles, logistics and environmental variables. The most prominent reason was because it may be used as an ecological corridor that is a connecting landscape for the population observed near the town of Bristol (Figure 6a) and is the area of the park where most Blanding's turtle observations have been made (Figure 6a) (QMNRF, 2008). Secondly, Carleton University (D. King) has a long standing scientific collaboration with the park that includes sharing of existing geo-spatial data such as high resolution digital elevation models, ortho-photographs and GIS layers that were advantageous to this project.

The pre-existing geospatial database includes: wetlands, lakes, streams, roads, buildings and trails in the park. For logistical reasons, the study area is close to the Geomatics and Landscape Ecology Lab where vehicles and equipment are stored, making intensive daily field work easy to conduct. In addition, it was easier to obtain a permit to conduct field work within the park than obtaining permission and access to multiple privately owned land areas.

Gatineau Park is a relatively natural environment when compared to the surrounding urban and agricultural areas. It has different environmental characteristics than the lowlands to the south in Ottawa, as it is on the Canadian Shield and has variable 
topographic relief. In particular, there is a variety of wetland vegetation communities including open grassland areas, deciduous, coniferous and mixed forest, and a multitude of wetlands (NCC, 2005) that may have potential as Blanding's turtle habitat.

The Ecozone of La Pêche Lake is in the Southern Laurentian Ecoregion and borders the Mixedwood Plain Ecozone, Common tree species found in the study area and surrounding regions are: Abies balsamea (L.) balsam fir ; Acer rubrum (L.), red maple; Acer saccharum (L.), sugar maple; Pinus strobus (L.), eastern white pine; Quercus rubra (L.), red oak; Tsuga Canadensis (L.), eastern hemlock; Betula papyrifera (L.), white birch; Populus tremuloides (L.), trembling aspen, and Tilia Americana (L.), basswood (NRCan, 2003; McGill University, 2008)

The average daily temperature ranges from $-11.5^{\circ} \mathrm{C}$ in winter to $20.7^{\circ} \mathrm{C}$ in summer. Rainfall varies from $19.6 \mathrm{~mm} / \mathrm{month}$ to $93.1 \mathrm{~mm} / \mathrm{month}$. Snowfall varies from 0 $\mathrm{cm} /$ month to $58.1 \mathrm{~cm} /$ month (Environment Canada, 2008). The elevation in the study area varies from 120 to $300 \mathrm{~m}$ (NRCan, 2007c). The area south of the park is separated by an escarpment and is lower lying with less relief, at 80 to $100 \mathrm{~m}$ (NRCan, 2007c). La Pêche Lake is the largest water body in the study area and is surrounded by a significant number of wetlands of different sizes and types (Figure 9). The Québec Topographic Database (BDTQ) (QMNRF, 2008) has 82 wetlands mapped in this research study area, none of which has a classified wetland type. The Conservation Atlas of Wetlands (Belanger and Grenier, 2003) has 14 wetlands mapped. There are also some wetland and waterbody (lakes, etc.) vector datasets available from the National Topographic Database (NTDB) (NRCan, 2007c) (Figure 9). 


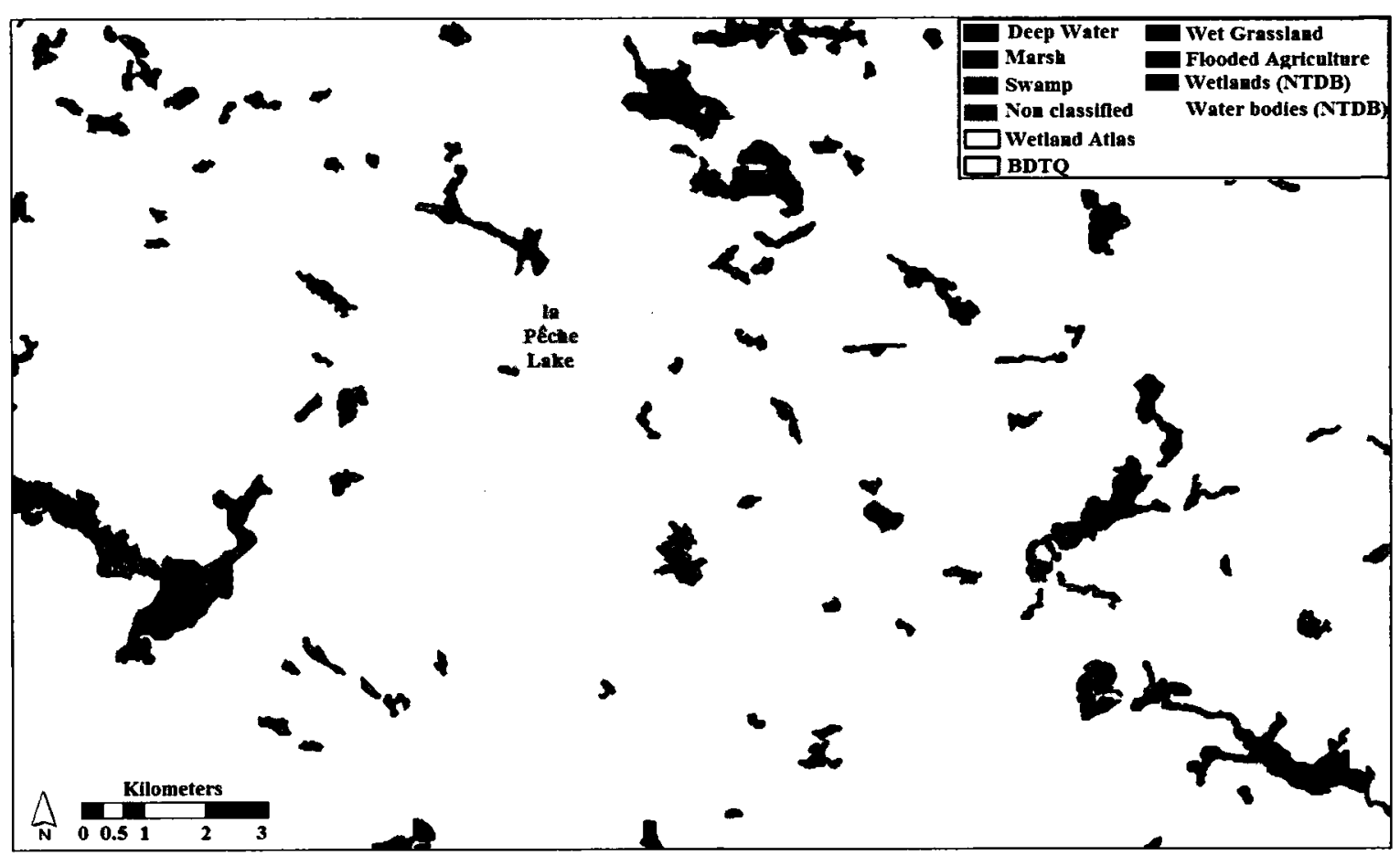

Figure 9: Existing water classified in the study area, including: wetland layers from Ducks Unlimited and Wetlands of Eastern Ontario and water bodies. White signifies forest, urban or agricultural areas. Note that during this research many more small wetlands were identified than are shown on this map. Source: NRCan, 2007c; Ducks Unlimited Canada, 2008

\subsection{Field Site Selection and Data Acquisition}

Field reconnaissance was carried out between May and September 2009 in two different sections. Field work was conducted to learn about and develop experience in searching for and observing Blanding's turtles, to evaluate a variety of wetland types for habitat features, and to validate potential habitat classifications using those attributes as well as known Blanding's observation locations.

The first portion of field reconnaissance was the Blanding's turtle population distribution inventory that was carried out with support from members of the following organizations: QMNRF, the Nature Conservancy, Canadian Wildlife Service (CWS), the NCC and two other Masters students. 
The main criteria used to select wetlands to survey were: size, distance from road and identified clustered wetlands. To locate wetlands in the inventory area, existing geospatial data were used. A wetland map was provided by Ducks Unlimited Canada (2008) that included polygons classified into 8 wetland types: Pond, Wet meadow; Marsh; Swamp (dominated by tree or shrub swamp); Inundated agriculture; Bog; Peatlands; Aquatic plant and Unclassified. Among the 104 wetland polygons in the NW section of Gatineau Park, 89 were categorized as unclassified so it was difficult to develop a prioritized list of wetlands to visit. Instead, routes were designed based on accessibility, to visit as many wetlands as possible.

The second phase of field work was spent surveying various types of wetlands with the study area between June and August. Several data sources were utilized to locate wetlands to survey and plan routes. The NCC provided leaf-off spring digital highresolution (20 cm pixels) aerial photographs that were ortho-rectified and tiled. Potential wetlands were visually identified, outlined in a GIS and categorized according to known information and priority for field survey (Table 2). Each category was symbolized by colour in the GIS layer to aid planning routes for each day's excursion (Figure 10).

Access into field sites was initially made from a road, trail or lakeshore. Wetland distances from roads varied from being adjacent to up to about $3 \mathrm{~km}$. Distance between wetlands could vary from tens to hundreds of metres. Topography was considered when selecting travel routes for field sites. To efficiently locate wetlands, geo-referenced points were selected as routes to enter, exit and traverse between wetlands. A point was also geo-referenced in the centre of each wetland or in the particular area of the wetland that was important to survey if it was a large wetland or extensive complex. 
Table 2. Polygons that outlined potential wetland survey locations (Figure 10) were manually created and categorized based on characteristics that were visually interpreted in orthophotos.

\begin{tabular}{|c|c|c|c|}
\hline $\begin{array}{l}\text { Colour } \\
\text { category }\end{array}$ & Size & $\begin{array}{l}\text { Wetland } \\
\text { description }\end{array}$ & Survey priority \\
\hline Pink & Very small & $\begin{array}{l}\text { Ephemeral or small } \\
\text { wetland; possibly } \\
\text { full or partial } \\
\text { shadow from } \\
\text { topography or tree } \\
\text { canopy }\end{array}$ & $\begin{array}{l}\text { Low priority but visit if } \\
\text { nearby. }\end{array}$ \\
\hline Red & Any size & $\begin{array}{l}\text { Wetland vegetation } \\
\text { mounds or groups of } \\
\text { wetland vegetation } \\
\text { (islands), trees, logs. }\end{array}$ & $\begin{array}{l}\text { High priority; highest } \\
\text { within wetland } \\
\text { variation; more } \\
\text { attributes needed for } \\
\text { classification and } \\
\text { validation. } \\
\end{array}$ \\
\hline Green & Any size & $\begin{array}{l}\text { High wetland } \\
\text { vegetation cover; } \\
\text { may be mostly dried } \\
\text { up in summer. OR } \\
\text { mostly open water } \\
\text { with not much } \\
\text { wetland vegetation } \\
\text { or logs }\end{array}$ & $\begin{array}{l}\text { Medium to high } \\
\text { priority }\end{array}$ \\
\hline Orange & $\begin{array}{l}\text { Sometimes part } \\
\text { of a wetland } \\
\text { complex }\end{array}$ & $\begin{array}{l}\text { All or partially dried } \\
\text { up. Very little water } \\
\text { in spring imagery. }\end{array}$ & $\begin{array}{l}\text { Low priority; visit if } \\
\text { nearby. }\end{array}$ \\
\hline Light purple & $\begin{array}{l}\text { Any size. } \\
\text { Sometimes part } \\
\text { of a wetland } \\
\text { complex with } \\
\text { more water } \\
\end{array}$ & $\begin{array}{l}\text { Mostly continuous } \\
\text { wetland vegetation; } \\
\text { no visible water. }\end{array}$ & $\begin{array}{l}\text { Low priority; visit if } \\
\text { nearby. }\end{array}$ \\
\hline Bright Pink & $\begin{array}{l}\text { Usually small } \\
\text { or linear } \\
\text { following } \\
\text { topography }\end{array}$ & Likely shadow & Low priority. \\
\hline Yellow & Any size & $\begin{array}{l}\text { Previous Blanding's } \\
\text { observation }\end{array}$ & $\begin{array}{l}\text { High priority to } \\
\text { describe known habitat }\end{array}$ \\
\hline
\end{tabular}




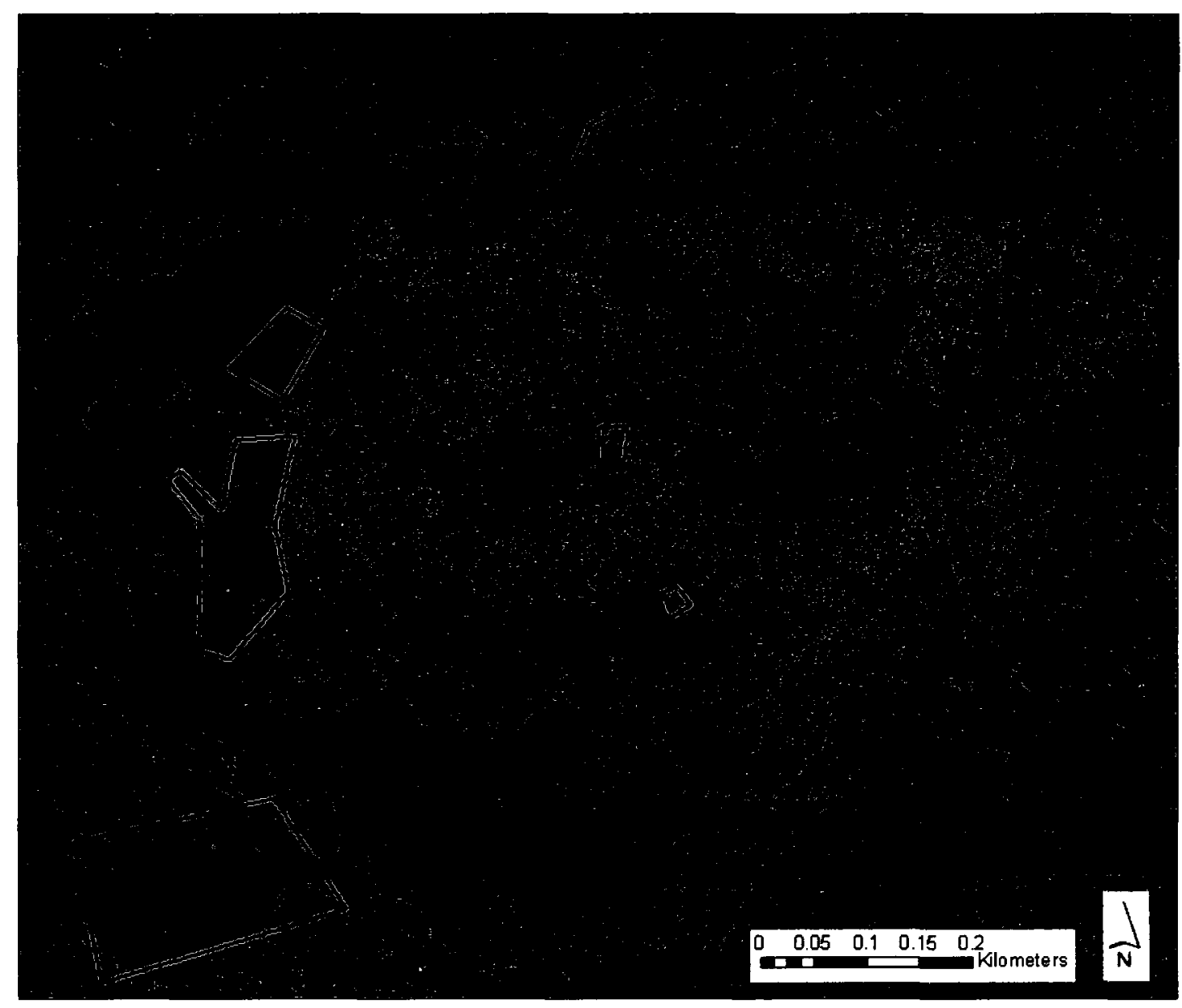

Figure 10. Example subarea showing potential survey wetlands. Green: large open water; Light purple: continuous wetland vegetation, dry; Orange: almost dried up, very little water with lots of wetland vegetation; Pink: very small wetland or shadow; Red: wetland vegetation, trees, logs. Orthophoto source: NCC (2007).

In instances that a wetland complex could not be adequately surveyed from one observation point, a second observation was recorded from another location. Instances where more than one observation was recorded were due to an insufficient view from one angle for reasons including: the presence of physical barriers such as islands or standing trees, the variable composition of large wetlands or complexes often including different wetland vegetation types, hydrologic characteristics, or differing amounts of the selected habitat features (as described below). 
Data forms (Appendix 1) were created to record descriptions of each wetland. A Garmin Global Positioning System (GPS) receiver was used to geo-reference wetland observation sites (expected horizontal accuracy of 5-10m) and to locate geo-referenced wetland points created in the planning process. The geo-referenced observation sites were used for classification training and validation. Binoculars were used to make Blanding's turtles observations and to assess other wetland attributes such as wetland vegetation species and structure. Field photos were generally taken with a view angle perpendicular to the shore so the reader could look at both the location and a field photo, and visualize what area the field photo covers when comparing to the orthophoto and classification. The orthophotos and classification examples in later sections will show the GPS-derived locations of where the photographs were taken, symbolized by a yellow square with a green dot in the center.

Wetland vegetation forms were identified and their coverage of the wetland was estimated in $10 \%$ increments. The recorded wetland vegetation forms were: sedge tussocks (wetland vegetation mounds), shrubs, trees and dead trees. Sedge tussocks are used by Blanding's turtles for thermoregulation and camouflage from potential predators and were important to note in field records. Two wetland vegetation types not present in the spring imagery were recorded: floating aquatic and emergent grasses (graminoid). If the wetland vegetation was submerged it was recorded as N/A. A sketch of wetland vegetation types in the wetland was made when the wetland was not too complex and heterogeneous (e.g., treed swamp), in which case simple groupings of wetland vegetation and water were sketched. 
The abundance of logs was recorded in the following range categories: none $(0)$, small (1-5), medium (5-10) and abundant (10+). Logs are important for Blanding's turtles, for sun basking in spring and late summer. The degree of log abundance could also be related to the size of a wetland, but this was not recorded on the data collection form as the presence and number of logs was felt to be important in wetlands of any size.

Water depth was visually categorized as follows: shallow water that may dry up by fall, $<0.5 \mathrm{~m}$; more stable water level, conducive to habitat, $>0.5 \mathrm{~m}-2 \mathrm{~m}$; and water over $2 \mathrm{~m}$ deep, which is likely colder, usually void of wetland vegetation and less likely to be suitable habitat.

The degree of sun exposure and reason for reduced exposure was noted for later use in accuracy assessment in instances where a shaded wetland or portion of a wetland was not correctly classified but was surveyed in the field. A sun exposure rating of 'closed' was used to indicate a denser and/or more distributed canopy over the wetland, hindering exposure to aerial remote sensing.

The size of small wetlands was measured using a laser range finder, directing the laser to the opposing wetland edge or shoreline on two different sides of the wetland. The wetland size can be used for classification validation since small classified wetlands could in reality be a shadow or forest, causing errors of commission.

Additional data (Appendix 1) directly related to rating Blanding's turtles habitat but not used further in this thesis were recorded, including water and air temperature, sand presence or absence, turtle egg shell observations and water depth. 


\subsection{Acquisition, Processing and Classification of High Resolution Digital Orthophotos}

\subsubsection{Image Acquisition and Mosaicking}

Each orthophoto tile constituted $4 \mathrm{~km}^{2}$ with $20 \mathrm{~cm}$ nominal ground pixel size. The images were acquired May 6, 2007 from 12:00-16:30 for the NCC by a contractor. Two different cameras, a Wild RC-20 and a Zeiss Top 15 (with colour $23 \mathrm{~cm}$ film that was later digitized), were used in two planes flying simultaneously. The lens focal length was approximately $153 \mathrm{~mm}$ and the average scale was 1: 16000. Images covering the study area were obtained from the NCC. In total, for the $16 \times 10 \mathrm{~km}$ area with $4 \times 2 \mathrm{~km}$ removed (agricultural land), 38 tiles were used in this research.

There are several advantages to using orthophotos compared to high resolution satellite optical imagery, including: 1) orthophotos can be acquired at a lower cost than satellite imagery; 2) there is more frequently an archive of orthophotos available (good for temporal analysis such as change detection); 3) acquisition can usually be planned for a specific time, whereas satellite orders may not be acquired by a satellite company if another order takes priority (or the company may not acquire an imagery order for other reasons); 4) orthophotos can be acquired at a higher resolution than satellite imagery, which was critical to this research.

Visible spectrum colour orthophotos may not provide optimal spectral information compared to several satellite sensors that offer more frequencies of the electromagnetic spectrum. Orthophotos acquired with sensors for other portions of the spectrum, such as near or mid infrared and microwave wavelengths, can be very useful in vegetation mapping (and determining what is not vegetation, such as water and logs). 


\subsubsection{Selecting a Suitable Classification Approach}

Due to the large file sizes and intensive processing required, the approach taken was to initially create a wetland mask and then use that for subsequent classification.

Classification was conducted in two phases. The goal of the first phase was to separate wetlands from other land cover types, including: agriculture, forest, roads, trails, hydroline, built-up areas (e.g., camp Gatineau). The second phase of classification focused on within the wetlands for the final classes: Water, Wetland Vegetation and Logs. Class names will be distinguished by being capitalized in all sections to follow (e.g., Agriculture, Water, Wetland Vegetation, Lake, Log, Deciduous Forest).

An object-based approach to classification was initially hypothesized to be a superior classification approach to single pixel-based techniques due to the data source being utilized (high spatial resolution; low spectral resolution) and literature identifying the benefits of this approach over traditional pixel-based classification (Burnett and Blaschke, 2003; Grenier et al., 2007; Lucieer, 2008). An object-based approach increases the types of attributes that can be used to map thematic classes, it considers neighbouring pixels (topology), and it is amenable to multi-scale classification compared to pixel-based methods that essentially process single pixels at a single scale (Burnett and Blaschke, 2003).

The steps used to classify wetlands and within wetland attributes in the study area and subsequent calculation of Blanding's turtle habitat suitability are provided in an overview in Table 3. Details are given in subsequent subsections. 
Table 3. Overview of main steps used in this research.

\begin{tabular}{|c|c|}
\hline Step & Classification phase and method description \\
\hline \multicolumn{2}{|r|}{ Classification Phase 1: Classifying wetland to create a wetland mask } \\
\hline 1 & Resampled $20 \mathrm{~cm}$ orthophoto tiles to $1 \mathrm{~m}$ and mosaicked \\
\hline 2 & Applied GLDV ASM texture measure to red spectral band. \\
\hline 3 & Performed maximum likelihood classification (MLC) of texture image. \\
\hline 4 & Created a wetland mask (bitmap) from the MLC map. \\
\hline 5 & $\begin{array}{l}\text { Removed erroneously classified wetlands (mainly shadow between trees) using } \\
\text { object-based classification. }\end{array}$ \\
\hline \multicolumn{2}{|r|}{ Classification Phase 2: Classification of within wetland features } \\
\hline 6 & Performed multi-resolution segmentation within the Wetland/water class. \\
\hline 7 & $\begin{array}{l}\text { Conducted object-based classification of wetland habitat classes and removed } \\
\text { non wetland classes. }\end{array}$ \\
\hline 8 & $\begin{array}{l}\text { Conducted quantitative and qualitative accuracy assessments of Wetland and } \\
\text { with-in Wetland feature classification. }\end{array}$ \\
\hline \multicolumn{2}{|r|}{ Habitat suitability mapping } \\
\hline 9 & Buffered Water polygons by $20 \mathrm{~m}$ to create Wetland entities. \\
\hline 10 & $\begin{array}{l}\text { Clipped Log and Wetland Vegetation polygons of all classes using Wetland } \\
\text { extents. }\end{array}$ \\
\hline 11 & $\begin{array}{l}\text { Calculated the total area of Water in each wetland and removed Wetlands with } \\
<100 \mathrm{~m}^{2} \text { Water. }\end{array}$ \\
\hline 12 & Calculated Wetland Vegetation cover and the number of Logs in each wetland. \\
\hline 13 & $\begin{array}{l}\text { Developed and implemented categories based on: Wetland size, Wetland } \\
\text { Vegetation cover (\%) and number of Logs (Section 3.6.1). }\end{array}$ \\
\hline 14 & $\begin{array}{l}\text { Developed and applied a score to each habitat feature sub-category based on } \\
\text { wetland size and expert knowledge of Blanding's turtle habitat feature selection. }\end{array}$ \\
\hline 15 & Wetland habitat suitability scores were assigned to a habitat suitability level. \\
\hline 16 & $\begin{array}{l}\text { Wetlands with Blanding's turtle observations were assessed to verify if they } \\
\text { coincided with high habitat suitability. }\end{array}$ \\
\hline 17 & $\begin{array}{l}\text { A Blanding's turtle habitat suitability map was created showing the distribution } \\
\text { of classified wetlands and their associated habitat suitability. }\end{array}$ \\
\hline
\end{tabular}




\subsubsection{Extraction of Spectral Information}

Prior to creating a wetland mask, an object based segmentation approach was first tested on the entire orthotile. The high resolution orthophoto tiles have a large file size (286 MB) making object-based classification very computer processing intensive so it could only be applied to one orthotile at a time. When two orthophoto tiles were merged into a mosaic and used, there was often a system failure, so classification of a mosaic was therefore not an option.

High resolution images provide details of the landscape not visible in medium or low resolution images, providing more realistic details of highly heterogeneous landscapes, which can present many benefits and challenges in classification of landcover types, and classification of wetlands specifically due to their spatial heterogeneity and diversity of identifiable thematic classes (Grenier et al., 2007). For this leaf-off spring imagery, the shadows between tree crowns and shadows cast from tree trunks and branches can cause misclassification since they were spectrally similar to Water. This, plus the high correlations (lack of independent information) between the three spectral bands (R, G, B) and the lack of a near infrared spectral band led to a decision to use an object based classification approach with image texture as a primary information type. In particular, green wetland vegetation such as coniferous trees could not be easily distinguished from dark features such as water and shadow without a NIR band but it had a quite distinct texture that differed from smooth water and shadows.

Besides the spectral limitations of the orthophotos, spring leaf-off imagery presented additional challenges. Most of the area of each photo was occupied by deciduous forest with ground visible beneath the leafless canopy (Figure 11). Wetland vegetation in 
spring was almost always senescent and thus appeared spectrally similar to the deciduous forest floor that was mainly comprised of senescent leaves (Table 4 and 5). Conversely, a benefit of spring imagery is that water levels were high in most water bodies and there was less forest canopy covering wetland edges.

The spectral range for all potential landcover classes was assessed (Table 4) and showed that image brightness (Digital number (DN) extracted) for all vegetation classes overlapped significantly, thus limiting the potential of spectral information in classification.
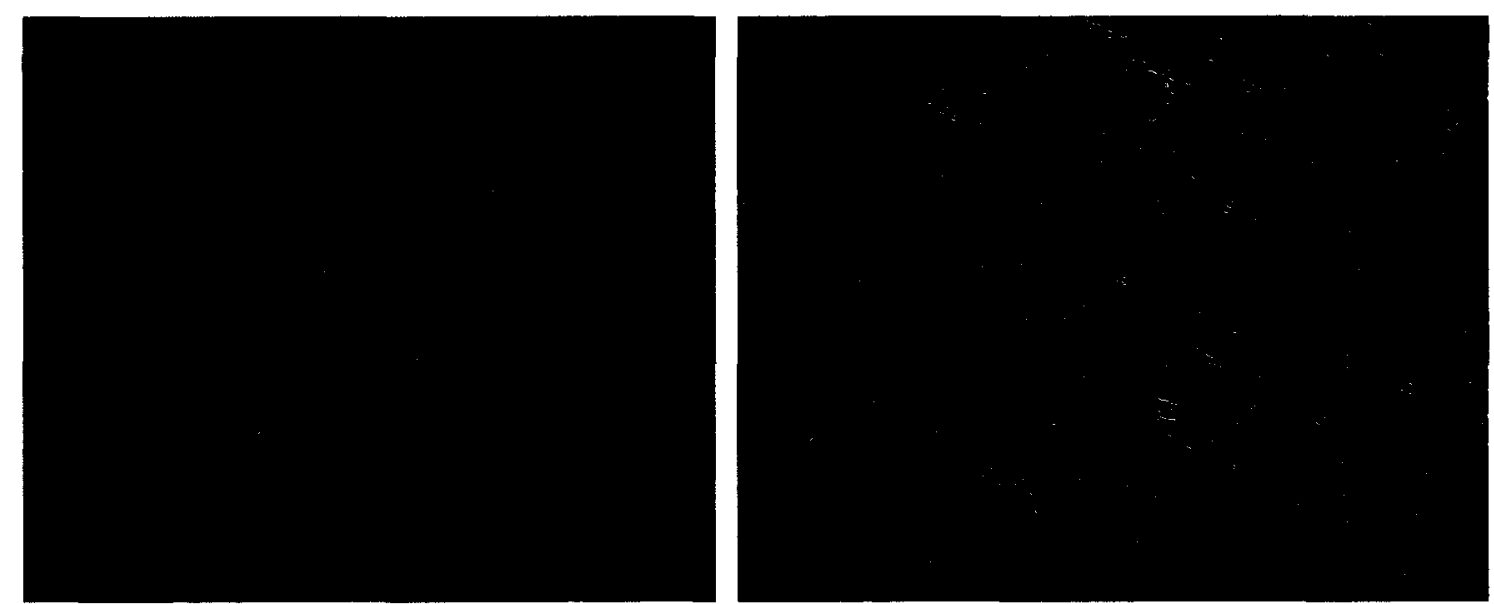

Figure 11. Orthophoto examples of continuous wetland vegetation (Left) and (leaf-off) deciduous forest (right).

Additional testing for some pixel-based maximum likelihood classifications using the spectral bands as input confirmed that the resulting classifications were of low accuracy. Table 5 shows a subjective assessment of spectral overlap between classes based on the data in Table 4 and these iterative classification tests. Leaf-off deciduous forest (and associated ground) and wetland vegetation were highly confused, as were water, shadows and coniferous wetland vegetation (due primarily to the significant shadowing of the crowns). 
Table 4. Manual extraction of spectral signatures (DN) from targeted landcover types and attributes yielded the Minimum (Min.) and Maximum (Max.) spectral range.

\begin{tabular}{|l|rr|rr|rr|}
\cline { 2 - 8 } \multicolumn{1}{c|}{} & \multicolumn{9}{|c|}{ Spectral Band } \\
\hline \multirow{2}{*}{$\begin{array}{l}\text { Land class } \\
\text { sampled }\end{array}$} & \multicolumn{2}{|c|}{ Red } & \multicolumn{2}{c|}{ Green } & \multicolumn{2}{c|}{ Blue } \\
\cline { 2 - 8 } Conifer & 121 & 157 & 131 & 165 & 113 & 140 \\
\hline $\begin{array}{l}\text { Wetland } \\
\text { vegetation }\end{array}$ & 112 & 190 & 108 & 183 & 102 & 173 \\
\hline $\begin{array}{l}\text { Continuous } \\
\text { wetland } \\
\text { vegetation }\end{array}$ & 130 & 218 & 152 & 211 & 166 & 198 \\
\hline $\begin{array}{l}\text { Deciduous } \\
\text { forest* }\end{array}$ & 135 & 241 & 128 & 233 & 130 & 226 \\
\hline $\begin{array}{l}\text { Deciduous } \\
\text { tree trunk }\end{array}$ & 103 & 151 & 93 & 138 & 83 & 132 \\
\hline $\begin{array}{l}\text { Wetland } \\
\text { Log }\end{array}$ & 103 & 187 & 101 & 184 & 99 & 180 \\
\hline $\begin{array}{l}\text { Light } \\
\text { water }\end{array}$ & 74 & 81 & 74 & 80 & 72 & 74 \\
\hline Shadow & 52 & 73 & 61 & 74 & 58 & 69 \\
\hline Water & 40 & 61 & 47 & 68 & 48 & 66 \\
\hline
\end{tabular}

*Mainly sunlit senescent groundcover

Table 5. Overlap of land cover types in their spectral signature range. The box insets outline grouped land cover types and patterns of confirmed overlap ("yes") or separation ("no"). The light grey box outlines consistent overlap with wetland vegetation (high $\mathrm{DN}$ ), the medium grey identifies a cover type that has some overlap with the wetland vegetation group and the shadow/water group (medium DN). The darkest grey denotes the dark classes, with very little overlap (low DN).

\begin{tabular}{|c|c|c|c|c|c|c|c|c|c|}
\hline $\begin{array}{l}\text { Landcover } \\
\text { types }\end{array}$ & Conifer & $\begin{array}{l}\text { Wetland } \\
\text { veg }\end{array}$ & $\begin{array}{l}\text { Cont. } \\
\text { veg }\end{array}$ & $\begin{array}{l}\text { Decid. } \\
\text { forest }\end{array}$ & $\begin{array}{l}\text { Tree } \\
\text { trunk }\end{array}$ & $\begin{array}{l}\text { Wetland } \\
\text { Log }\end{array}$ & $\begin{array}{l}\text { Light } \\
\text { water }\end{array}$ & Shadow & Water \\
\hline $\begin{array}{l}\text { Conifer } \\
\text { Wetland }\end{array}$ & $\mathrm{n} / \mathrm{a}$ & yes & yes & yes & yes & yes & no & no & no \\
\hline veg. & yes & $n / a$ & yes & yes & yes & yes & yes & no & no \\
\hline Cont. veg. & yes & yes & $\mathrm{n} / \mathrm{a}$ & yes & yes & yes & no & no & no \\
\hline $\begin{array}{l}\text { Decid. } \\
\text { forest }\end{array}$ & yes & yes & yes & $\mathrm{n} / \mathrm{a}$ & yes & yes & yes & no & no \\
\hline $\begin{array}{l}\text { Tree trunk } \\
\text { Wetland }\end{array}$ & yes & yes & yes & no & $\mathrm{n} / \mathrm{a}$ & yes & yes & no & no \\
\hline Log & yes & yes & yes & yes & yes & $\mathrm{n} / \mathrm{a}$ & yes & no & no \\
\hline Light water & no & yes & no & yes & yes & yes & $\mathrm{n} / \mathrm{a}$ & no & no \\
\hline $\begin{array}{l}\text { Shadow } \\
\text { Water }\end{array}$ & $\begin{array}{l}\text { no } \\
\text { no }\end{array}$ & $\begin{array}{l}\text { no } \\
\text { no }\end{array}$ & $\begin{array}{l}\text { no } \\
\text { no }\end{array}$ & $\begin{array}{l}\text { no } \\
\text { no }\end{array}$ & $\begin{array}{l}\text { no } \\
\text { no }\end{array}$ & $\begin{array}{l}\text { no } \\
\text { no }\end{array}$ & $\begin{array}{l}\text { no } \\
\text { no }\end{array}$ & $\begin{array}{l}\text { n/a } \\
\text { yes }\end{array}$ & $\begin{array}{l}\text { yes } \\
\text { n/a }\end{array}$ \\
\hline
\end{tabular}

Decid.=Deciduous; Cont.=Continuous; Veg.= Wetland vegetation 


\subsubsection{Texture Analysis}

Following the conclusion that spectral information was not good enough to distinguish the classes of interest, testing of texture algorithms was conducted on subsets of 4 or 5 image tiles in columns. These mosaics were re-sampled to $1 \mathrm{~m}$ pixels using by nearest neighbour resampling technique because it retains the grey levels which is ideal if classification is to be performed following registration (PCI Geomatics, 1999a). A mosaic format was preferred for classification because it would be necessary to apply the algorithms over all 38 tiles, which was not feasible at the $20 \mathrm{~cm}$ resolution due to the intensive processing required in relation to the available computing power.

Several grey level co-occurrence matrix (GLCM) texture measures (Homogeneity, Contrast, Angular Secondary Moment (ASM), Mean, Entropy, Standard Deviation, Dissimilarity, Inverse Difference) and Grey level difference vector ((GLDV) ASM) were calculated. All textures were derived from the red spectral band, which appeared visually to have the greatest differences in texture between land cover types. A few different window sizes were tested $(3,5,11,25)$. The minimum window size that led to maximum discrimination of landcover types was determined by testing window sizes that could accurately locate boundaries between different texture regions. No specific directions were tested; the texture calculated was an averages of 4 directions $(0,45,90,135$ degrees) (PCI Geomatics, 1999b). The goal of the texture analysis was to attempt to discriminate Water/wetlands from upland classes (mostly deciduous and coniferous forest) in order to mask out non wetland areas for the next classification phase.

The range of each texture measure was extracted for each thematic class and class overlap was evaluated. An example result for the Standard Deviation texture measure is 
shown in Table 6 where Wetland Vegetation and Conifer forest land cover types overlap completely, which would produce complete confusion in classification. More than half of the range for Deciduous Forest was separate from the other classes. The only class with an exclusive spectral range (for the tested texture measures) is Water, and it was also separate from all other classes for the Contrast texture measure.

From the table, it can be seen that there is significant overlap between classes, but that for ASM, there was the least overlap between Water and the other classes so it was adopted to classify Water. ASM also showed good separation between Conifer and Wetland Vegetation (Table 6). GLDV ASM demonstrated good separation of Water from Coniferous forest and Wetland Vegetation and Deciduous Forest from Conifer and Wetland Vegetation (Table 6). The majority of the texture range for the Wetland Vegetation class is separate from Water and Deciduous Forest classes.

GLDV ASM with a $5 \times 5\left(25 \mathrm{~m}^{2}\right)$ window size provided the best results in separating Wetlands/Open water from upland classes. A small window size was chosen due to the heterogeneous landcover and fine resolution imagery (Chen et al., 2004). ASM responds in an inverse manner to increasing texture; high values indicate low texture. Thus, visually, the texture image showed coniferous forest as dark with white speckles where between crown shadow was uniform, and open water as almost white. The shadows in both coniferous and deciduous forest were expected to be confused with water in classification. Wetland Vegetation usually appeared medium to dark grey. 


\subsubsection{Classification of Land Cover Types}

\subsubsection{Supervised Classification (MLC) and Object-based Classification}

A supervised classification procedure was initiated by selecting representative areas of each targeted class that were provided to the classification algorithm (maximum likelihood (MLC)). The MLC assigns each pixel in the image to the class that it most resembles based on the probability distribution derived from the training data for each class (Wei and Chow-Fraser, 2007).

The texture image (GLDV ASM) (Section 3.3.3; example given in Figure 12) was utilized in supervised maximum likelihood classification of the broad land cover classes:

Agriculture, Water (and mixed with wetland vegetation) and Other (dominated by forest). The Agriculture class was merged with the Other class after classification to exclude it from the wetland output mask. Each mosaic of tiles ( 4 or 5 in each) as described earlier was classified separately. Training sites selected for each classification process were chosen based on visual interpretation of land cover classes in the original high resolution aerial orthophoto, since the classes were easily discernable.

The threshold (number of standard deviations from the mean to retain in the training data for classification) and bias (expected relative proportion (weight) of the given class in the landscape) values were selected based on visual assessment of a preview of classification results (Figure 12) generated by the software. These user-defined parameters were kept as consistent as possible between mosaics without jeopardizing classification accuracy. The threshold value was 3.0 for all classes except for one mosaic where a value of 4.0 produced visibly better accuracy. In most mosaics, the bias value for Other and Water was set to one. In one mosaic the Other bias was set to 0.5 and in 
another to 1.5. The Water class bias value was varied between mosaics $(0.25-4.0)$ in relation to the relative amount of visible water present (i.e. very large bias value in the mosaic including La Pêche Lake; smaller values in other mosaics). Although subjective, this process was simple and quick to implement.

Table 6 . Illustration of the digital number range (min-max) for each land cover type using GLCM textures (except for GLDV ASM) on the red band.

Abbrev: Min.=minimum; Max.=maximum

\begin{tabular}{|c|c|c|c|c|c|c|c|c|}
\hline \multirow[t]{2}{*}{ Texture } & \multicolumn{2}{|c|}{ Water } & \multicolumn{2}{|c|}{$\begin{array}{c}\text { Deciduous } \\
\text { Forest }\end{array}$} & \multicolumn{2}{|c|}{ Conifer Forest } & \multicolumn{2}{|c|}{$\begin{array}{c}\text { Wetland } \\
\text { Vegetation }\end{array}$} \\
\hline & Min. & Max. & Min. & Max. & Min. & Max. & Min. & Max. \\
\hline Entropy & $\begin{array}{r}-6.82 \mathrm{E}- \\
07 \\
\end{array}$ & 1.1 & 1.4 & 2.0 & 1.7 & 2.3 & 1.6 & 2.6 \\
\hline $\begin{array}{l}\text { Standard } \\
\text { Deviation }\end{array}$ & 0.1 & 0.7 & 0.7 & 4.0 & 3.0 & 9.0 & 3.0 & 9.0 \\
\hline Homogeneity & 0.6 & 1 & 0.2 & 0.6 & 0.0 & 0.8 & 0.0 & 0.4 \\
\hline Dissimilarity & 0.0 & 0.9 & 0.3 & 4.5 & 3.5 & 9.0 & 2.0 & 10.0 \\
\hline $\begin{array}{l}\text { Inverse } \\
\text { difference }\end{array}$ & 0.6 & 1.0 & 0.3 & 0.8 & 0.1 & 0.5 & 0.2 & 0.5 \\
\hline GLDV ASM & 0.2 & 1.0 & 0.2 & 0.8 & 0.0 & 0.2 & 0.1 & 0.3 \\
\hline $\mathbf{A S M}$ & 0.3 & 1.0 & 0.1 & 0.8 & 0.0 & 0.2 & 0.1 & 0.3 \\
\hline Mean & 0.0 & 3.8 & 14.0 & 30.0 & 0.0 & 21.0 & 14.0 & 30.0 \\
\hline Contrast & 0.0 & 1.3 & 1.3 & 25.0 & 12.0 & 200.0 & 7.0 & 150.0 \\
\hline
\end{tabular}

The resulting classification included wetlands and lakes for the class and an Other class representing terrestrial land cover types, as well as shadows erroneously classified as Water (Figure 13). To resolve the misclassified instances of shadow, first a minimum size threshold (e.g., $500 \mathrm{~m}^{2}$ ) was considered, but applying this rule removed some potentially important small wetland areas (or hydrological features) (Figure 14), so the approach was abandoned. 


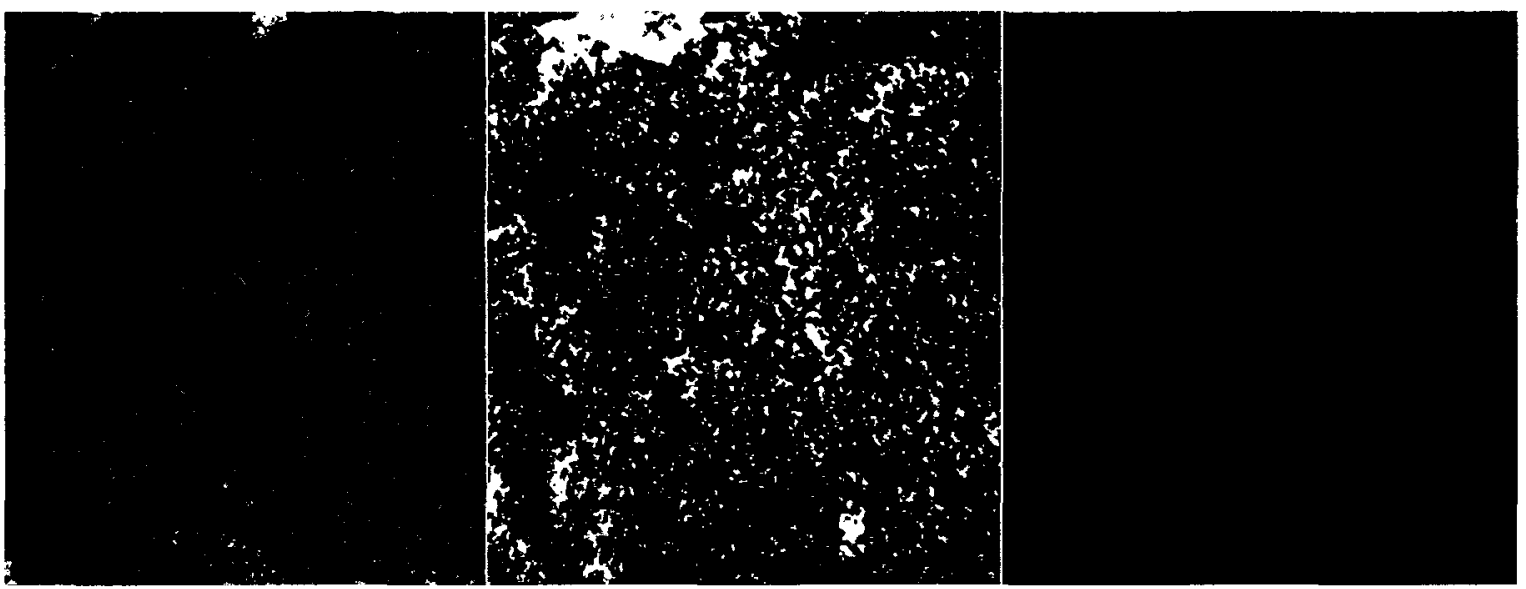

Figure 12. Example orthophoto (left), GLDV ASM texture (middle) and MLC classification (right) (Right: Water=blue; Other=green).

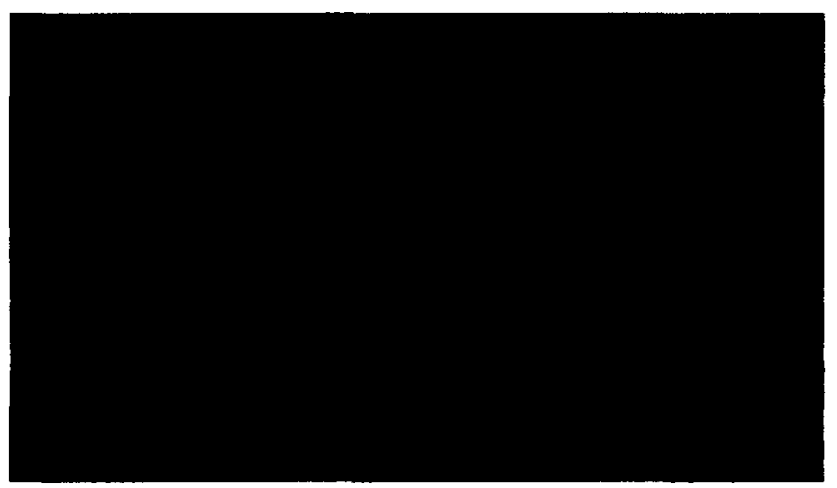

Figure 13. Example of shadows in forest that were erroneously classified as Water (Lakes/wetlands) and subsequently removed. Water=blue; Other=green

Segmentation was conducted on the pixel-based map produced from the MLC to produce objects that were dominantly composed of either Wetland or Other, in order to remove almost all erroneous tree shadow objects as well as very small water bodies. To classify objects as Water or Other a hierarchical classification approach was used, along with a standard nearest neighbour (SNN) sample selection. The image input was not the aerial orthophoto mosaic, it was the two classes from the supervised classification (that were exported as a bitmap, given a codes of 0 for Other and 1 for Water). To segment the small water objects (mainly misclassified shadow), after iterative testing of different parameters the following were selected within the multi-resolution segmentation 
parameters and homogeneity criterion: Scale parameter $=10$; Shape $=0.2$;

Compactness $=0.8$. The shape value was low to give more priority to spectral properties (colour). The compactness value is high given the sharp boundaries between the two classes in the input map.

The final results were visually assessed to be a refinement of the original MLC map of Water and Other classes. A bitmap mask of these classes was exported and then overlaid onto the red band (Figures 15 and 16). This wetland mask was used in subsequent within wetland feature mapping.

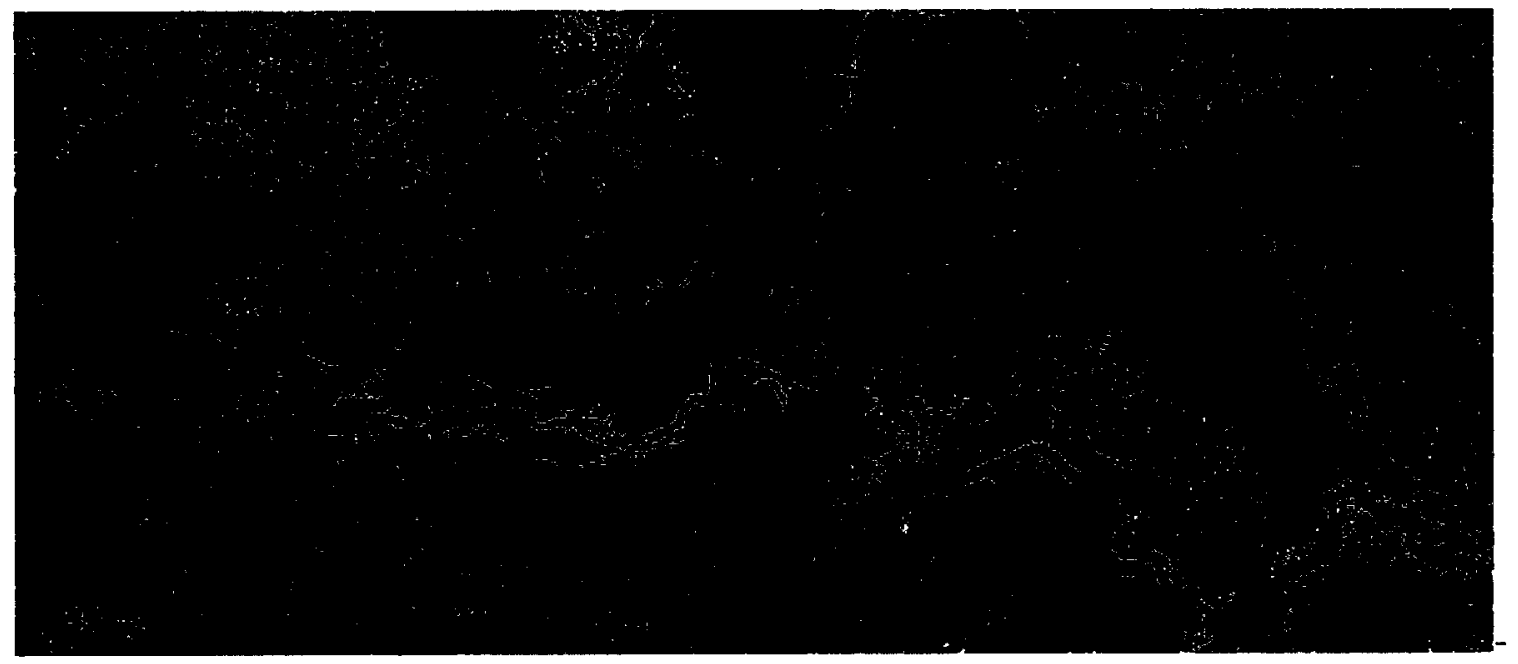

Figure 14. Example of Water class objects (blue) that would have been removed if a size threshold of $500 \mathrm{~m}^{2}$ was applied. Potentially important hydrological features in a wetland could be removed if a size threshold is utilized to address removal of misclassified shadow (Figure 13). Wetland vegetation is green. 


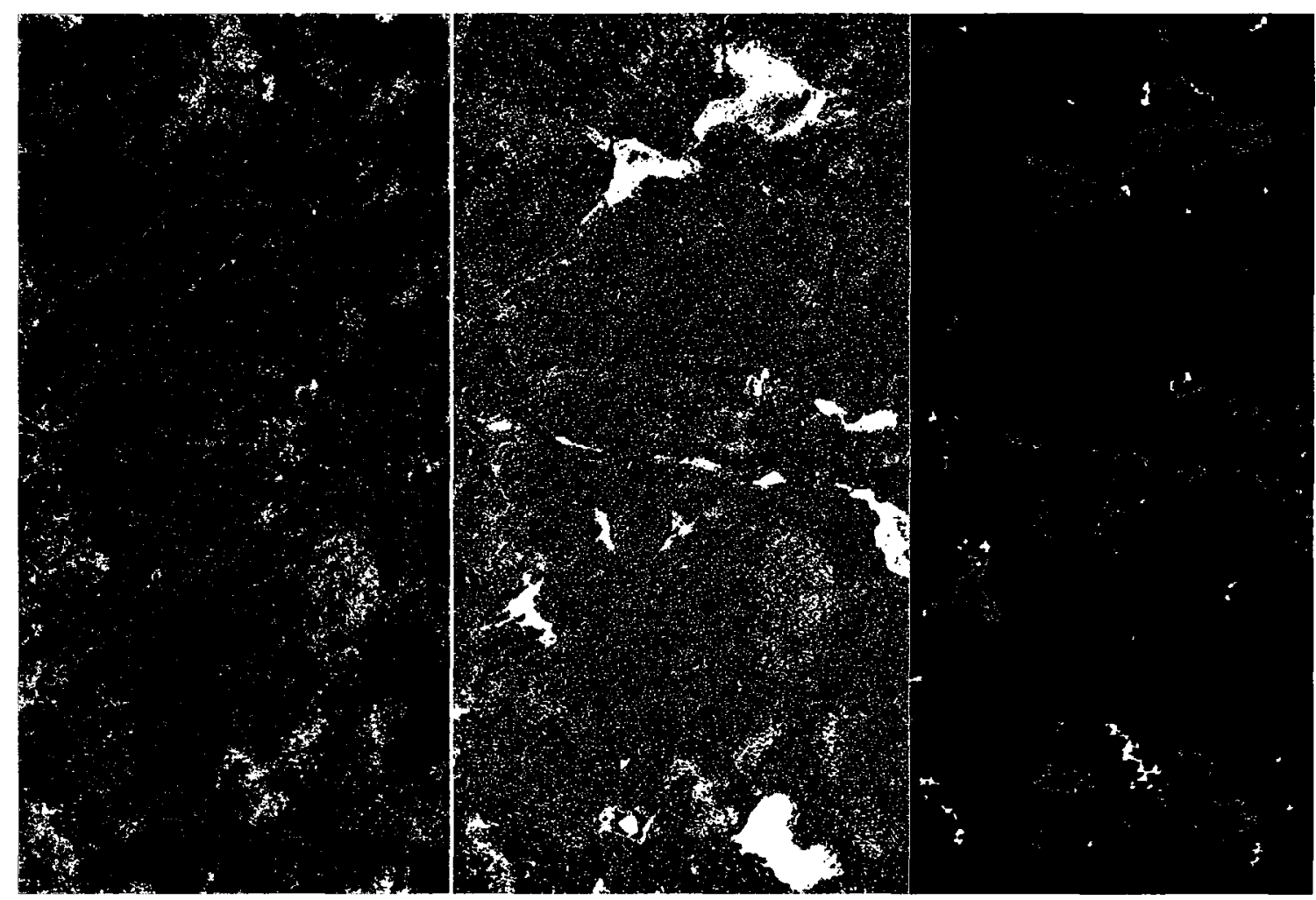

Figure 15. Orthophoto (left) used to conduct texture (GLDV ASM) (centre) analysis that was a component in producing the wetland mask (right).

\subsection{Object-Based Segmentation and Classification of Wetlands and Wetland Features}

\subsubsection{Wetland Segmentation}

Using the image data within the masked wetland areas, the following object-based segmentation and classification procedure was carried out to define wetlands as whole objects as well as to delineate subareas within wetlands.

A top down classification approach was utilized where the main landcover classes were first segmented at a coarse object level to classify wetlands and non-wetlands and later a finer object level was used to identify thematic classes (c.f. Grenier et al., 2008). Scale parameters were chosen based on iterative and systematic testing of different scale parameter, colour, (shape) smoothness and compactness. A large scale parameter was 
chosen that created larger objects delineating the broader landcover regions into Wetland, Lake (specifically La Pêche Lake because it was the only lake with vast open water) and Deciduous Forest.

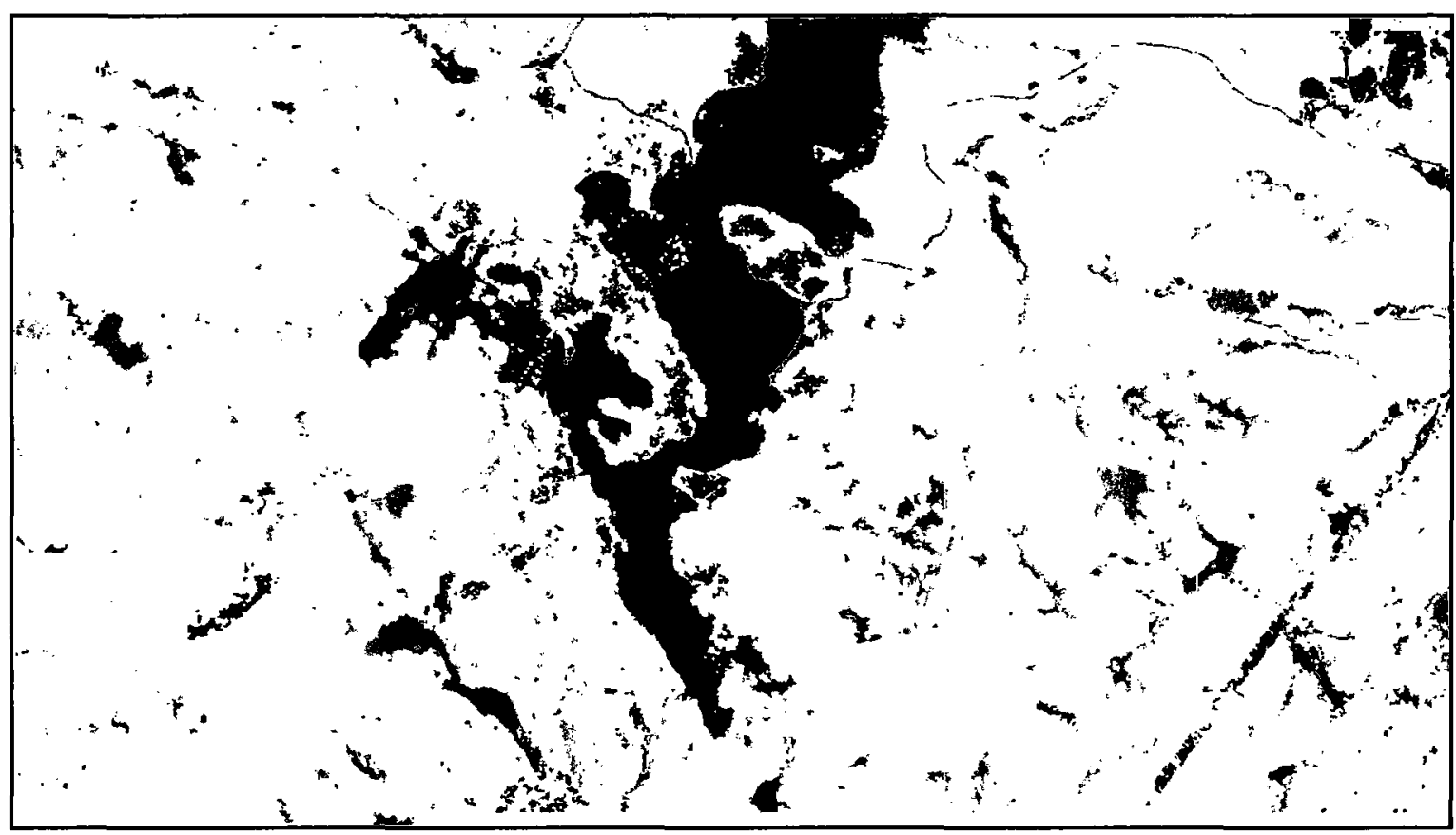

Figure 16. The original red band air photo image is shown within each masked object. Some errors still present in the mask include the electricity line corridor (lower right), agriculture (top right) and deciduous forest (near centre), usually illustrated by dark grey.

Several scale parameters were tested as is commonly required in such multi-scale object segmentation (Burnett and Blaschke, 2003; Grenier et al., 2007; Varela and Diaz, 2008) and segmentation was tested on each spectral band separately. Scale parameters values from 100-700 were intended for coarse object levels (Lake, Wetland, Deciduous Forest), mainly defining whole land cover entities. Values of 75-100 were used for finer objects within wetlands (wetland vegetation, logs).

The main Scale parameter values tested were 700, 500, 300, 200, 100, 85, 75, 70, 65, 60, 50, 20 and 10 using several other homogeneity criterion values (e.g., Shape: 2, 
Compactness: 1; Shape: 4, Compactness: 7). The resulting segmented objects were analyzed visually to determine how well they represented each targeted thematic class.

Scale values of 700 and 500 were deemed too large, even for the coarse object level, as they did not delineate wetland boundaries from continuous wetland vegetation well. The Scale value of 300 produced the optimal results for the coarse level, by delineating the focal lake (La Pêche), deciduous forest, wetland boundaries and continuous wetland vegetation. Scale values of 100 and 200 were not suitable for the coarse level because they segmented within the targeted objects.

The final Scale values chosen for the coarse object level were therefore: Scale: 300 ; Shape: 0.2 ; and Compactness 0.1 . This coarse level segmentation partially used spectral brightness (weight $=0.8$ ) to process the image into relatively (for this object level) homogeneous objects. The compactness criterion was given a low value $(0.1)$, in order to give the 'smoothness' criterion a higher weight $(0.9)$, which created objects with long smoothly varying boundaries that were not compact in shape.

The 'Feature View' tool in the object-based software (Definiens AG, 2007) was used to test various input parameters (minimum and maximum), for an expression, such as mean brightness value or contrast texture (e.g., 200-500) by temporarily highlighting areas that meet the input parameters. While looking at test areas the feature view assisted in verifying whether the parameters included the targeted feature classes adequately, by assessing whether the objects were highlighted when using the specified parameters. The object information table was also used to evaluate attribute information of individually selected objects. Object attribute information can also be exported in table format to determine patterns to discriminate between landcover classes. 
The majority of mosaics followed the same process rule set for the coarse object level classification, with the exception of two mosaics that had the large Lake (La Pêche) and some Deciduous Forest remnants (retained in wetland mask). Through testing of several parameters, the GLCM Contrast texture was found to best discriminate between these Deciduous Forest remnants and Wetland Vegetation or Water.

Specifically, at a 45 degree angle, the texture of Deciduous Forest objects was consistently over $200 \mathrm{DN}$, whereas Wetland segmented objects had a Contrast texture commonly under $200 \mathrm{DN}$ (water was commonly under $100 \mathrm{DN}$ ). A minimum threshold of $200 \mathrm{DN}$ for Contrast texture feature therefore used to classify and remove these Deciduous Forest remnants.

To ensure no potential water bodies or wetlands were misclassified as Wetland Vegetation in the coarse object level, another object feature was utilized. All objects with a mean brightness value $\leq 120 \mathrm{DN}$ were assigned to the Water class. This brightness value threshold was identified in the initial spectral extraction process (Section 3.3.2). Objects from each class were merged with their bordering objects, as long as they belonged to the same class. For two mosaics that included Lac La Pêche the Water objects that were over $7,000,000 \mathrm{~m}^{2}$ were reassigned to the Lake class.

The final output classes were: Deciduous Forest, Water and Lake. The Deciduous Forest class also contained portions of land cover types that should have been removed during creation of the wetland mask (Section 3.3.4). The Water class contained other attributes related to wetlands besides Water that were to be segmented in the finer object level, including: Wetland Vegetation and Logs. 


\subsubsection{Within Wetland Log and Vegetation Segmentation}

Following wetland delineation, within wetland objects were segmented and a hierarchical rule set involving shape, size, context and texture was used to assign the segmented objects to specified classes: Water, Wetland Vegetation and Logs.

To illustrate a set of rules implemented in the segmentation and classification process, Figure 17 is an example of the process tree used to classify the three classes for one of the mosaics. Each line in the process tree includes a symbol that denotes the process conducted. To better understand how each process is connected to previous processes and ultimately to assign objects to specific classes, Figure 18 illustrates an alternative way to explain the process tree of Figure 17. The details of segmentation processing are given in this section and the details of classification are given in 3.4.3.

Defining the scale for the within wetland features involved extensive testing of parameters on several image subsets. Subsets were used to provide a reasonable processing demand and a comprehensive class hierarchy that could be transferrable to other images within the mosaic. The results of each parameter combination were visually analyzed to determine an optimal set for segmentation of the focal objects. Wetland vegetation and logs within wetlands vary in size, therefore a scale parameter that is too small (e.g., 5 or 10 ), may produce multiple segments per object, while a scale that is too large will not delineate the focal objects accurately. 


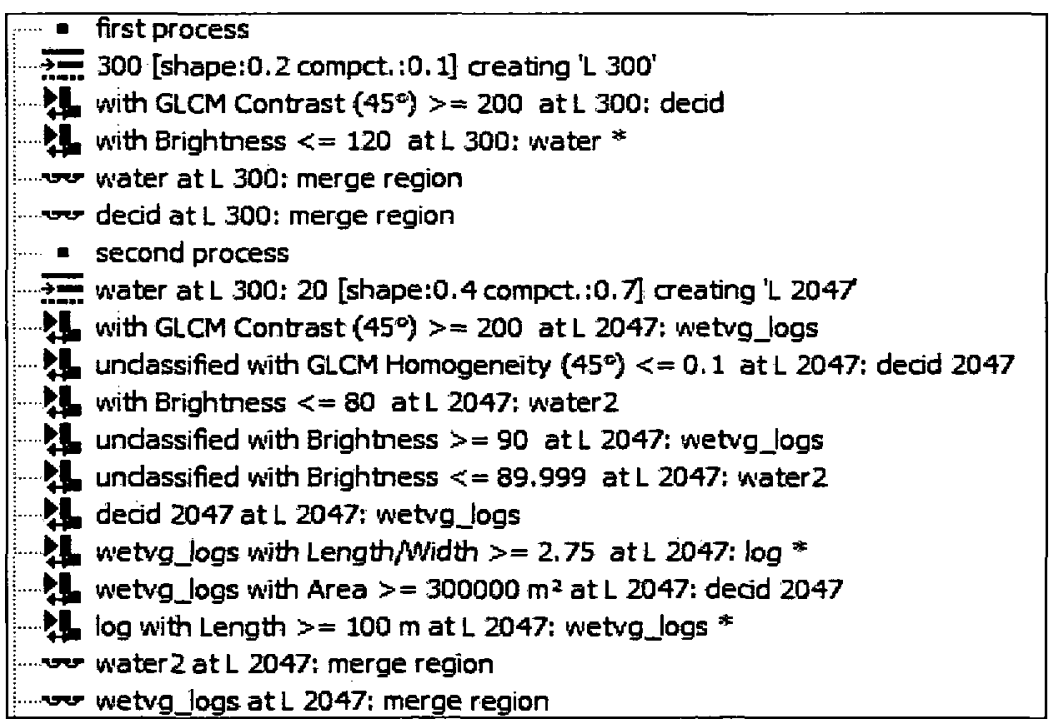

Figure 17. An example of a process tree used to classify wetlands and within wetland attributes (Logs, Wetland Vegetation and Water). The symbol is 'Assign class' and $\mp$ is 'multi-resolution segmentation' and is 'merge region'

Scale values of $100,75,50$ and 20 were tested (Figure 19) with 100, 75 and 50

deemed too coarse for the targeted classes, because they did not accurately define the edges of logs or wetland vegetation from water. The finer segmentation scale parameter of 20 was concluded to be the best for delineating log and wetland vegetation objects (Figure 20).

All three bands (Red, Green and Blue) were tested using image subsets, with the same scale parameters and criteria to determine if one band was better suited to delineate logs. The blue band delineated most logs well but sometimes the resulting object was slightly larger than the actual log. The green band produced fewer segments and had greater errors of omission. The red band usually produced the smallest, most precisely delineated log objects and was deemed to be the optimal band. In some instances a log was segmented into more than one object but there were fewer instances where the delineation was too large. 


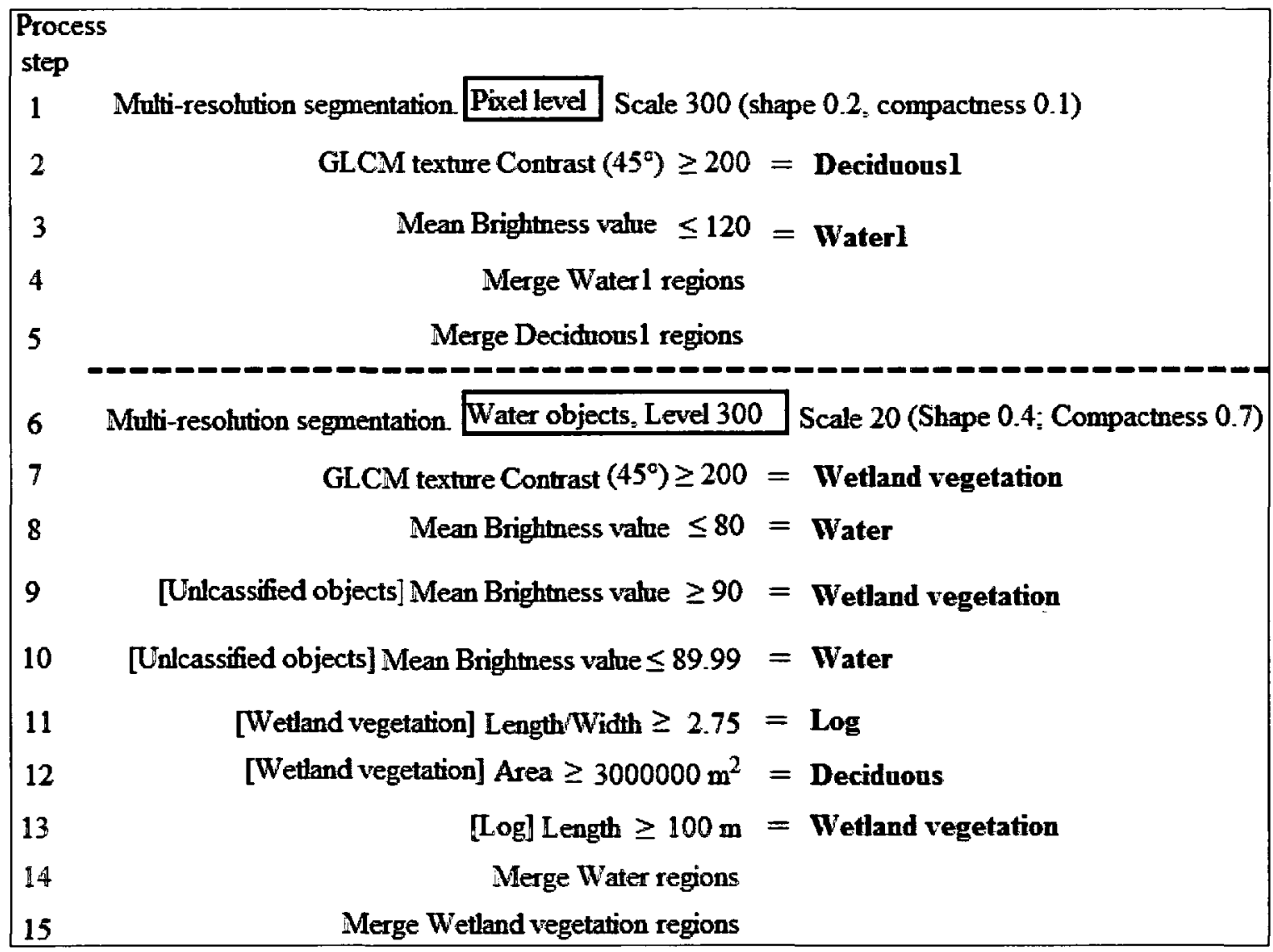

Figure 18. A translation of the processing tree in Figure 17, to illustrate an example of the processing steps (listed on the left) used to classify wetlands and within wetland attributes in one orthophoto mosaic. Text in bold signifies output classes and text in brackets indicates the object filter used.

Using the optimal scale parameter of 20 on the red band, the shape and compactness criteria were fine tuned for optimal Log and Wetland Vegetation delineation. The criteria of Shape $=0.4$ and Compactness $=0.7$, were found to be best as smaller values of shape and/or compactness produced overly detailed segments for the target classes that would require merging before classification. Larger shape and/or compactness values created slightly larger objects than was needed to delineate the focal features. In combination with these parameter values, the corresponding Colour value was 0.6 and Smoothness value was 0.3 . The above parameters were applied in segmentation of the Wetland class 
that had been derived from the object level above (300:0.2, 0.1). Figure 21 shows the complete hierarchical segmentation process.

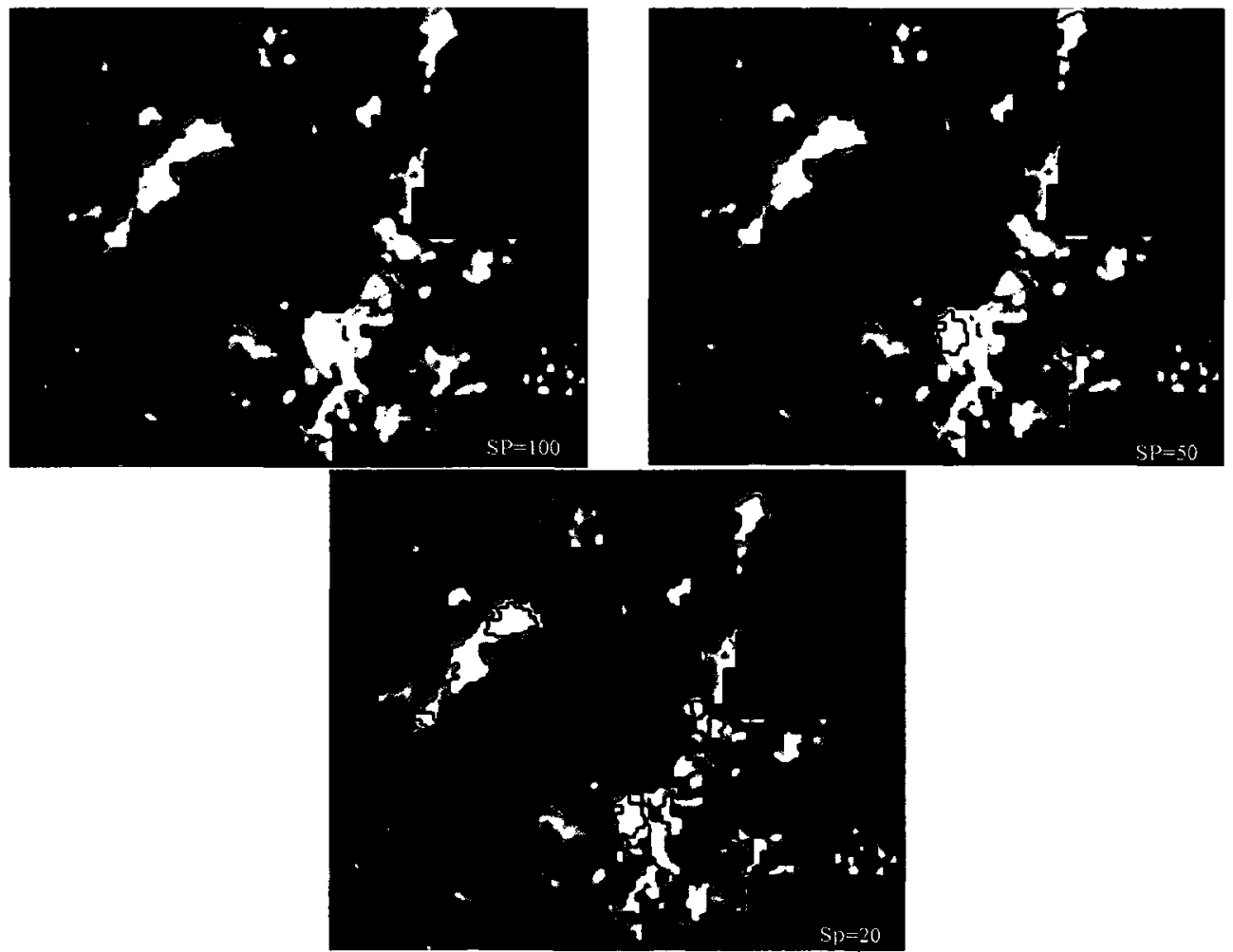

Figure 19. Example segmentation of a portion of a wetland in the red band to determine the optimal scale parameter level for the target wetland classes of Log and Wetland

Vegetation. Top left: Scale $=100 ;$ Top right: Scale $=50$; Bottom: Scale 20

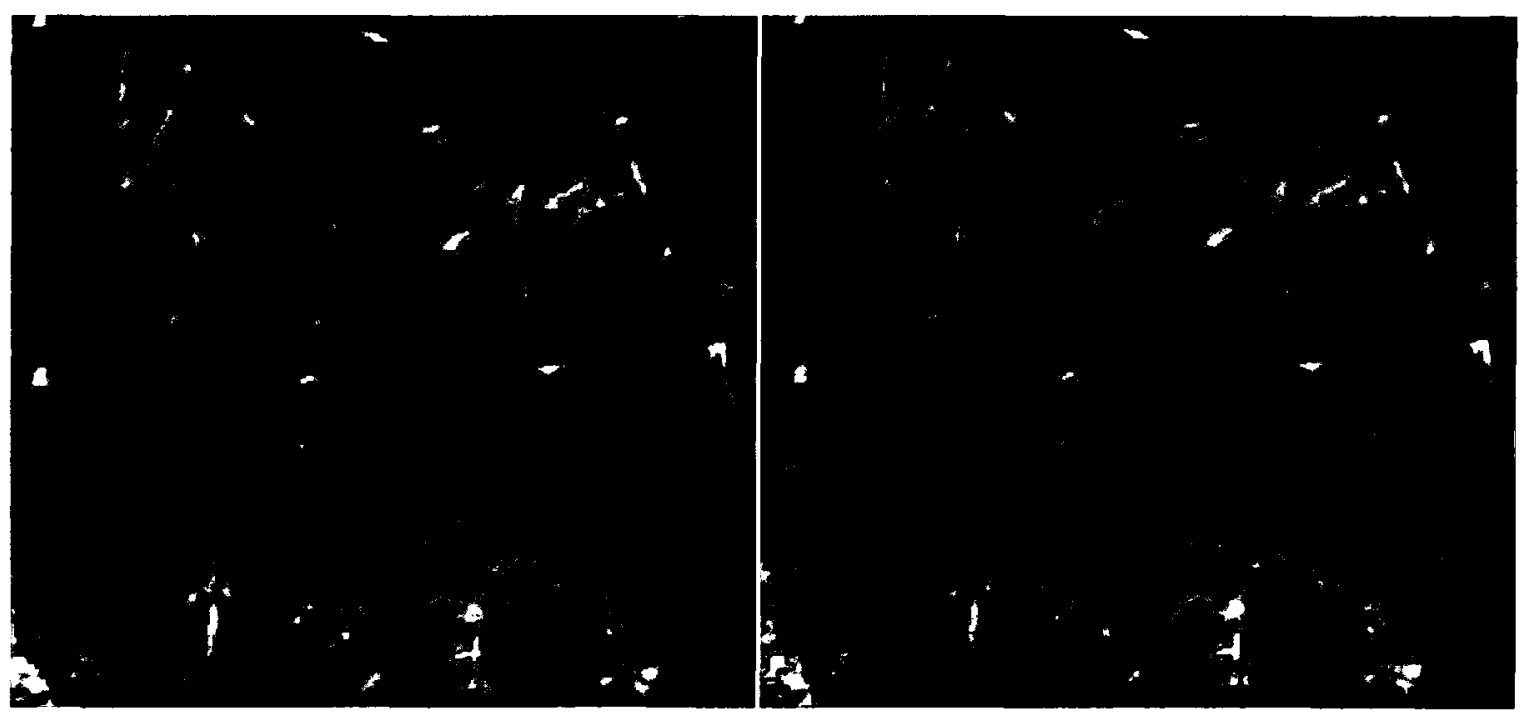

Figure 20. Within wetland segmentation of the blue band (left) and red band (right). The red band produced more detailed segments with better delineation of the boundaries of Logs and Wetland Vegetation. 


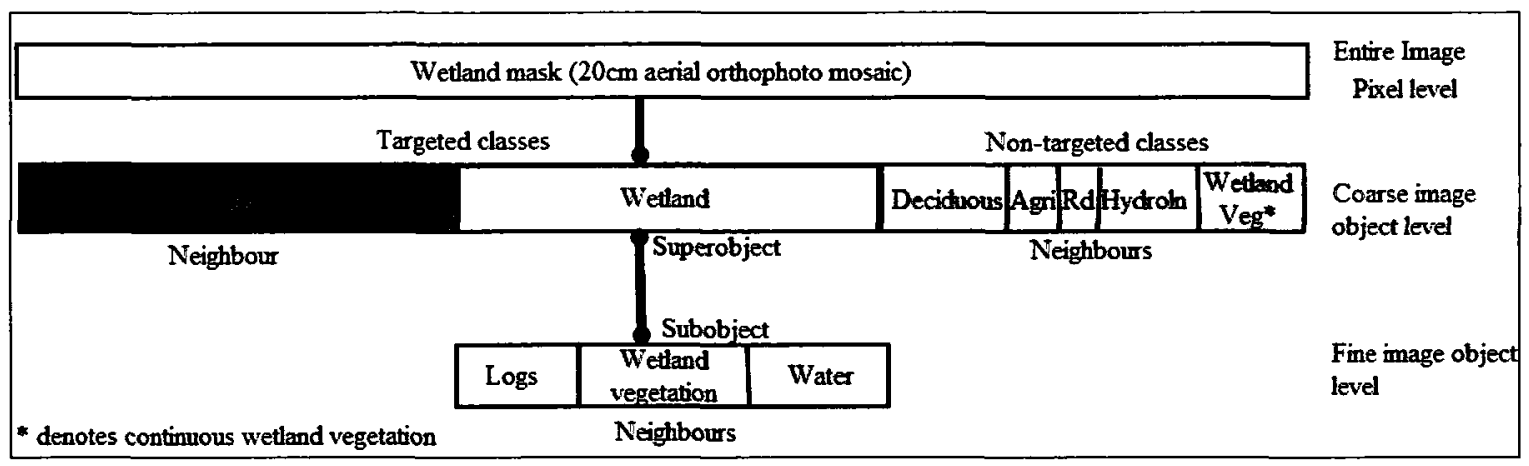

Figure 21. Within the image object hierarchy, each image object is linked to its neighbours, its super-object and its sub-object.

\subsubsection{Classification of Wetlands and Within Wetland Objects}

Following segmentation of wetlands and within wetland objects, the objects were classified using a rule set developed to produce maximum accuracy of classification and to remove as much of the residual erroneous areas of non-target classes (deciduous forest, road, agriculture and a hydroline) that remained within the wetland mask. These nonwetland portions could be manually removed but one of the objectives of the research was to make the process as automated and transferrable across a large area (multiple mosaics) as possible.

A simplified illustration summarizing the form of the adopted hierarchical classification is given in Figure 22. 


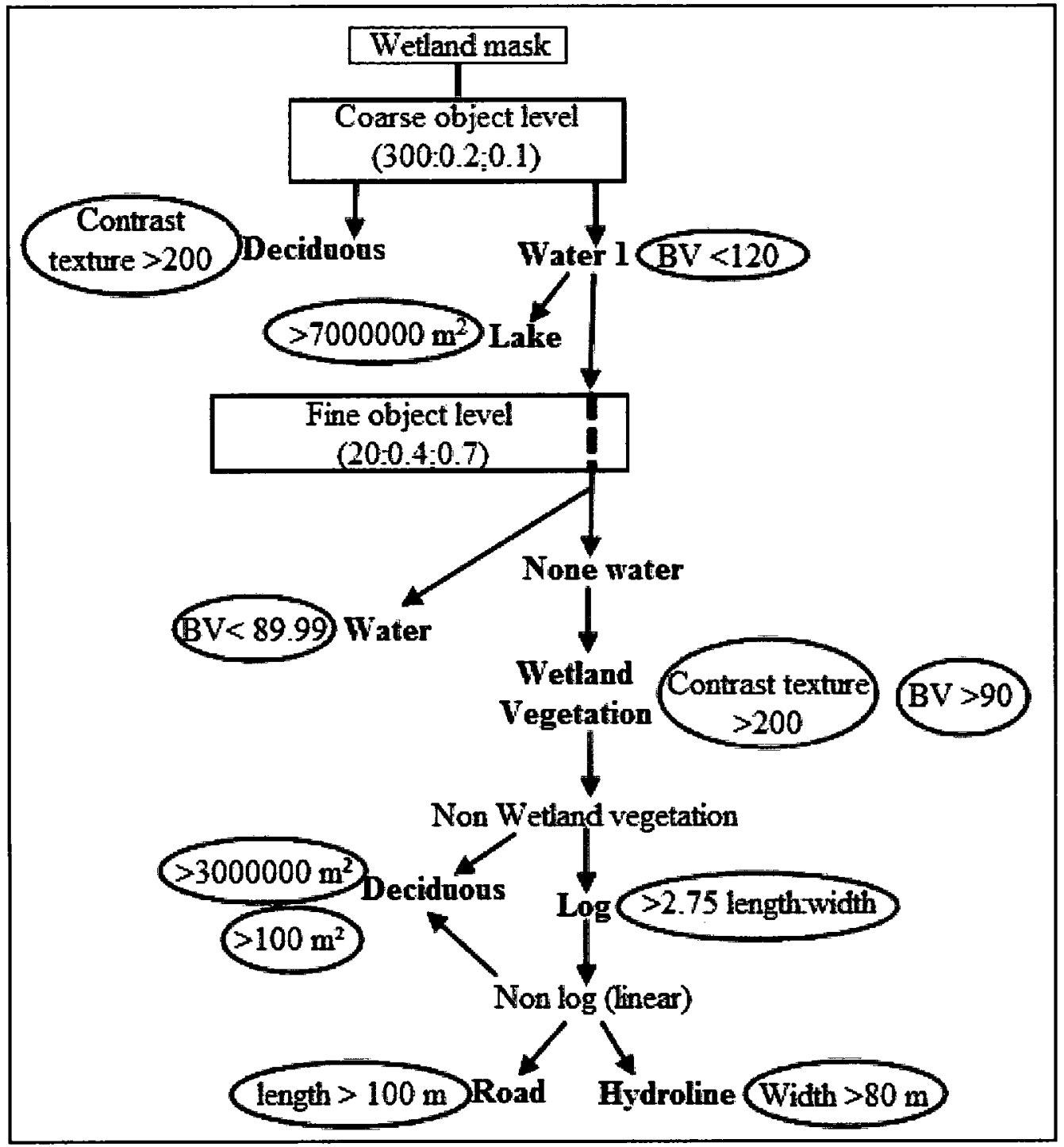

Figure 22. A simplified illustration of the classes used in the image object hierarchy (boxes). Text inside circles refers to rules used in classification; bold text refers to final classes that were mapped within the wetland mask; arrows refer to connections to classes or object levels; the dashed line represents the class that was segmented at a second object level.

\subsubsection{Classification of Deciduous Forest}

Testing of several texture measures and sampling angles found that homogeneity sampled at $45^{\circ}$ typically had a value under 0.1 for Deciduous Forest and over 0.1 for Wetland Vegetation in seven of the nine mosaics. This rule was applied to these mosaics to separate residual Deciduous Forest from the remainder of the wetlands. For the other two 
mosaics thresholds of 0.135 and 0.118 , respectively, were found to be more appropriate because the deciduous forest (trees and shadows) in these mosaics appeared more spatially uniform. For one mosaic some deciduous forest still remained classified as Wetland Vegetation after application of the Homogeneity texture rule. Additional rules used for this mosaic were one or a combination of area and texture thresholds (minimum or maximum). The inherent texture of the deciduous area changed depending on the size of the object and this was used to finely tune the classification of the two vegetation classes (Deciduous and Wetland Vegetation).

The following thresholds of area and texture measures were used in this mosaic to classify Deciduous Forest objects: 1) Area $>38000 \mathrm{~m}^{2}$ and Homogeneity texture $<0.1$; 2) Area $>6000 \mathrm{~m}^{2}$ and Homogeneity texture under 0.089; 3) Area $>20000 \mathrm{~m}^{2}$ and Homogeneity texture $>0.13$ and a Contrast texture $\geq 200$. It would also be an option to manually classify these small Deciduous Forest areas if it is not feasible to determine the upper and lower thresholds of area and texture.

Finally, for a few remaining misclassified areas, two specific rules based on area and topology were applied:

1. Deciduous Forest misclassified as Wetland Vegetation and larger than a specified size $\left(20000 \mathrm{~m}^{2}, 25000 \mathrm{~m}^{2}, 62000 \mathrm{~m}^{2}\right)$ was assigned to the Deciduous Forest class. This area threshold worked well because all of the interpreted wetland vegetation objects were segmented at the fine (small) object level, whereas most deciduous objects were segmented at the coarse (large) object level. 
2. Erroneously classified Deciduous Forest (misclassified as Wetland Vegetation) that was enclosed by Deciduous Forest was reassigned to the Deciduous Forest class.

3. In the end, there were only two deciduous forest objects that had to be manually removed because a rule could not be found to classify them separate from the Wetland Vegetation class that would not have negative consequences across the entire scene.

\subsubsection{Classification of Water}

To classify Water, the darkest of the classes, mean brightness was used for all mosaics. The threshold used varied slightly as follows: 90 (6 mosaics), 80 (2 mosaics), 85 (1 mosaic). In seven mosaics the only other rule that was applied to objects prior to this threshold rule was the GLCM Homogeneity texture $(<0.1)$ assigning objects to the Deciduous Forest class. Therefore all objects in the scene with under the specified mean brightness value were assigned to the Water class unless they had the specific Deciduous Forest class trait (low homogeneity texture).

In two mosaics, portions of La Pêche Lake were present and an additional rule had to be added that used an area threshold $\left(>7000000 \mathrm{~m}^{2}\right)$ to assign these Water objects to the class Lake.

\subsubsection{Classification of Wetland Vegetation}

Within wetland segmented objects that did not belong to the Water class were generally the focal habitat features Wetland Vegetation and Log. The characteristics of the objects that should belong to the targeted classes were explored to identify common attributes 
(e.g., mean brightness) that could be used in classification. As wetland vegetation was generally darker than logs, several mean brightness thresholds were tested but the brightness ranges throughout the study area overlapped significantly and in some places wetland vegetation brightness also overlapped with Water. Consequently, texture was used as an initial means to separate these classes. The following rules, found through iterative testing and visual validation to be highly accurate, were applied to classify Wetland Vegetation:

1) The mean brightness of objects was used as a minimum threshold to classify Wetland Vegetation in all nine mosaics. However, the threshold value and placement in the rule set sequence varied amongst mosaics as overall brightness varied slightly between images. Objects with a Mean Brightness (also referred to as mean digital number is (DN)) over the following thresholds were assigned to the Wetland Vegetation class: $85 \mathrm{DN}$ (1 mosaic), $90 \mathrm{DN}$ (6 mosaics), $110 \mathrm{DN}$ (1 mosaic), $120 \mathrm{DN}$ (1 mosaic). Sometimes this rule was applied before the Contrast texture rule below and sometimes after, depending on which provided the best separation of wetland vegetation and did not result in Deciduous Forest being re-classified as Wetland Vegetation.

2) Objects with a contrast texture $>200$ sampled at $45^{\circ}$ were assigned to Wetland Vegetation in four mosaics. In all but one of these, the rule was applied immediately after the multi-resolution segmentation at the fine object level.

3) In one mosaic Wetland Vegetation was reassigned to the Hydro-line class, using a maximum area threshold. The hydro-line was not segmented at the fine object level, making for larger sized objects that could be discriminated from Wetland Vegetation. 


\subsubsection{Classification of Wetland Logs}

Wetland vegetation objects were well separated from Water and Deciduous Forest using the rules described above. Logs had similar mean brightness and texture distributions as Wetland Vegetation so other rules were required to separate them. They were often represented as straight linear objects in Water (Figure 23), but in other instances they were clustered together or mixed/bordered Wetland Vegetation (Figure 24). From iterative testing, the following rules were developed for assigning objects to the $\log$ class:

1) All objects from the Wetland Vegetation class with a length/width ratio $\geq 2.75$ were classified as Log. This separated most distinct linear objects from Wetland Vegetation.

2) In three mosaics, Log objects longer than a specified length (20 m (2 mosaics), $100 \mathrm{~m}$ ) were reclassified to other classes.

3) The linear objects too large to be logs in five mosaics were classified as either Wetland Vegetation or Deciduous Forest using a size threshold of $100 \mathrm{~m}^{2}$, $200 \mathrm{~m}^{2}, 300 \mathrm{~m}^{2}, 500 \mathrm{~m}^{2}, 600 \mathrm{~m}^{2}$.

The quantities chosen as thresholds for reassigning objects of the Log class or Linear class (to follow) are high values representing the size and length that are distant from the actual log size.

\subsubsection{Classification of Linear, Road and Hydroline}

There were two mosaics that required more complex process trees and a significant amount of time to accurately assign all objects to their most suitable class. The Log class 
is a parent to the Linear class; therefore all Linear objects had a length/width ratio $\geq 2.75$. The Linear class was used in one mosaic to separate different linear objects into suitable classes. The following is a description of the rules used to assign the objects to the Linear class and the subclasses created from Linear:

1) In one mosaic Linear objects wider than $100 \mathrm{~m}$ were reclassified as Hydro-line

2) Objects from the Log class were assigned to Linear if they exceeded a specified length threshold of $20 \mathrm{~m}$.

3) The Linear objects were reassigned to Wetland Vegetation if they exceeded a specific width of $80 \mathrm{~m}$.

4) Linear objects were reassigned to Deciduous Forest if their distance to Deciduous Forest was $0 \mathrm{~m}$.

5) If the Linear class was surrounded by Water it was reassigned to the class Log.

6) The shoreline of La Pêche Lake created bright and linear objects. If the distance to La Pêche Lake was $0 \mathrm{~m}$ then the object was reclassified as Lake.

7) All remaining Linear objects that had not been reclassified were reassigned back to their original class, Wetland Vegetation. 

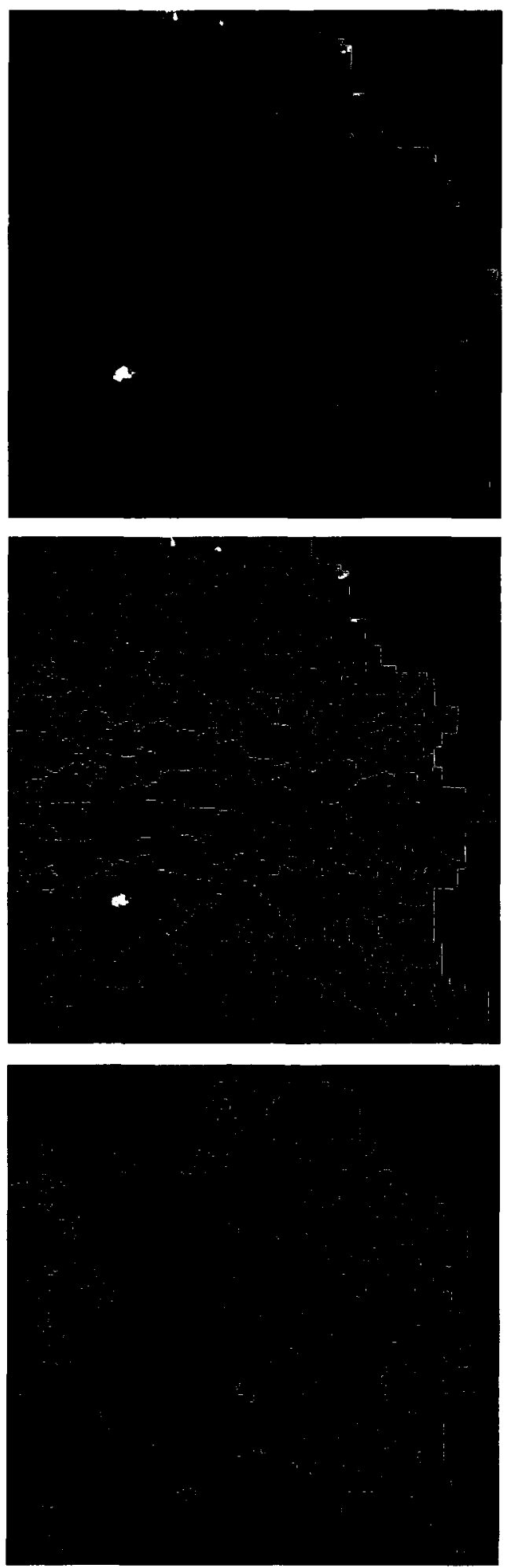

Figure 23. Orthophoto of part of a wetland (top)* compared to the same image segmented (centre with orange outlined objects) and the final classification result (bottom). A log is outlined in red in the orthophoto (top) and remains in red in the segmented image (centre) and classification result (bottom). Blue is Water and green symbolizes Wetland Vegetation. *Source: NCC, 2007. 


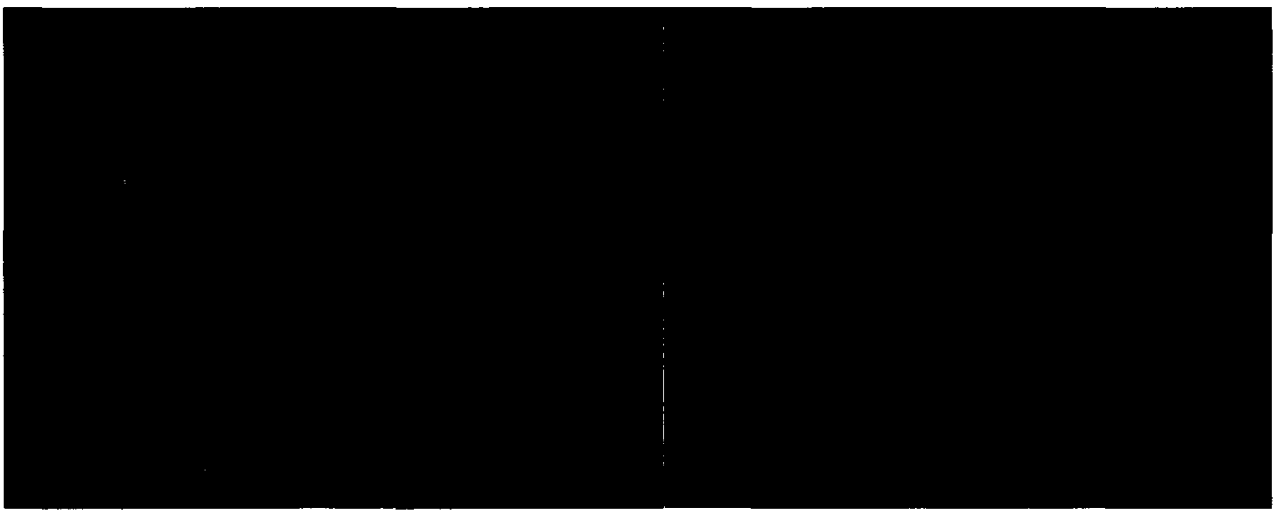

Figure 24. Example of Logs (brown) partially enclosed or bordering Wetland Vegetation (green). Water is blue. Orthophoto source: NCC, 2007.

\subsubsection{Agriculture}

A couple of objects were composed of agricultural fields, and were manually removed because no rules were found to discriminate them from other classes. The southern section of the study area was dominated by agriculture, and had no visible wetlands. The southern $800 \mathrm{~m}$ of all of the orthotiles (except the two farthest east that did have wetlands) was removed from the initial wetland mask and hence these areas were not included in the segmentation and classification process. Manual classification or removal of objects is commonly conducted once it becomes more efficient than developing and applying automated rule sets (Bock et al., 2005; Grenier et al., 2007; Benoit et al. 2008). It was necessary in this study to remove or reclassify a relatively small number of residual objects.

Some rules and parameters applied could be refined or made more variable between mosaics to improve classification accuracy, however this would have been even more time consuming. Most of the variation in rules and parameters was restricted to two mosaics which had an additional landcover class (Lake) and more instances of Deciduous Forest left in the wetland mask that needed to be separated from Wetland Vegetation. 


\subsection{Classification Accuracy Assessment}

Only the relevant classes for wetland and Blanding's turtle habitat suitability mapping were assessed for accuracy (i.e., Lake, Wetland and the wetland attributes: Water, Wetland Vegetation, and Logs). The other non-targeted classes (Deciduous Forest, Hydro-line, Road, and Agriculture) that were erroneously retained in the initial wetland mask were not identified as suitable Blanding's turtle habitat so they were aggregated together as 'other' and the classification accuracy of that merged class was not evaluated.

\subsubsection{Wetland Classification}

Using GIS tools, 550 random points were placed within the study area extent (Figure 25). Each point was visually interpreted on the orthophoto mosaic to determine if it was: 1) Wetland: within at least $20 \mathrm{~m}$ of a wetland, 2) Lake: within $20 \mathrm{~m}$ of La Pêche Lake, 3) Other: further than $20 \mathrm{~m}$ from a wetland. These classes were compared to the thematic classification results in an error matrix. Before conducting the analysis it was decided that 50 wetland samples would be used for accuracy assessment.

From the 550 points, 52 were visually interpreted as wetlands. Two were randomly removed from further analysis (ID's 525 and 293) leaving 50 for accuracy assessment.

\subsubsection{Wetland Attribute Classification Accuracy}

The following sections describe the methods used to determine the accuracy of classification of within wetland habitat features of Water, Logs and Wetland Vegetation. 


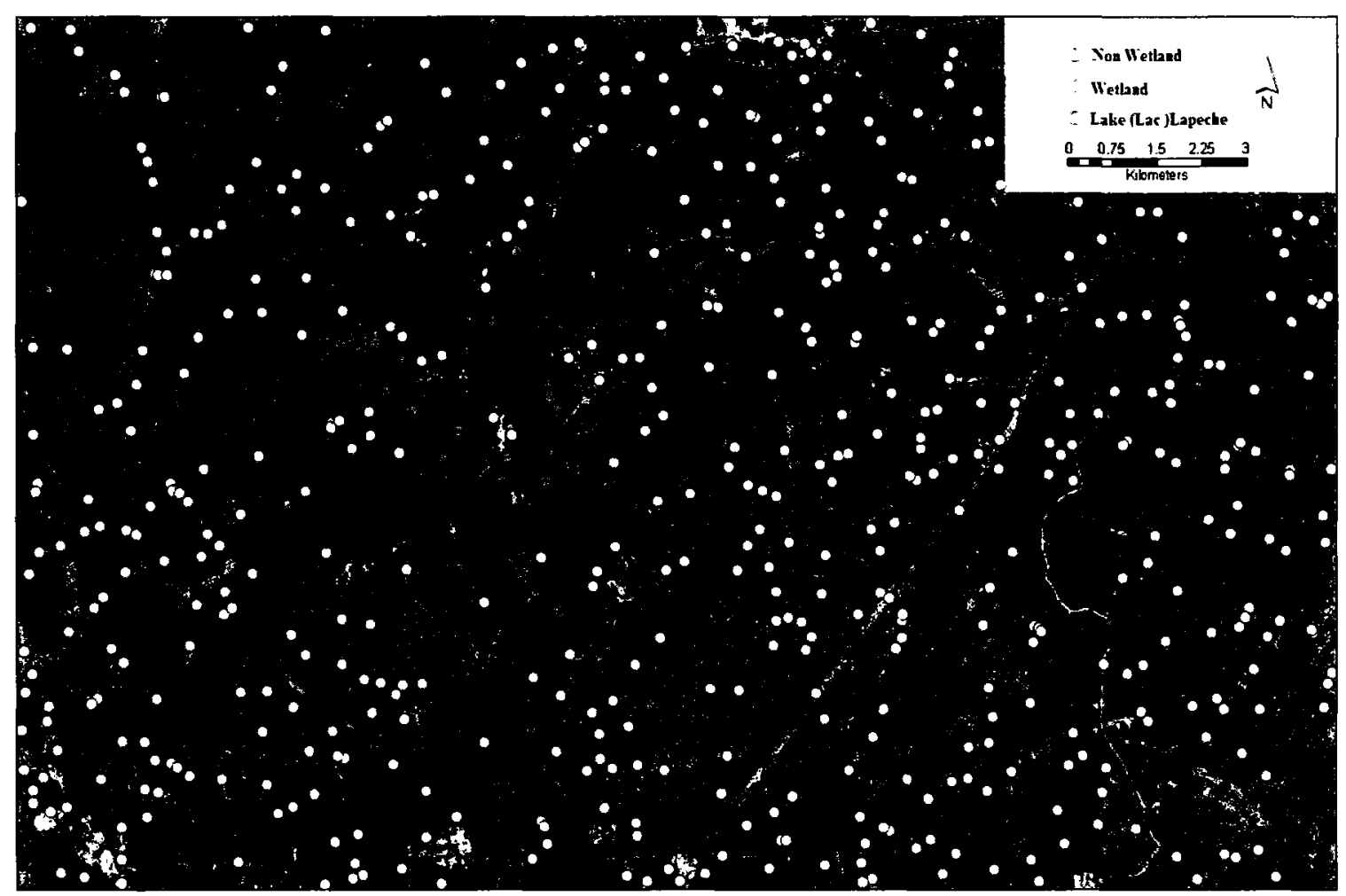

Figure 25. Random sample of 550 points interpreted as wetland (yellow), non-wetland

(Other) (pink), and Lake (orange).

\subsubsection{Classification of Wetland Vegetation, Logs and Water}

Five random points were placed within each of the 50 wetlands selected above and each point was visually interpreted on the orthophoto to determine if it was water, wetland vegetation or log and an error matrix was constructed. However, in selecting the five random points it became evident that because water is the dominant class by area within the wetlands, wetland vegetation or logs were rarely selected. Therefore, in each wetland where they existed, two visually interpreted logs and two wetland vegetation points were manually selected. The interpreted class was compared with the thematic classification as follows: for Wetland Vegetation, the area immediately surrounding the point in the classification map was considered for assessment; for Logs, if at least half of the log was classified then it was considered to be correctly classified. 
These test points were added to the random points in the error matrix analysis. Nine wetlands (out of 50) did not have logs present and one wetland had only one log present for validation. All wetlands had some wetland vegetation that could be used for validation. As there is potential for user bias in selecting the interpreted points, diligent care was taken to represent a range of the sizes, shapes, and brightness values that were present throughout the study area.

From the error matrix three accuracy metrics were calculated. Producer's accuracy is the proportion of the reference observations that are correctly classified. User's accuracy measures the proportion of each class that was correctly classified (Jensen, 2005), or the expected accuracy if the map was taken to the field and validated at given locations.

The Kappa coefficient (Equation 1, Foody and Atkinson, 2001) was calculated for the landcover classification and the wetland classes. The Kappa statistic was used in addition to calculating the producer's and user's accuracy because it takes into account the accuracy that would be obtained through random class assignment (Dwivedi et al., 2004).

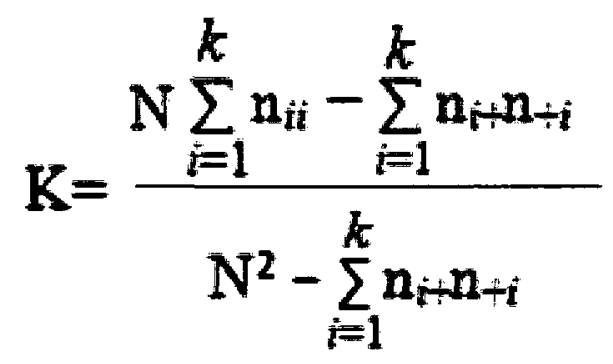

where $\mathrm{n}_{i i}$ is the sum of the number of pixels classified correctly, $\mathrm{n}_{i+}$ is the number of pixels classified into class $\mathrm{i}, \mathrm{n}_{+i}$ is the number of pixels classified into class $i$ in the reference data, $\mathrm{N}$ is the total number of observations and $k$ is the number of classes (Foody and Atkinson, 2002). 


\subsubsection{Visual photo interpretation evaluation of classification}

Of the 50 wetlands selected for the accuracy assessment (Section 3.5.1), 16 had been field surveyed between June and September of 2008 (Section 3.2). A qualitative accuracy assessment was conducted for these 16 wetlands by direct visual comparison between the orthophoto, the classification results, and field survey records (e.g., Table 7). All data associated with the assessment is available on the accompanying DVD.

Table 7. Example of a wetland evaluated for its three class components: A) Wetland Vegetation; B) Logs C) Water. (this example is from Wetland ID 230).

\begin{tabular}{|llr|}
\hline Feature & \multicolumn{1}{c}{ Comparison description } & Rating \\
\hline A & $\begin{array}{l}\text { Most of veg classified (75\% }+ \text { ). Missing a couple of } \\
\text { clusters of vegetation. Some conifer misclassified as } \\
\text { wetland vegetation. }\end{array}$ & good \\
\hline B & Abundant confirmed in orthophoto, field, classification. & very good \\
\hline C & $\begin{array}{l}\text { Confirmed open water in orthophoto, classification and } \\
\text { field visit. }\end{array}$ & very good \\
\hline
\end{tabular}

The accuracy of classification of the entire wetland boundary extent (within $20 \mathrm{~m}$ of Water) was estimated by visually comparing the area of the wetland on the orthophoto and the area classified as wetland on the map.

\subsection{Habitat Suitability Mapping}

\subsubsection{Merging Wetland Fragments, Associating Wetland Features to Individual Wetlands, and Extraction of Wetland Feature Metrics.}

To identify wetlands as discrete entities from the three classes of Water, Wetland Vegetation and Logs, several steps were conducted to unify fragmented wetland sections (buffer and merge) into more comprehensive wetlands units that could be further evaluated for their level of feasibility as potential Blanding's Turtle habitat. 
To calculate the total area of each classified wetland, several steps were implemented. All Water, Log and Wetland Vegetation objects were first associated with the identification number (ID) of the wetland in which they occurred. However, some individual wetlands that were visibly discernable in the orthophoto appeared as scattered wetland portions in the classification results because the segmentation process created multiple wetland objects separated by object(s) classified as 'Other', usually Deciduous Forest or continuous Wetland Vegetation (which often had small streams). To merge these wetland objects and create a single identifier for the wetland, a buffer was applied around each Water polygon.

Buffer sizes of $50 \mathrm{~m}, 20 \mathrm{~m}, 15 \mathrm{~m}, 10 \mathrm{~m}$, and $5 \mathrm{~m}$ were tested. A $50 \mathrm{~m}$ buffer was determined to be the largest justifiable size to test, based on habitat selection criteria for Blanding's turtles. The Blanding's turtles use Wetland Vegetation for camouflage, sun basking in spring and thermal regulation in summer. They particularly select within wetland vegetation such as sedge tussocks and bank wetland vegetation (Bourque, 2006; Edge, 2008) to be in close proximity to water in case of a need to escape as well as to utilize it as a potential food source. However, the $50 \mathrm{~m}$ buffer was deemed too large due to several instances of visibly separate wetlands up to $100 \mathrm{~m}$ apart being merged. Buffer sizes of $5 \mathrm{~m}$ and $10 \mathrm{~m}$ buffers were not large enough because in many cases polygons from the same wetland were not merged. Therefore, a $20 \mathrm{~m}$ buffer was selected as the best trade-off between accuracy of wetland extent (improved through polygon merging) and boundary inclusion (amount of Wetland Vegetation to include in relation to Blanding's turtle shoreline habitat needs). After the $20 \mathrm{~m}$ buffer was implemented, overlapping buffers were dissolved. Wetland identification numbers were then assigned 
to the resulting objects. All Water, Log and Wetland Vegetation objects were then associated with a unique wetland ID using specific tools in ArcGIS.

Upon completion of the above steps, the following metrics were calculated or extracted for each wetland: area of each polygon belonging to each class (Log, Wetland Vegetation and Water); number of Logs; percent cover of Wetland Vegetation and Water.

A minimum area of Water $\left(100 \mathrm{~m}^{2}\right)$ within a wetland was set as a threshold to retain the wetland for Blanding's turtle habitat suitability analysis as this would ensure their biological and physiological requirements can potentially be met. The aerial orthophotos were obtained in spring, when Water is generally at its highest due to snow melt and spring precipitation. Therefore, the Water in the classified map likely becomes reduced in extent during the summer, making $100 \mathrm{~m}^{2}(10 \mathrm{~m} \times 10 \mathrm{~m})$ a conservative minimum threshold for suitable habitat. In addition, this threshold served to reduce classification error, which was higher for objects smaller than $100 \mathrm{~m}^{2}$ (red polygons; Figure 26).

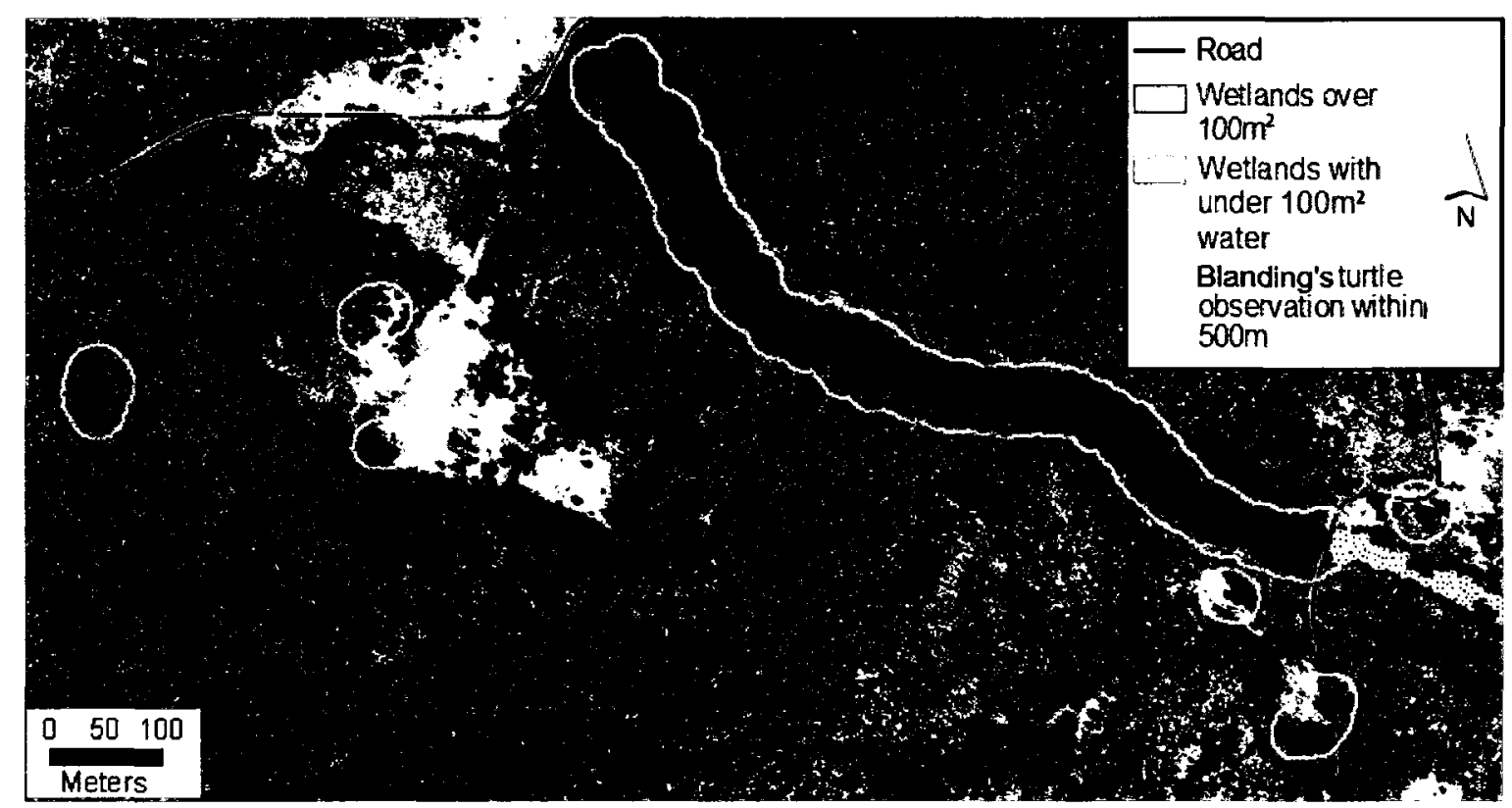

Figure 26. Example of classified wetlands that were removed (red) because they were less than the defined water area threshold of $100 \mathrm{~m}^{2}$. Blue wetlands were retained for habitat suitability analysis. 


\subsubsection{Developing a Habitat Suitability Score}

There are many possible attributes that can be included in a habitat suitability analysis, and many ways to combine them mathematically to produce suitability scores. In this

research, habitat suitability scoring system was formulated that incorporates the classified wetland features and the extracted metrics described above. Wetland size was divided into four categories, Wetland Vegetation into five categories and numbers of Logs/wetland was divided in three categories (Table 8).

A simple system was devised for final analysis that conveys the importance of the focal wetland attributes (Logs and Wetland Vegetation) to Blanding's turtle habitat selection, without removing potentially adequate habitat. Scores for each wetland attribute varied based on wetland size (Table 8). It was necessary to provide lower scores for medium and large wetlands with low per cent cover of Wetland Vegetation because the absolute area of Wetland Vegetation would be lower than in a very small or small wetland size. Very small and small wetlands with a very high percent Wetland Vegetation cover would not have as much Water available and would be evaluated as less suitable habitat, compared to medium and large sized wetlands. There were some scores that remained the same across wetland sizes, such as the medium and high Wetland Vegetation categories, because in any of the wetland sizes this percent cover should provide adequate habitat resources.

The Wetland Vegetation abundance range classes were developed with consideration of habitat requirements for Blanding's turtles. Beyond a certain area or \% cover of Wetland Vegetation, the suitability does not increase. The number of logs present in a wetland also reaches a threshold of maximum suitability. For instance, in a small 
wetland, a couple of logs are sufficient as optimal habitat (Dubois, 2009. pers. comm. October 2009). In a larger wetland the threshold is slightly higher so the maximum was set at 5 .

The total habitat suitability score for each wetland was calculated by summing the scores for Wetland Vegetation and Logs together and adding two points for being a wetland (versus 'Other" was scored as 0 ) using this scoring system, a wetland could potentially have a score of two to ten, depending on the proportion of Wetland Vegetation cover and the number of Logs available (also related to wetland size). The scores were then grouped into classes from unsuitable to very high suitability for map display and analysis (Table 9).

Table 8 .Wetland size classes and Wetland Vegetation classes associated with scores used in Habitat Suitability Analysis

\begin{tabular}{|c|c|c|c|c|c|c|}
\hline & Class & & & & core & \\
\hline & Wetland Veg & tation & & Wetla & Size $\left(\mathrm{m}^{2}\right)$ & \\
\hline & $\begin{array}{l}\text { Quantity } \\
\text { Description }\end{array}$ & $\begin{array}{c}\text { Percent } \\
\text { cover range }\end{array}$ & $\begin{array}{c}\text { Very } \\
\text { Small } \\
(<500)\end{array}$ & $\begin{array}{c}\text { Small } \\
(500-2499)\end{array}$ & $\begin{array}{c}\text { Medium } \\
(2500-22500)\end{array}$ & $\begin{array}{c}\text { Large } \\
(>22500)\end{array}$ \\
\hline & $\begin{array}{l}\text { None or } \\
\text { Very low }\end{array}$ & 0 to 4.99 & 0 & 0 & 0 & 0 \\
\hline & Low & 5 to 24.99 & 3 & 3 & 2 & 2 \\
\hline & Medium & 25 to 49.99 & 5 & 5 & 5 & 5 \\
\hline & High & 50 to 74.99 & 4 & 4 & 4 & 4 \\
\hline & Very High & 75 to 100 & 1 & 1 & 2 & 2 \\
\hline Log & 0 & & 0 & 0 & 0 & 0 \\
\hline & $1-5$ & & 3 & 3 & 2 & 1 \\
\hline & $>5$ & & 3 & 3 & 3 & 3 \\
\hline
\end{tabular}

Although not conducted for this research, if other land cover types were to be included in the habitat suitability map then anthropogenic land uses such as buildings, roads and agriculture should have scores of 0 , except possibly unused dirt roads and trails, which may be good nesting habitat. These were too difficult to map in this research but may be 
visually interpretable from the imagery, or they could be imported from an existing vector database. Forest could have a score of 1 because it is considered the habitat matrix that Blanding's turtles use to traverse between wetlands.

Table 9. Habitat suitability score related to ordinal scale habitat suitability level.

\begin{tabular}{|c|c|}
\hline $\begin{array}{c}\text { Habitat Suitability } \\
\text { Score }\end{array}$ & $\begin{array}{c}\text { Habitat Suitability } \\
\text { Level }\end{array}$ \\
\hline $2-3$ & Unsuitable \\
\hline 4 & Low \\
\hline $5-6$ & Medium \\
\hline $7-8$ & High \\
\hline $9-10$ & Very High \\
\hline
\end{tabular}

To evaluate the coherence of the habitat suitability scoring system, the score given to each wetland attribute (Log and Wetland Vegetation) based on wetland size was assessed by calculating every potential score scenario (Table 10). Assessment of score scenarios for each wetland size indicates that the scoring system adheres to expert knowledge and research done on Blanding's turtle habitat selection.

The score output scenarios (Table 10) show general trends of score increase or decrease dependent on the wetland size category and abundance of Wetland Vegetation and Logs. An unsuitable score (2-3) generally indicates a wetland with none or very low Wetland Vegetation cover and no Logs or very high Wetland Vegetation and no Logs. In general Low scoring (4) wetlands have over 1 Log present and none to very low (0-5\%) Wetland Vegetation cover or no Logs and at least low Wetland Vegetation abundance. Medium scored (5-6) wetlands generally have Logs and a minimal amount of Wetland Vegetation or no Logs and they consist of low to very high level (5\% - 75\%) of Wetland Vegetation cover. High scoring (7-8) wetlands commonly have low to high Wetland Vegetation $(5 \%-75 \%)$ cover and some Logs $(>1)$ present. Very High scoring (9-10) 
wetlands have medium to high ( $25 \%-75 \%)$ Wetland Vegetation cover and more than one Log present.

Table 10. Potential combinations of wetland attributes (Log and Wetland Vegetation) and their affiliated score totals (bold numbers) and suitability level (colour).

\begin{tabular}{|c|c|c|c|c|c|}
\hline & \multicolumn{3}{|c|}{ Logs abundance } \\
\hline & & & 0 & $1-5$ & $>5$ \\
\hline $\begin{array}{l}\text { Wetland } \\
\text { size }\end{array}$ & $\begin{array}{l}\text { Wetland } \\
\text { Vegetation Percent } \\
\text { Abundance }\end{array}$ & $\begin{array}{l}\text { Wetland } \\
\text { Vegetation } \\
\text { score/ Log score }\end{array}$ & 0 & 3 & 3 \\
\hline \multirow{5}{*}{$\begin{array}{l}\text { Very } \\
\text { small } \\
\text { and } \\
\text { Small }\end{array}$} & $0-4.99$ & 0 & 2 & & \\
\hline & $5-24.99$ & 3 & & 8 & 8 \\
\hline & $25-49.99$ & 5 & 7 & 5.? & nt) \\
\hline & $50-74.99$ & 4 & & g & 8 \\
\hline & $>75$ & 1 & 3 & & \\
\hline & & & 0 & 2 & 3 \\
\hline \multirow{5}{*}{ Medium } & $0-4.99$ & 0 & 2 & & \\
\hline & $5-24.99$ & 2 & & & 7 \\
\hline & $25-49.99$ & 5 & 7 & (s) & 4 \\
\hline & $50-74.99$ & 4 & & 8 & ( \\
\hline & $>75$ & 2 & $4: 5$ & & 7 \\
\hline & & & 0 & 1 & 3 \\
\hline \multirow{5}{*}{ Large } & $0-4.99$ & 0 & 2 & 3 & \\
\hline & $5-24.99$ & 2 & 4 & $=$ & 7 \\
\hline & $25-49.99$ & 5 & 7 & 8 & 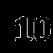 \\
\hline & $50-74.99$ & 4 & & 7 & 8 \\
\hline & $>75$ & 2 & 4 & & 7 \\
\hline & Unsuitable & & & & \\
\hline & Low & & & & \\
\hline & Medium & & & & \\
\hline & High & & & & \\
\hline & Veryhigh & & & & \\
\hline
\end{tabular}




\section{CHAPTER FOUR}

\section{RESULTS}

\subsection{Summary of Wetland Classification Results}

Wetland mapping and production of the wetland mask resulted in a total of 693 wetlands. The previously mapped wetlands and water bodies in this research study area (Figure 27) include: 1) 82 from BDTQ (1:20,000) (QMNRF, 2008) 2) 14 from Conservation Atlas of Wetlands (Belanger and Grenier, 2003) (3) 8 wetlands from NTDB (3 that don't overlap other data sources from 1 and 2 above) (NRCan, 2007b). 4) 282 water polygons from NTDB (NRCan, 2007b).

In total there were 101 wetlands previously mapped and 282 water bodies, compared to the 693 wetlands mapped in this research (590 after the $100 \mathrm{~m}^{2}$ Water threshold was applied). Some of the water bodies from NTDB spatially overlap the wetlands mapped from other sources. There are also many wetlands and water bodies mapped in this research that coincide with previously mapped wetland and water bodies (Figure 27) An accompanying DVD provides all map data (shp file format) from this research.

The wetlands mapped in this research are characterized mostly as 'Small' (41.56\%), 'Very small' (28\%) and 'Medium' (22.79\%) (Table 7). Large wetlands were not common in the study area $(7.5 \%)$.

After 133 wetlands with less than $100 \mathrm{~m}^{2}$ of Water were removed, the Very Small category decreased by $16.52 \%$ while the Small category had only 3 wetlands removed (Figure 28). 


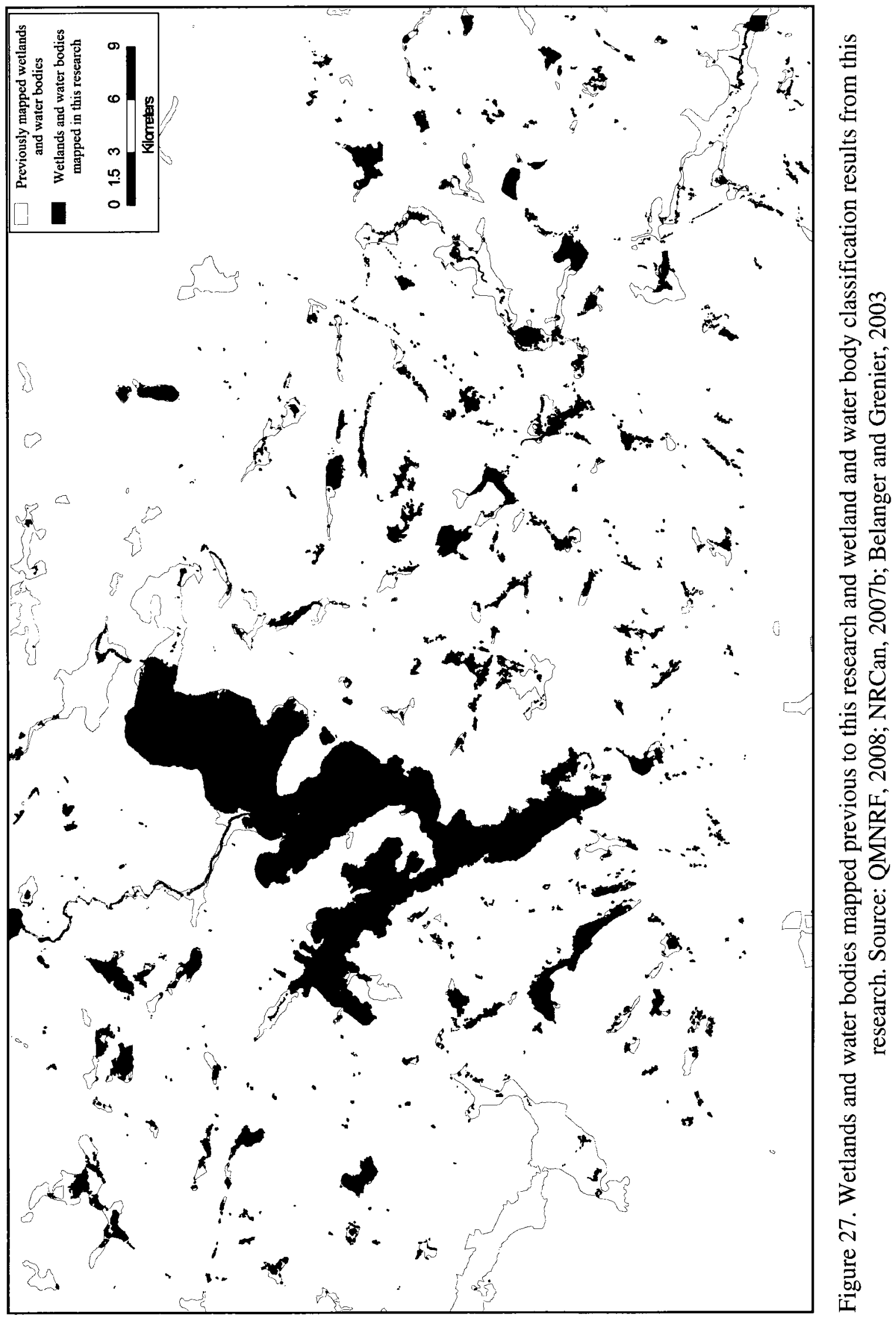




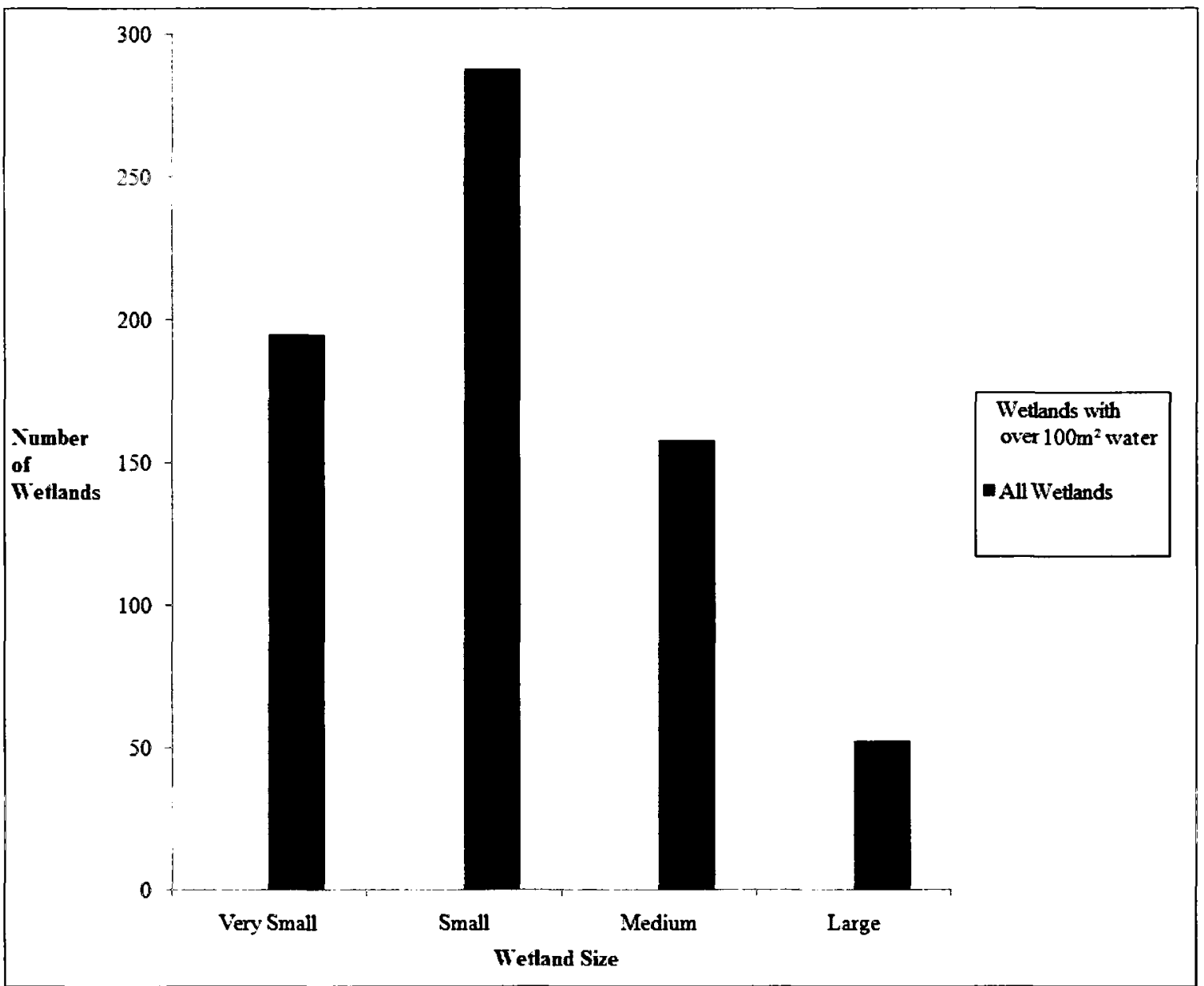

Figure 28. The number of wetlands mapped based on wetland size. The wetlands that contained more than $100 \mathrm{~m}^{2}$ of Water (grey bars) were retained for habitat suitability analysis.

Figure 29 shows the distribution of Wetland Vegetation cover for all classified wetlands, most $(71 \%)$ had $5 \%-50 \%$ cover. For wetlands retained with over $100 \mathrm{~m}^{2}$ of Water, this increased to $82 \%$.

Figure 30 illustrates the distribution of the classes for number of Logs in each wetland. Most wetlands had $\log (\mathrm{s})$ present $(84.84 \%)$ and almost half had over five Logs $(49.78 \%)$. Most of the removed wetlands with under $100 \mathrm{~m}^{2}$ of Water had 1-5 Logs and 49 wetlands were removed that had no Logs, however, the relative distribution of retained wetlands remained similar to the original set. Since almost all of the wetlands 
that had more than 5 Logs were not removed, this selective habitat characteristic was not greatly affected.

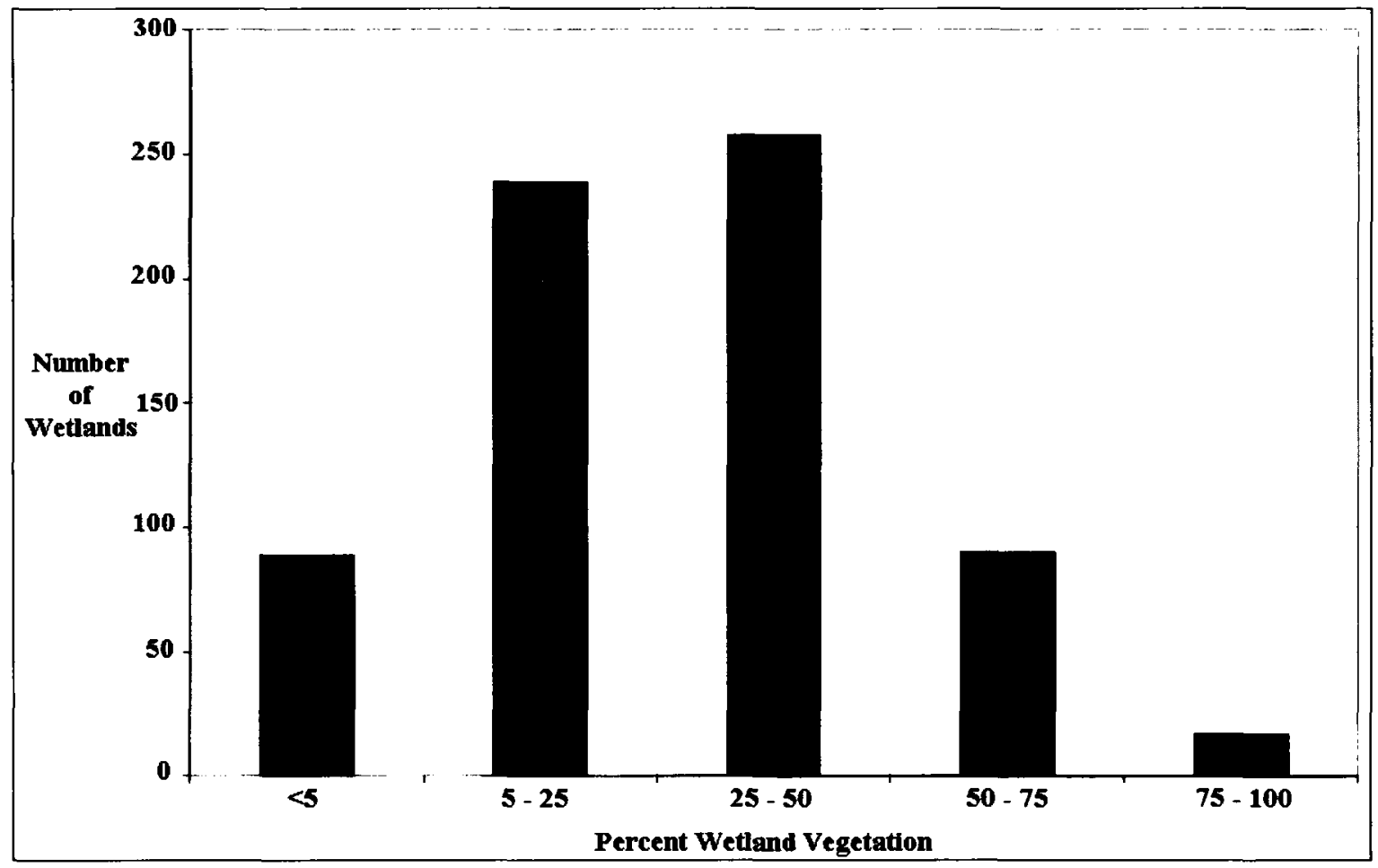

Figure 29. Percent Wetland Vegetation cover in all wetlands (all sizes).

\subsection{Wetland and Within Wetland Feature Classification}

\subsubsection{Qualitative Accuracy Results}

Visual photo interpretation revealed several strengths and weaknesses of the classification results when comparing the orthophoto to the classification result and field photographs. An accompanying DVD to this thesis provides the field, image and map data evaluated for this section. Water, Wetland Vegetation and Logs were classified very well in most wetlands (Figure 31). For classification result comparisons, refer to the legend in Figure 32. 


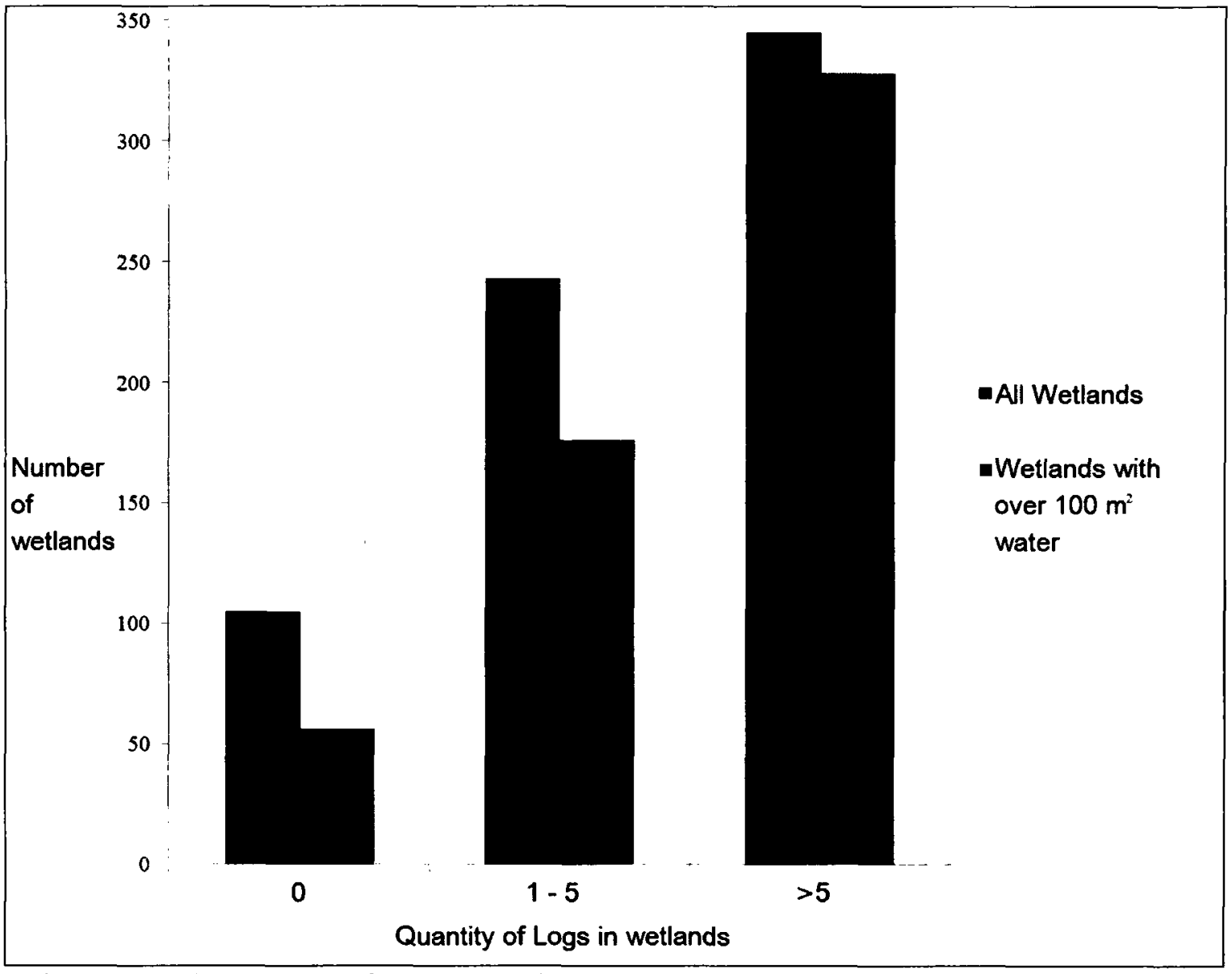

Figure 30. The number of wetlands related to the quantity of Logs, for all wetlands and wetlands with over $100 \mathrm{~m}^{2}$ of Water surface area.

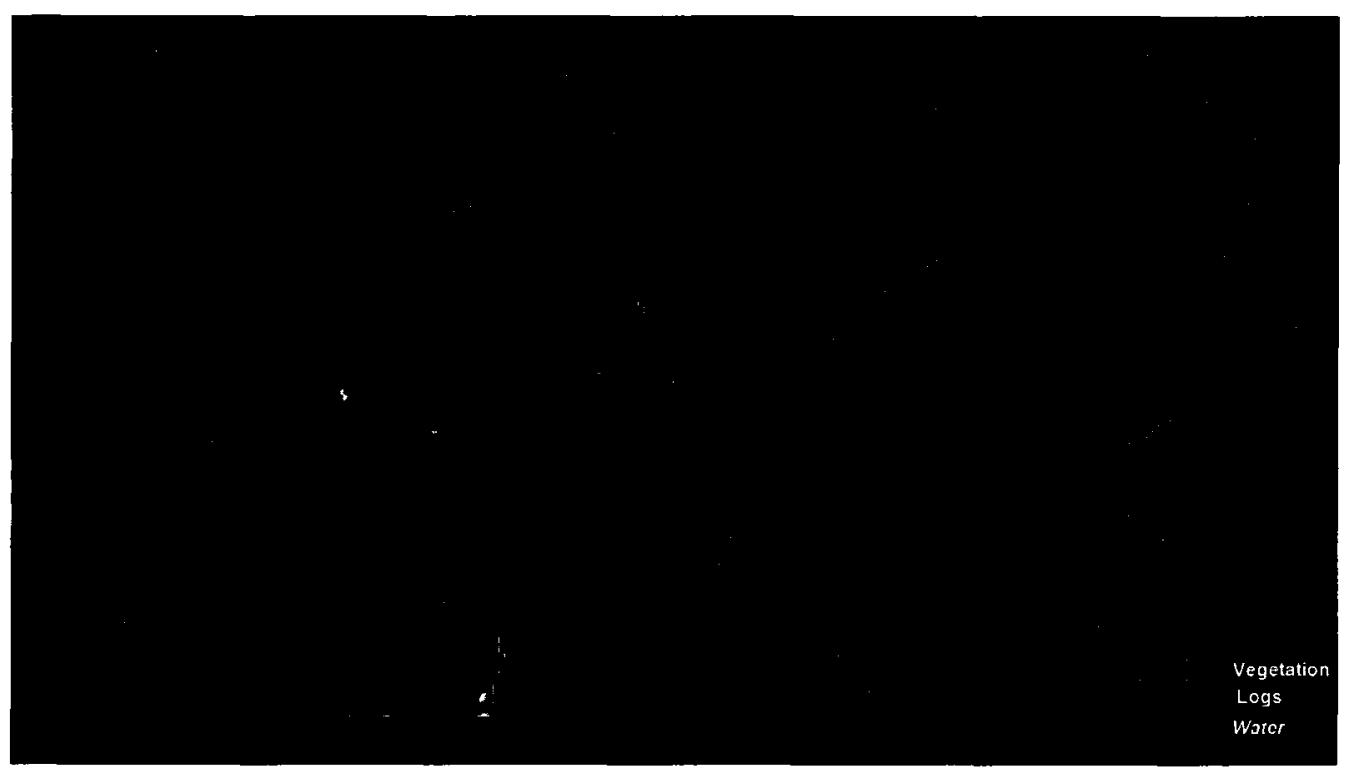

Figure 31. Orthophoto of a wetland (from wetland mask) compared to classification results of three wetland attribute classes critical to Blanding's turtle habitat mapping: Water, Logs and Wetland Vegetation. 


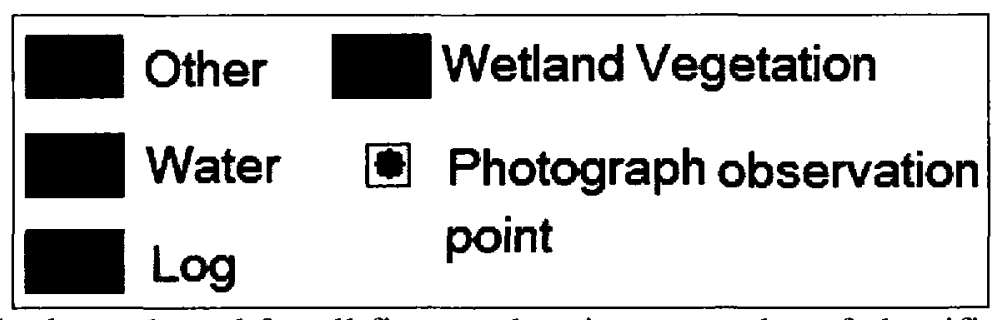

Figure 32. The legend used for all figures showing examples of classification results.

In several instances errors were evident in the classification results, including the misclassification of shadow on continuous vegetation or vegetation in the middle of a wetland as Water (e.g., Figure 33). Shadows are spectrally and texturally similar to water and are easily misclassified using mean brightness or texture measures. These misclassified areas could have been manually removed (e.g., as in Bock et al., 2005) but they formed only a small portion of the total area of continuous vegetation mapped within all the wetlands so they were deemed to be negligible for the purposes of mapping wetlands and the habitat features of Wetland Vegetation and Logs.

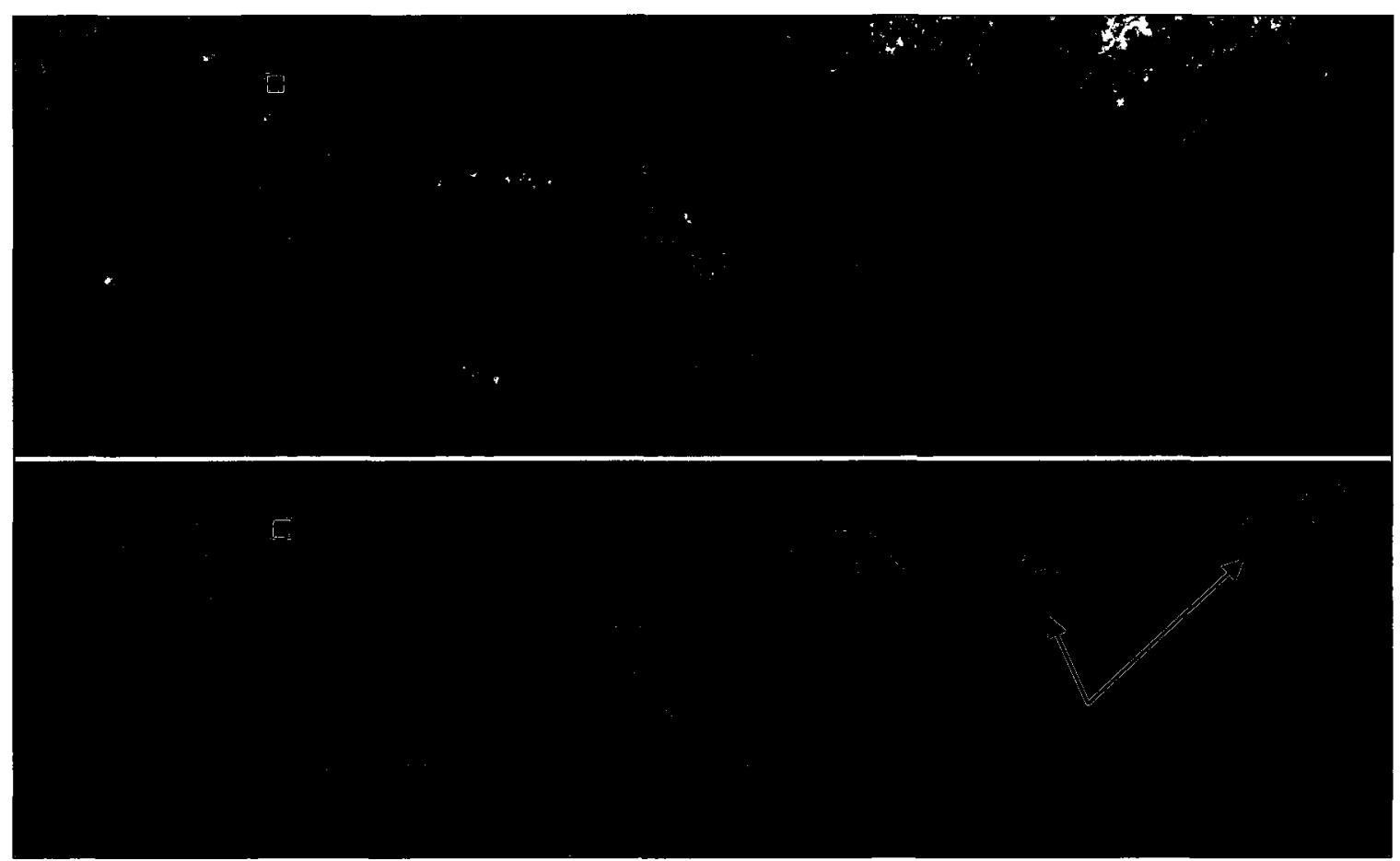

Figure 33. Orthophoto (top) and wetland classification (bottom). The shadows cast from the conifer trees onto continuous vegetation (upper image red arrows) are misclassified as Water (lower image black arrows; two blue polygons). 
In several instances portions of a wetland were connected by very narrow water structures, and these small linear sections were not included in the classification result. Consequently they were assigned to the "Other" class, making the wetland portions appear separated (Figure 34). In some instances the wetland sections are close together but have forest canopy above the narrow sections (connecting the larger sections), which make these portions appear as separate wetland entities. Again, these areas are very small in relation to the water bodies that were captured, but they could represent good habitat.

In several instances, there was continuous wetland vegetation separating the portions of wetland that had more open water (and logs and dispersed wetland vegetation present), and since many of these continuous wetland vegetation sections were not included in the final classification results it made the wetland appear fragmented and disconnected. The continuous vegetation was often not included in the original wetland mask. The $20 \mathrm{~m}$ buffer improved the connection of fragmented classified wetlands but was not always large enough (section 3.6). A future wetland map could use different buffer sizes to join wetland sections farther apart.

The wetland mask used for within wetland classification retained limited continuous vegetation. The time of image acquisition (May, leaf-off) and the limited spectral resolution of the aerial orthophoto data made classification of continuous vegetation difficult, because it was often confused with deciduous forest (senescent ground). The deciduous forest areas were erroneously retained mainly in one mosaic, requiring rules to distinguish the objects consisting of deciduous forest from the wetland vegetation. Textures and area threshold rules were used to distinguish the vegetation classes in this 
mosaic. Although these rules were feasible to distinguish the vegetative classes for one mosaic it would be less efficient and more computationally difficult to use over the entire study area, which is why the production of the original wetland mask was an important initial step.

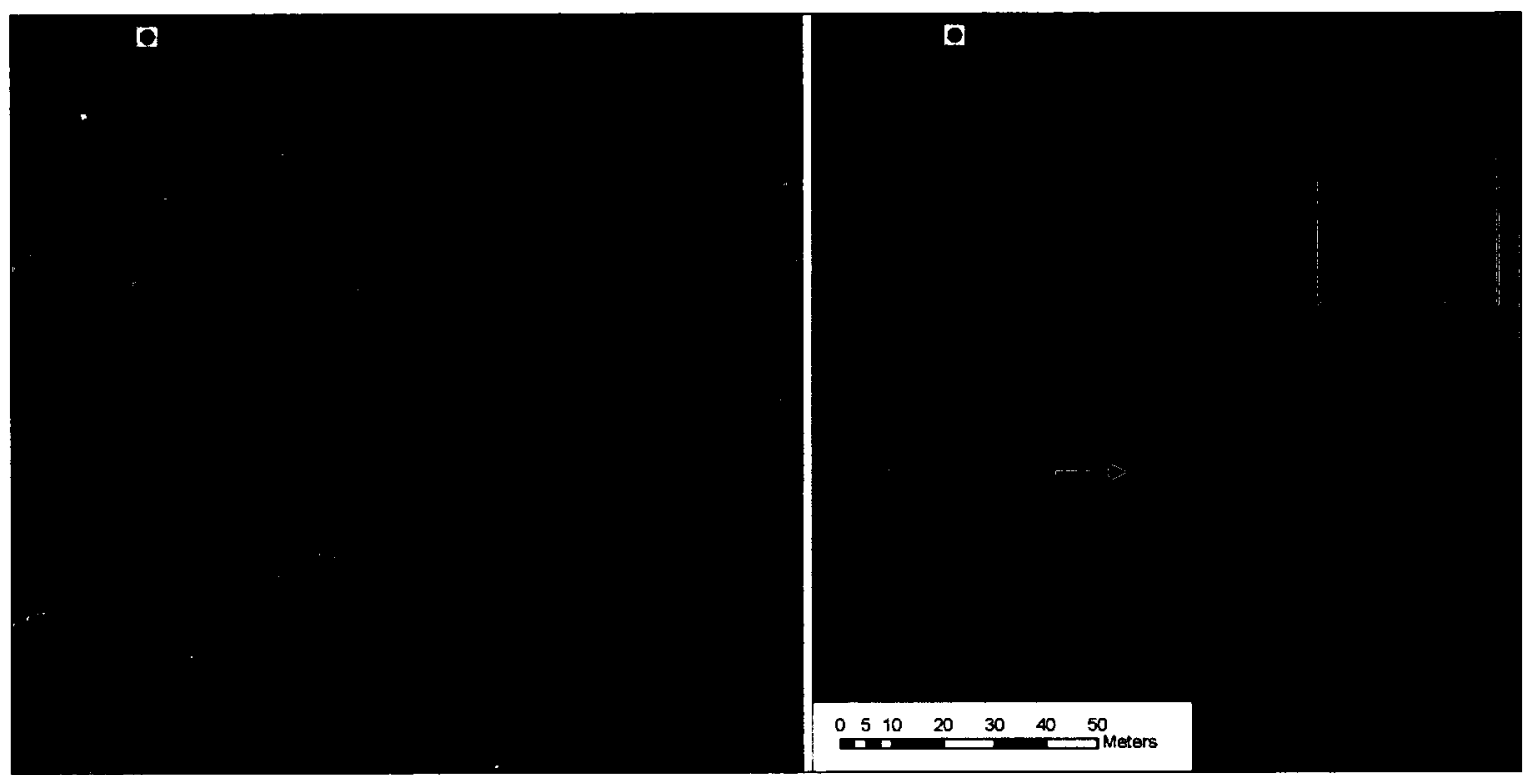

Figure 34. Orthophoto (left) and wetland classification (right). Sections of wetland were not included in the wetland mask (red arrow compared to black) and there are missing narrow water sections (Red box compared to black).

The habitat scoring system developed for this thesis is based on all-season habitat requirements, not specific activity periods related to specific seasons. Wetland surveying during the turtle inventory (Parc de la Gatineau, 2007) was limited (biased) to around the Eardley-Masham road and consequently Blanding's turtle observations were also limited to this area. Wetland surveying was done in the summer for this research which was not temporally ideal for finding Blanding's turtles, because it is difficult to find turtles that are most likely camouflaged or less visible in vegetation or the water column during the warm summer months.

Classified Wetland Vegetation was in general agreement with the orthophoto and field survey data (Appendix 2). Discrepancies were mostly due to field surveying in summer 
when more floating aquatic vegetation and emergent grasses were observed than was visible in leaf-off spring orthophotos. The spring imagery used in this research (Figure 35 (I) did not have extensive floating aquatic vegetation present (Figure 35-II), although it is apparent in summer when comparing the spring orthophoto to a summer satellite image (Figure 35-III) and the summer field photograph (Figure 35-IV).

The spring imagery used in this research (Figure 36-I) did not have extensive emergent grasses and other vegetation present to classify (Figure 36-II), because these vegetation types grow later in summer, as shown in a summer satellite image Figure 36 (III) and photograph (Figure 36-IV)

Coniferous trees on the edges of wetlands were also sometimes misclassified as Wetland Vegetation. A limited amount of continuous wetland vegetation (vegetation islands, continuous vegetation on periphery and bank vegetation) was present in the classified map, but most was removed in the initial wetland mask.

Logs were usually classified well (Appendix 2) but in some areas they were not included in the wetland mask generated from the first phase of classification. There were several instances where logs were misclassified as Wetland Vegetation or vice versa and there were instances where partially submerged logs were classified as Water.

The degree to which each wetland was delineated and fully classified was visually evaluated by assessing wetland extent (area). Visual interpretation revealed that the delineated extent was over $90 \%$ of what was visually estimated for 10 of the 16 sampled wetlands (Figure 37). For 5 wetlands about $75 \%$ - $90 \%$ of the interpreted area was delineated. There was one instance where about $50 \%$ of the wetland extent was not classified (Figure 34) due to reasons discussed previously. 


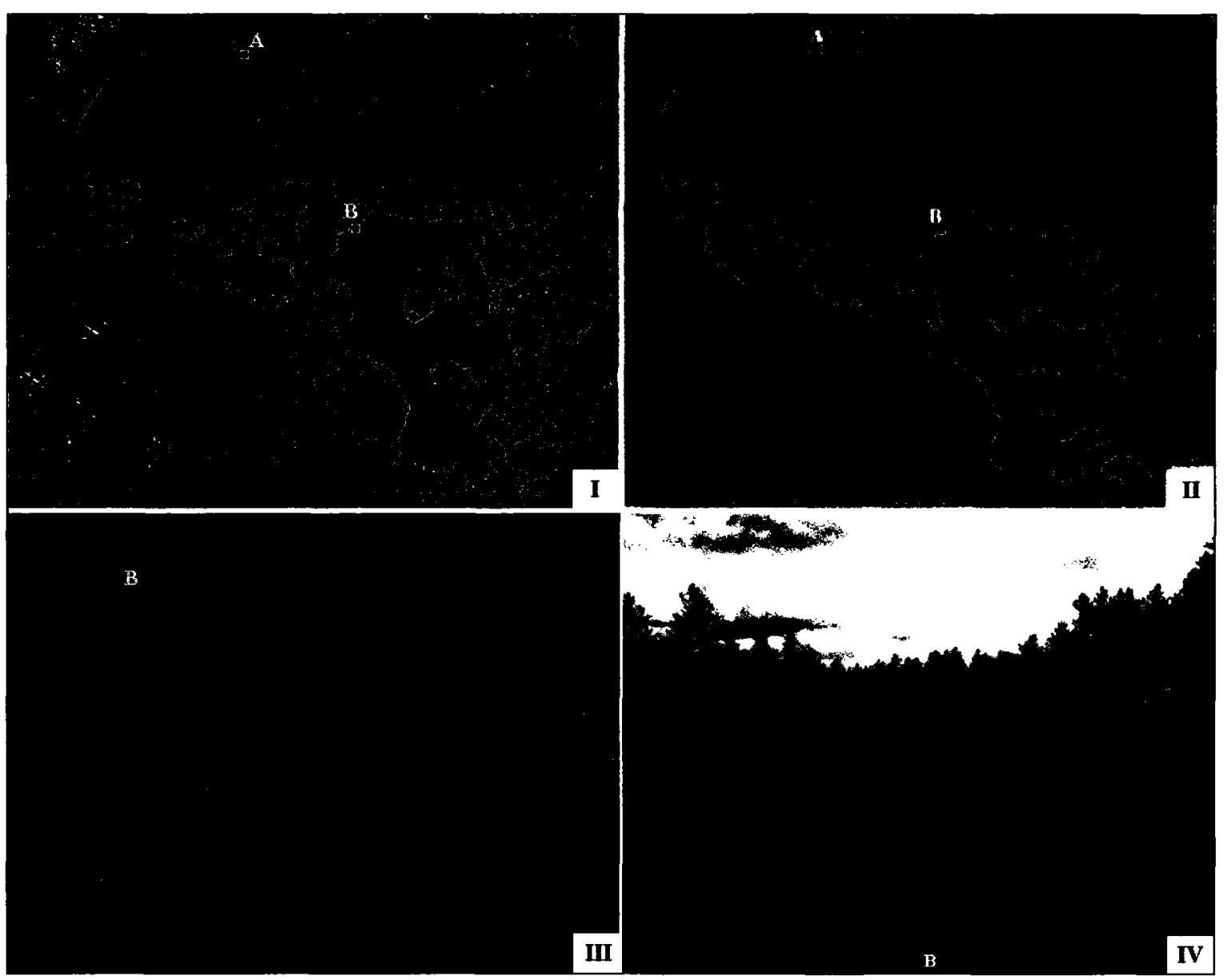

Figure 35. Spring Orthophoto (I)* and wetland classification (II). Satellite image of the same wetland in summer (III)**, exhibiting increased wetland vegetation compared to spring orthophoto. Photograph taken in summer of the wetland at location B (IV)***, also illustrates the abundance of floating aquatic vegetation that is present in summer but not apparent in spring. Sources: ${ }^{*} \mathrm{NCC}, 2007 ;{ }^{* *}$ Google Earth, 2009. *** Author, 2008. 


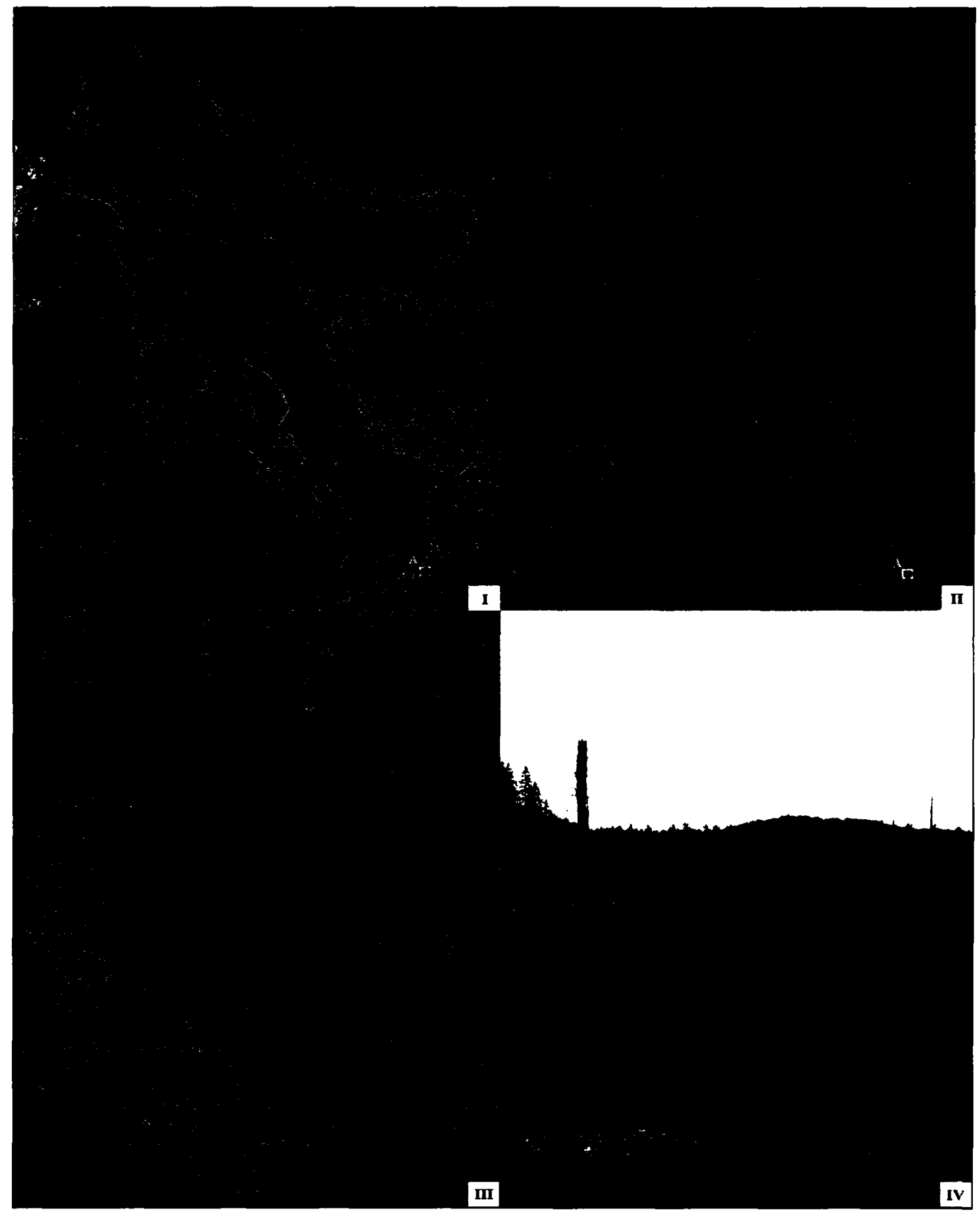

Figure 36. Spring orthophoto (I)* and wetland classification (II). Satellite image of the same wetland in summer (III)**, exhibiting increased wetland vegetation compared to spring orthophoto. Photograph taken in summer of the wetland at location A (IV)** also illustrates the abundance of vegetation (mostly emergent grasses) that is present in summer but not apparent in spring. A Blanding's turtle was at this wetland in 2009, as recorded in a telemetry study by the QMNRF. Sources: *NCC, 2007; **Google Earth, 2009. ***Author, 2008. 


\subsubsection{Wetland Types}

One of the objectives of this research was to identify and distinguish four types of wetlands that can be grouped from the classification results: 1) wetlands with abundant Logs and Wetland Vegetation (Figure $38 \mathrm{a}, \mathrm{b}$ ), which could be used in summer or spring by Blanding's turtles; 2) open Water wetlands that may be used for overwintering (Figure 39); 3) wetlands with Logs and open Water (Figure 40 and 41); 4) wetlands with high Wetland Vegetation abundance, Water and $1-5$ Logs which may be used in summer (Figure 42).

Only $10 \%$ of classified wetlands had 'none to very low' Wetland Vegetation $(<5 \%$ cover), while only $9 \%$ had 5 or fewer Logs. It was mainly medium and large wetlands that had $5-25 \%$ Wetland Vegetation cover and over 5 Logs. Wetlands meeting these criteria were usually open Water wetland types such as ponds (Figure 40 and 41) or open pools in bogs that are potential overwintering habitat.

All wetlands with over 50\% Wetland Vegetation cover and no Logs were small or very small wetland sizes. Wetlands with over 50\% Wetland Vegetation cover and 1 - 5 Logs were all small or very small wetland sizes except for one wetland that was medium size (Figure 41). Most errors occurred where shadows and trees were misclassified as Water and Wetland Vegetation. Chui and Couloigner (2004) also found spectral similarities between wetlands and open vegetation and that they were best distinguished using texture.

In other instances of high Wetland Vegetation cover without Logs, the wetland was not fully delineated in the classification and logs were present that were not classified. In some instances wetlands could potentially have more vegetation than represented in the 
final classification because Wetland Vegetation that existed more than $50 \mathrm{~m}$ from Water was removed.

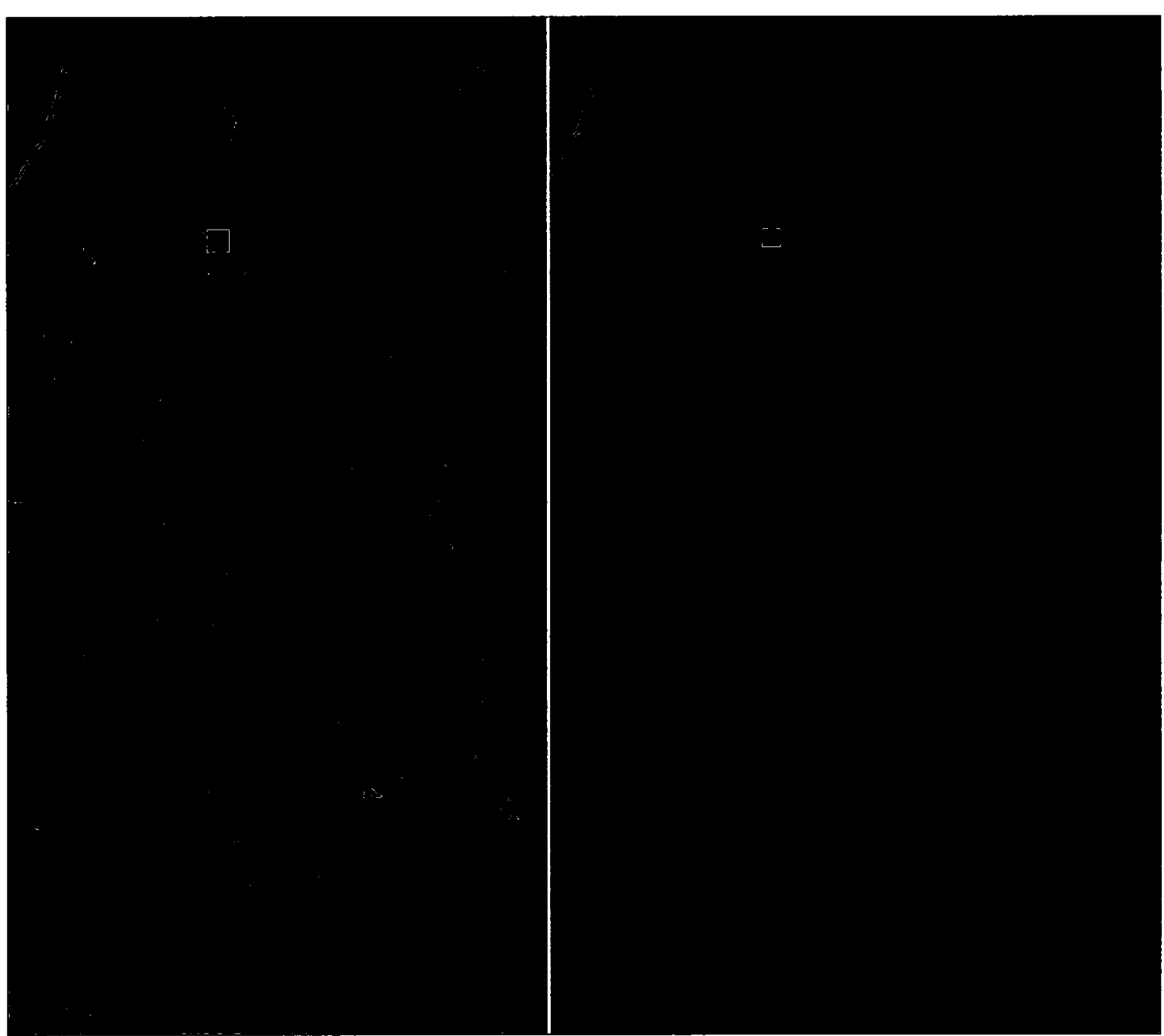

Figure 37. Orthophoto (left)* and wetland classification (right). Wetland boundary estimated to be $>90 \%$ classified when compared to orthophoto. *Source: NCC, 2007.

Wetland types and features can vary within a single wetland and especially in wetland complexes. Instead of having one wetland that has only logs or only a high abundance of Wetland Vegetation, it is more common to find wetlands that have different sections that are characterized by one of these attributes or a mixture of both (e.g., Figure 43). In wetlands with high vegetation cover and no apparent logs it is also possible that the logs are covered by vegetation. 


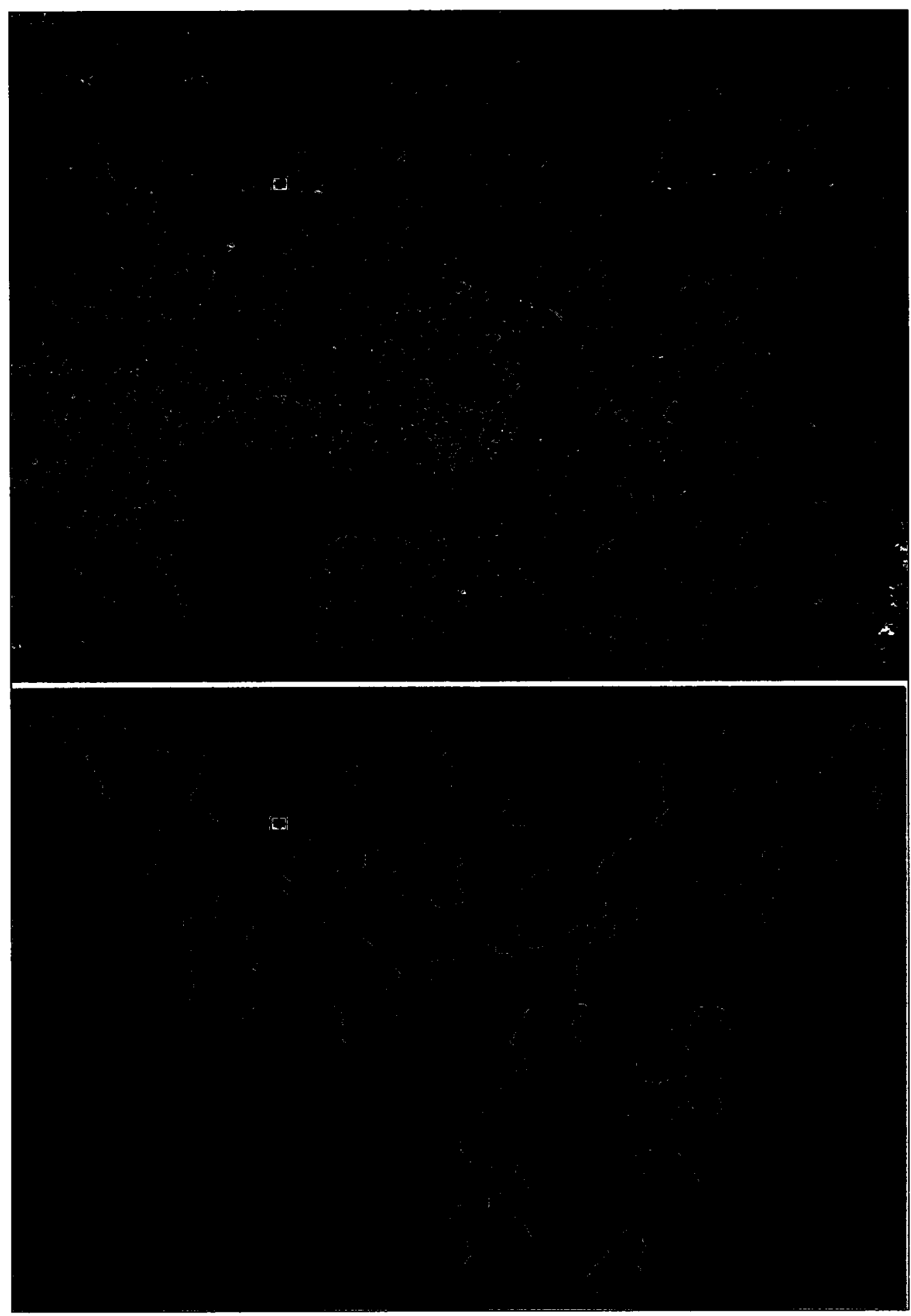

Figure 38a. Orthophoto (top)* and wetland classification (bottom). An example of a wetland characterized by abundant Logs and Wetland Vegetation. *Source: NCC, 2007. 


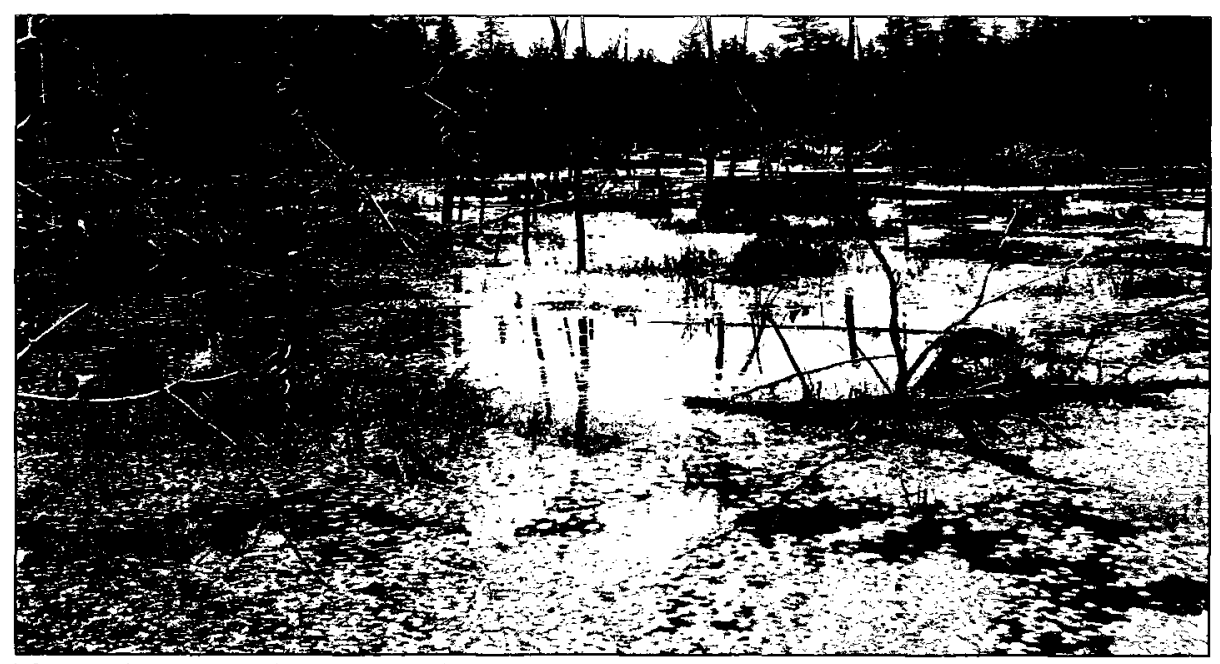

Figure 38b. Photograph of a wetland. Corresponding orthophoto and classification are shown in Figure 38a. Source: Author, 2008.

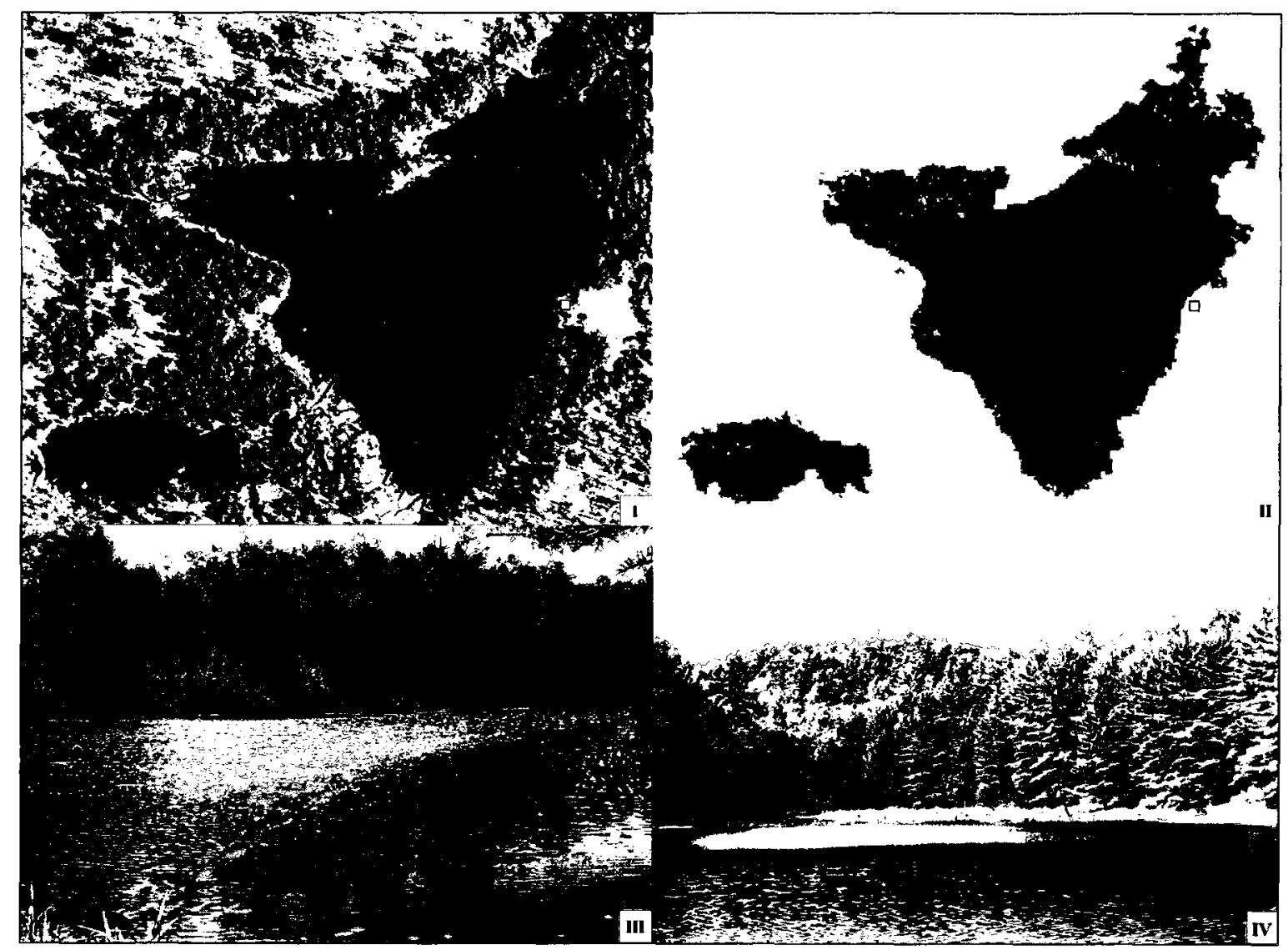

Figure 39. Two open Water wetland examples. Orthophoto (I)* and wetland classification (II), photograph of smaller wetland in left of orthophoto (III)** and the larger wetland (IV)**. Both of these wetlands have low vegetative cover and over 5 Logs. Sources: *NCC, 2007; **Author, 2008. 


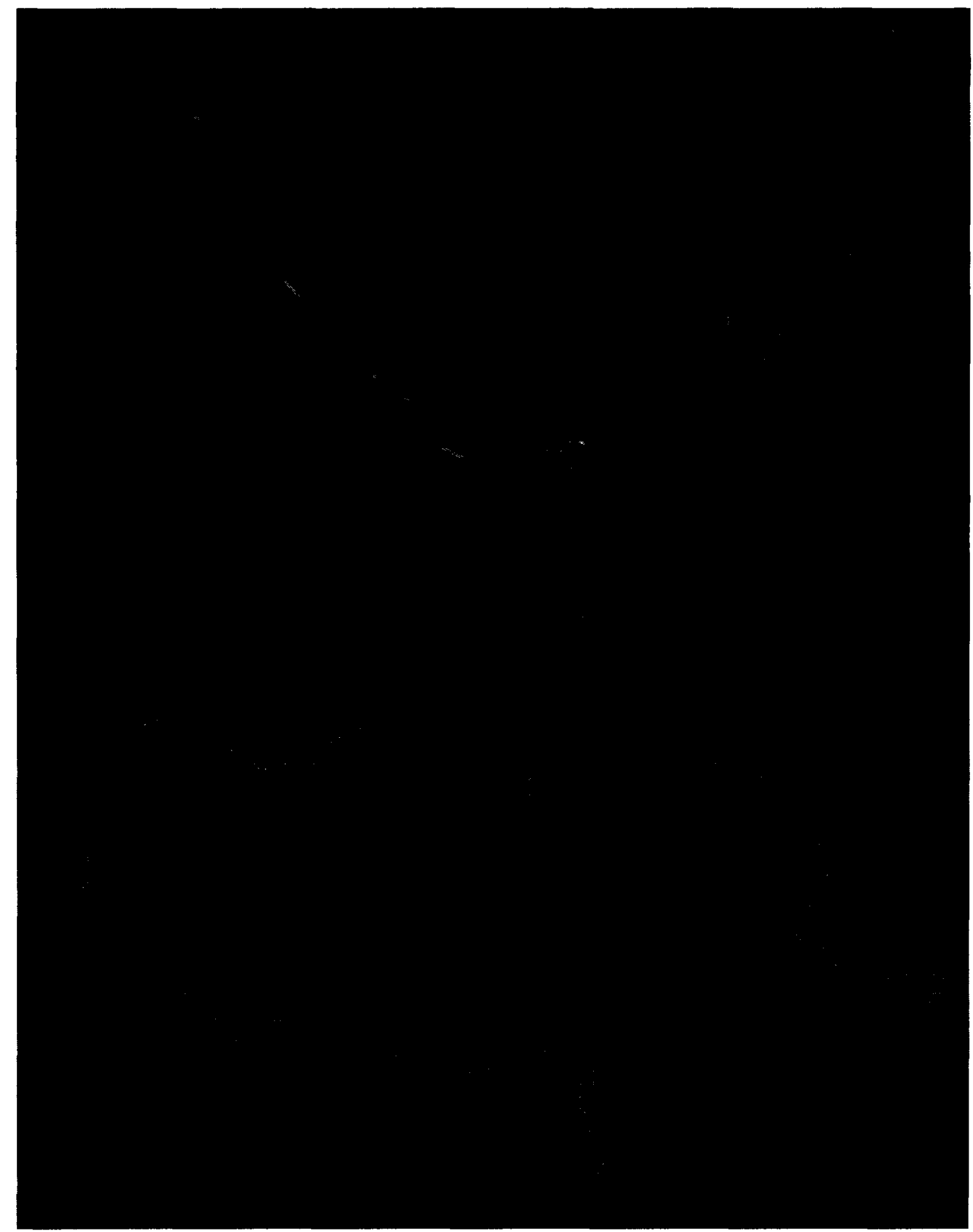

Figure 40. An example of a wetland with very abundant Logs and low Wetland Vegetation cover $(<25 \%)$. This wetland has characteristics that could be potentially suitable for overwintering or spring Blanding's turtle habitat. Orthophoto source: NCC, 2007. 


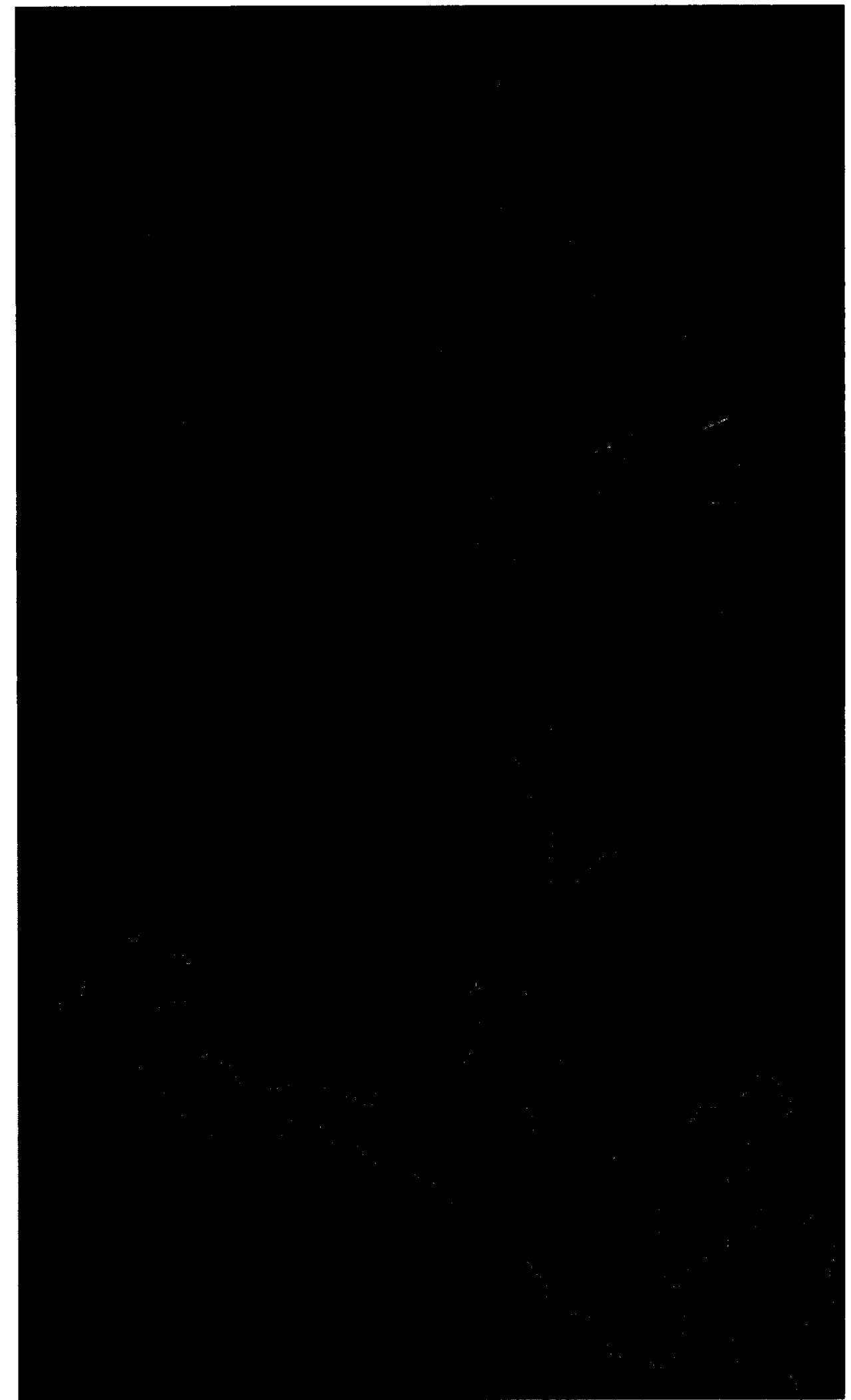

Figure 41. An example of a wetland with plenty of open Water, a high abundance of Logs and medium (25-50\%) Wetland Vegetation cover. Orthophoto source: NCC, 2007. 


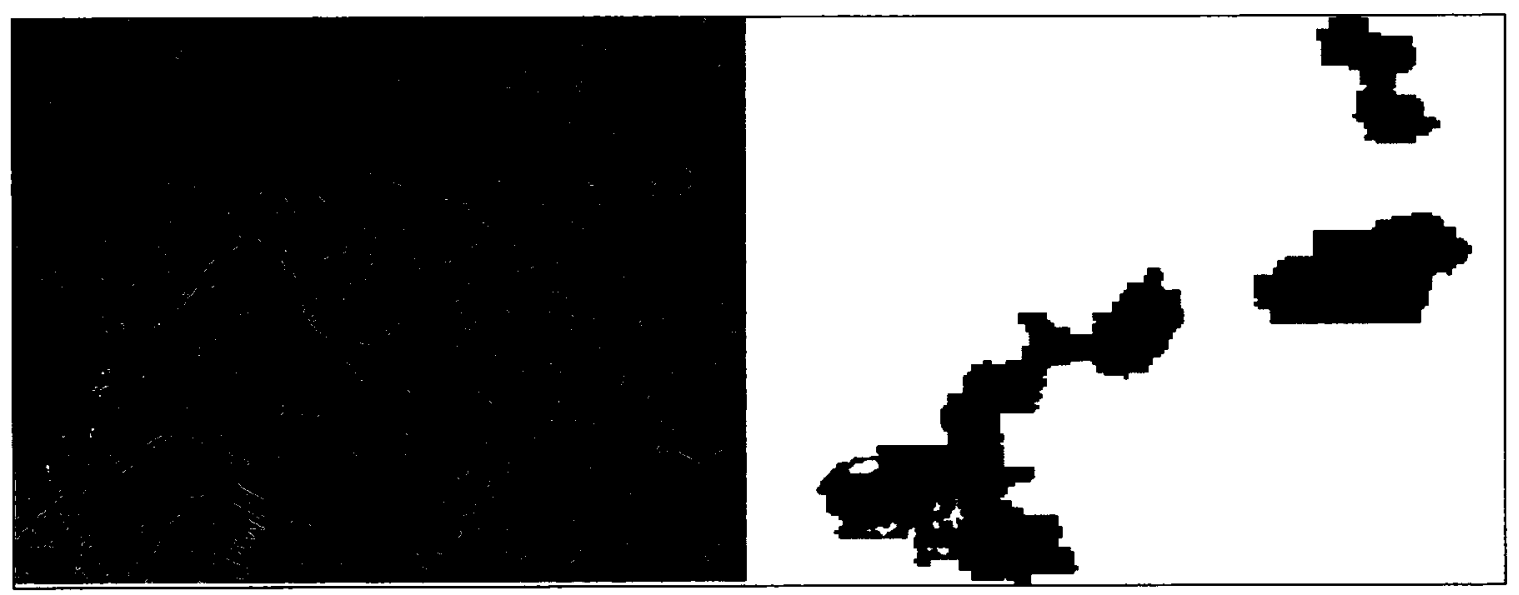

Figure 42. Orthophoto (left) and wetland classification (right). The wetland has over $50 \%$ Wetland Vegetation cover and only 1 classified Log. Orthophoto source: NCC, 2007.

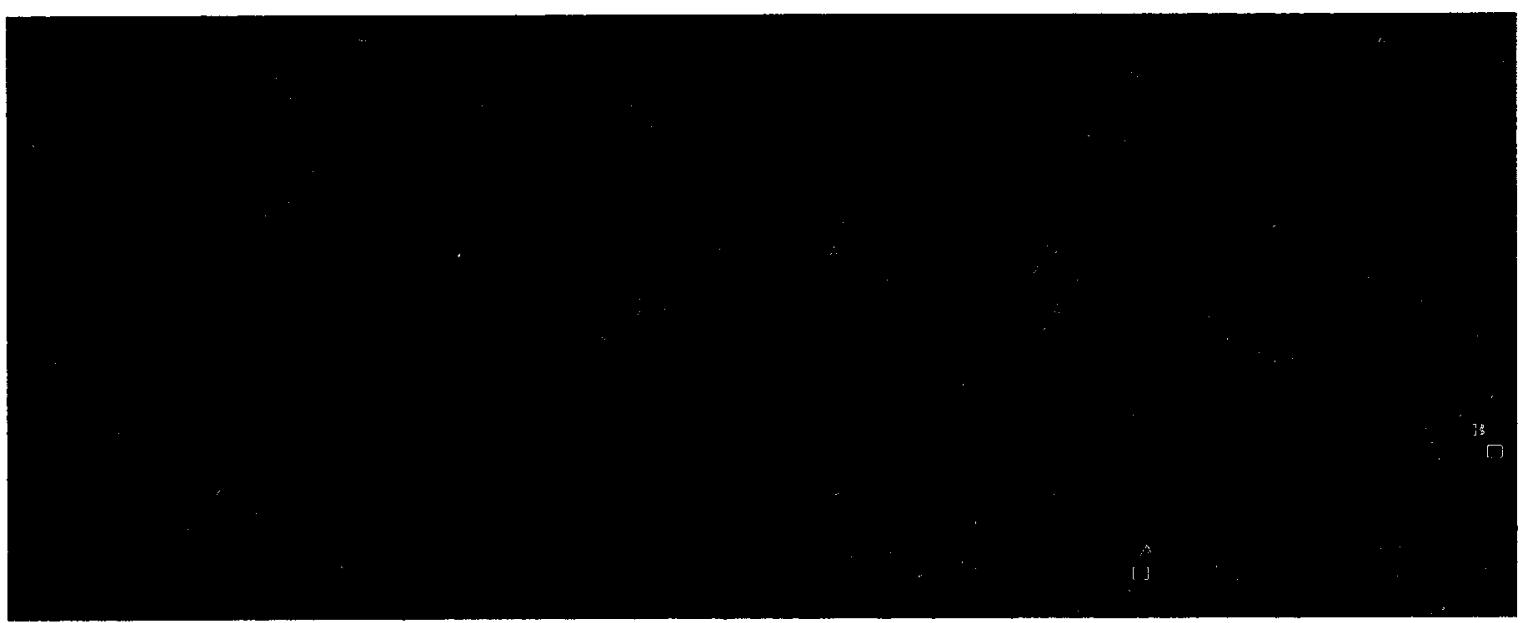

Figure 43. Orthophoto (top) and wetland classification (bottom). One section of this wetland is characterized by open Water and Logs while the other section has more is dominated more by Wetland Vegetation. Orthophoto source: NCC, 2007. 


\subsection{Quantitative Accuracy Results}

The error matrix for the first phase of classification of coarse objects (Wetlands, Other and Lake) is given in Table 11.

The producer's and user's accuracies for each class were the same, with Lake having the highest accuracy, followed by Other and lastly the Wetland class. The overall accuracy was high $(97.5 \%)$.

The Kappa coefficient $(\mathrm{K})$ for the land cover classes was 0.91 meaning more accurate than what would result for a completely random classification (Bock et al., 2005).

Table 11. Error matrix for landcover object classification.

\begin{tabular}{l|l|r|r|r|r|r|}
\multicolumn{1}{c|}{} & \multicolumn{7}{c|}{ Reference Interpretation } \\
\cline { 2 - 7 } & Wetland & Other & \multicolumn{1}{c|}{ Lake } & \multicolumn{1}{c|}{ Total } & \multicolumn{1}{c|}{$\begin{array}{c}\text { User's } \\
\text { Accuracy (\%) }\end{array}$} \\
\cline { 2 - 8 } $\begin{array}{l}\text { Result } \\
\text { Ressification }\end{array}$ & Wetland & 59 & 7 & 0 & 66 & 89.4 \\
\cline { 2 - 8 } & Other & 7 & 448 & 0 & 455 & 98.5 \\
\cline { 2 - 8 } & Lake & 0 & 0 & 27 & 27 & 100.0 \\
\cline { 2 - 8 } & Total & 66 & 455 & 27 & 548 & $\begin{array}{l}\text { Overall } \\
\text { accuracy=97.5 } \\
\text { Kappa = 0.91 }\end{array}$ \\
\hline
\end{tabular}

The error matrix for the wetland attribute classes Water, Wetland Vegetation and Logs is given in Table 12. These results show a high accuracy for Water and Wetland Vegetation, and a lower but still acceptable producer's accuracy for Logs. 
Table 12. Error matrix for Wetland feature classification.

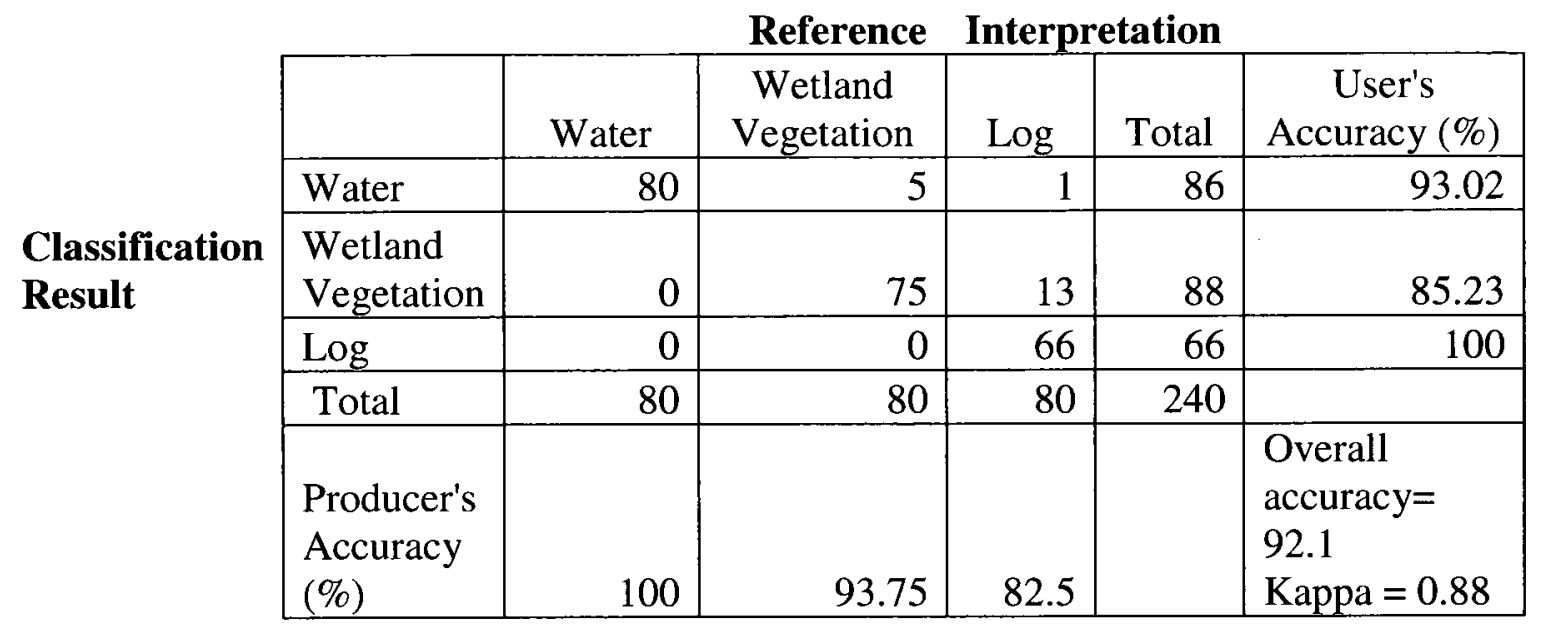

\subsection{Habitat Suitability Mapping}

\subsubsection{Habitat Suitability Score Distribution}

The classified wetlands showed a similar habitat suitability score distribution to that of the retained wetlands after application of the $100 \mathrm{~m}^{2}$ area threshold. Consequently, only the retained wetlands analysis is presented here (Figure 44). Figure 45 shows the corresponding suitability score distribution. The two most common scores were 10 (36.79\% of wetlands) and 7 (26.25\% of wetlands) and most of the wetlands scored within that range while very few received scores of 4 or less.

Blanding's turtle observations within $500 \mathrm{~m}$ of wetlands (grey bars; Figure 45) with a score of 7 or higher, confirm the applicability of the scoring scheme of habitat attributes (Wetland Vegetation and Logs). There are more wetlands mapped in the study area with a habitat suitability score from 7 to 10 , however the wetland availability does not linearly increase with the Blanding's turtle observations, therefore the scoring scheme applied to habitat features is credible. 


\subsubsection{Wetland Suitability and Blanding's Turtle Observations}

A large number of wetlands $(87 \%)$ had a habitat suitability score above 7 . Figure 46 shows a strong relation between habitat suitability score and the number of wetlands within $500 \mathrm{~m}$ of a Blanding's turtle observation, i.e. there are many more wetlands with high and very high scores that are near observation locations (88\%). Alternatively, there is a higher probability of a Blanding's turtle observation in areas of high habitat suitability. Figure 47 shows a subarea on the Eardley-Masham Road in the middle of the study area where most observations have been made. Most of the wetlands were rated high or very high suitability.

The relation between suitability class and the number of wetlands within $500 \mathrm{~m}$ of a turtle observation increases non-linearly with higher scores having proportionally more wetlands within $500 \mathrm{~m}$ of an observation than would occur with a linear trend. This shows that the selected habitat features (Wetland Vegetation and Logs) that comprise the suitability score have a strong association with Blanding's observations.

Examples of wetlands with high or very high suitability and Blanding's turtle observations are displayed in Figures 48-49. Visual assessment of these figures illustrates the high degree of heterogeneous wetland characteristics (open water spatial distribution, vegetation abundance and type, logs, wetland shape and size, wetland complexes, etc.). 


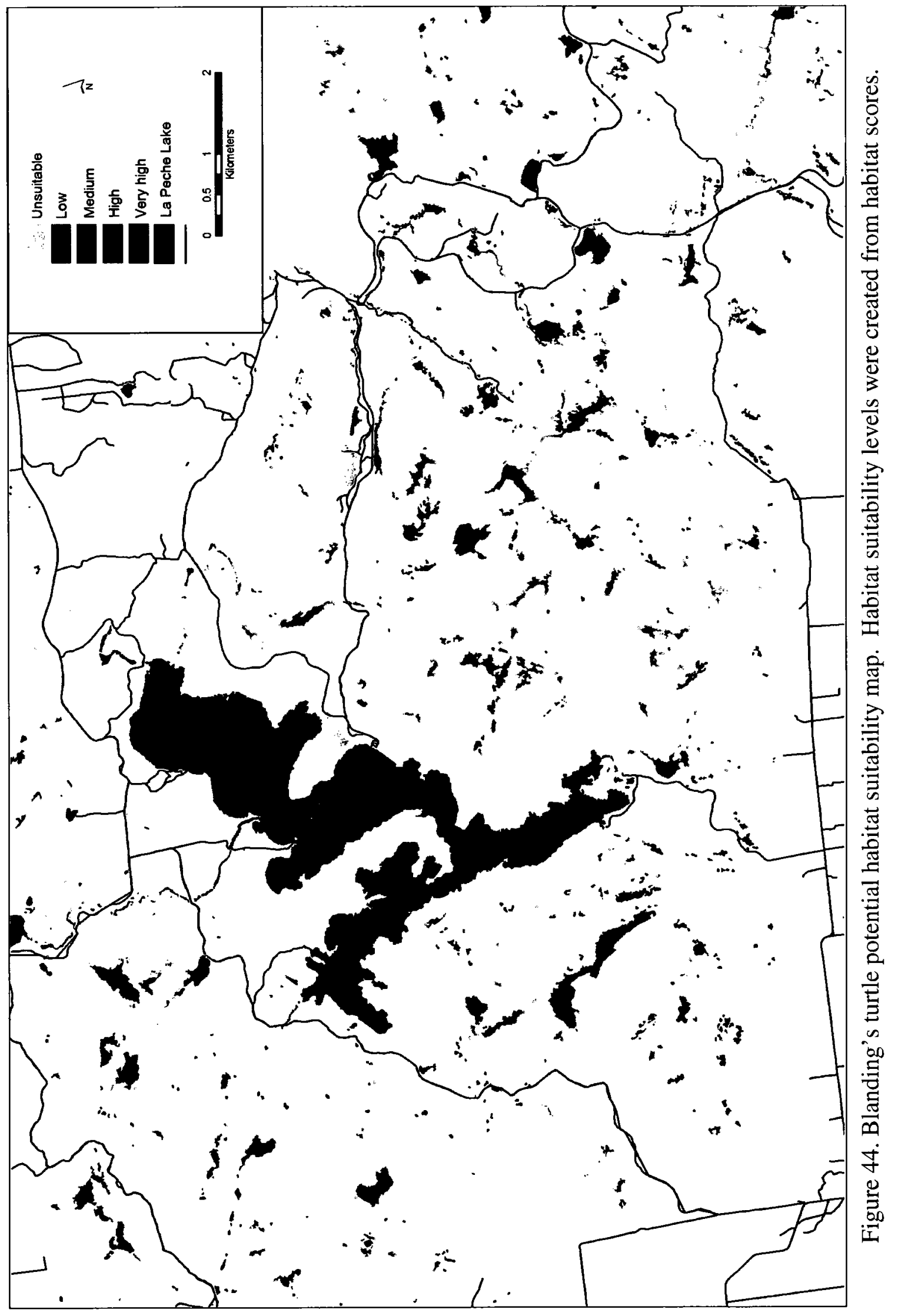




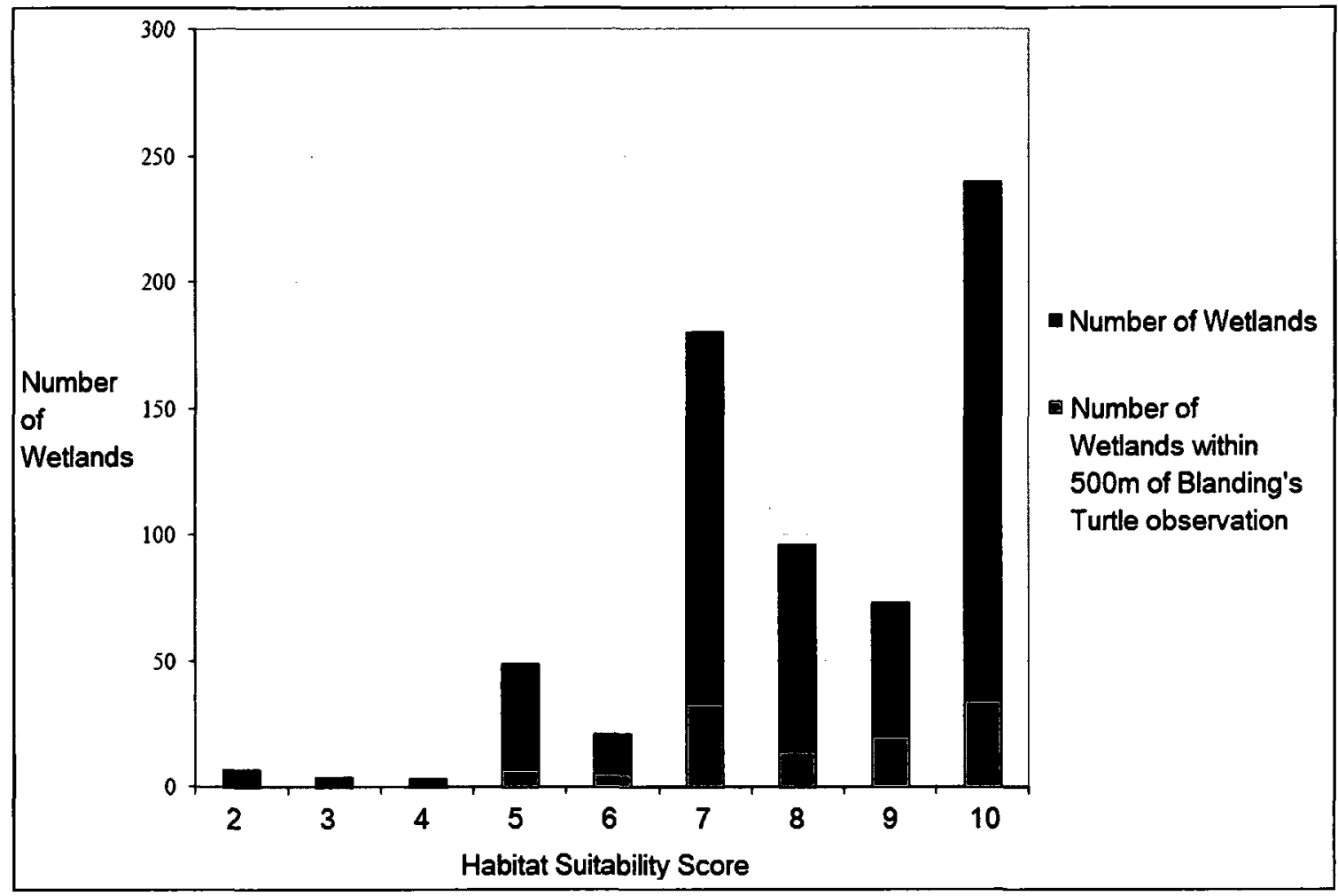

Figure 45. Habitat suitability score distribution for all available wetlands (minimum 100 $\mathrm{m}^{2}$ Water; Black) and the habitat suitability score of Wetlands within $500 \mathrm{~m}$ of a Blanding's turtle observation (Grey).

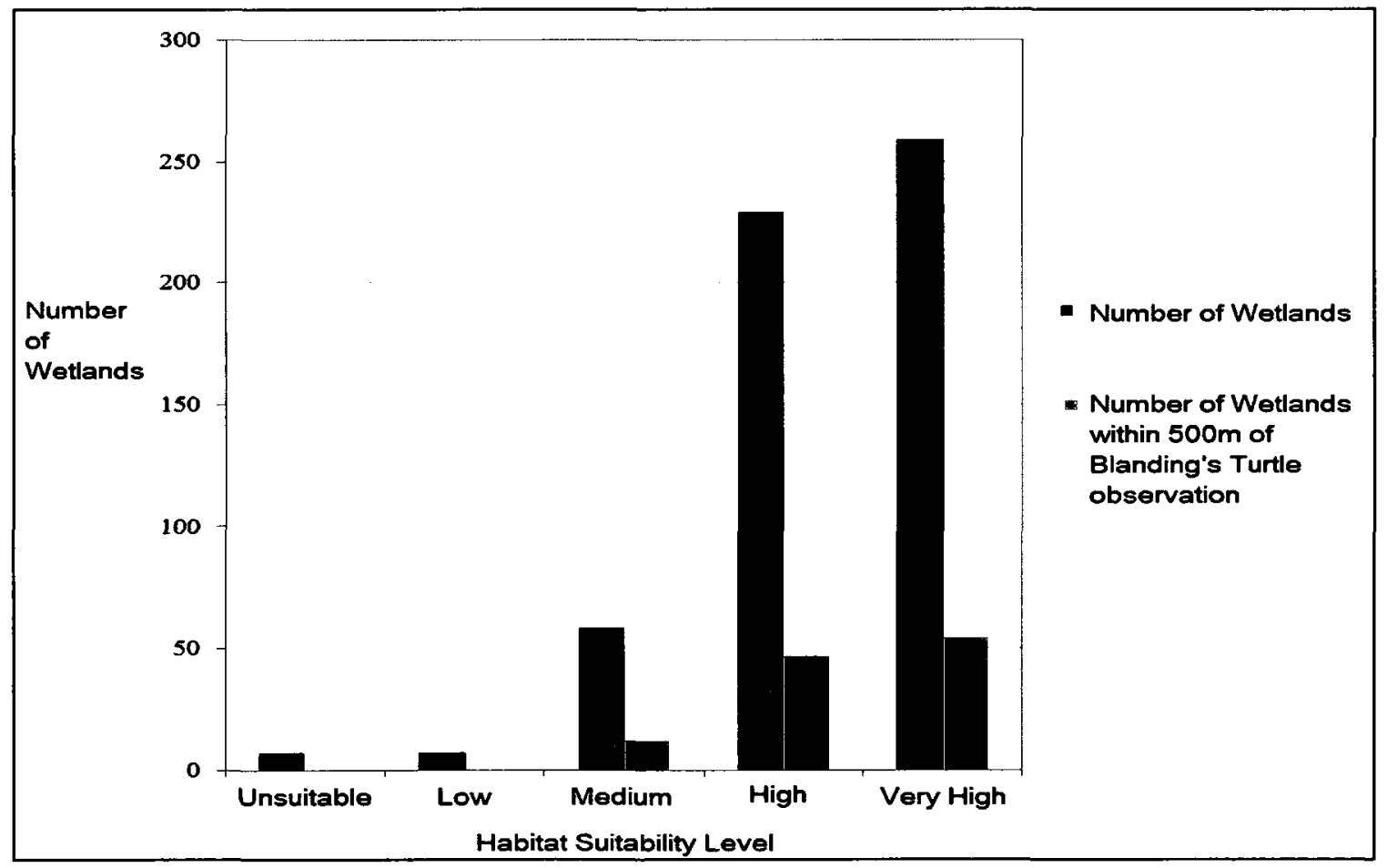

Figure 46. Habitat Suitability level related to the number of wetlands and the number of wetlands within $500 \mathrm{~m}$ of a Blanding's turtle observation. 


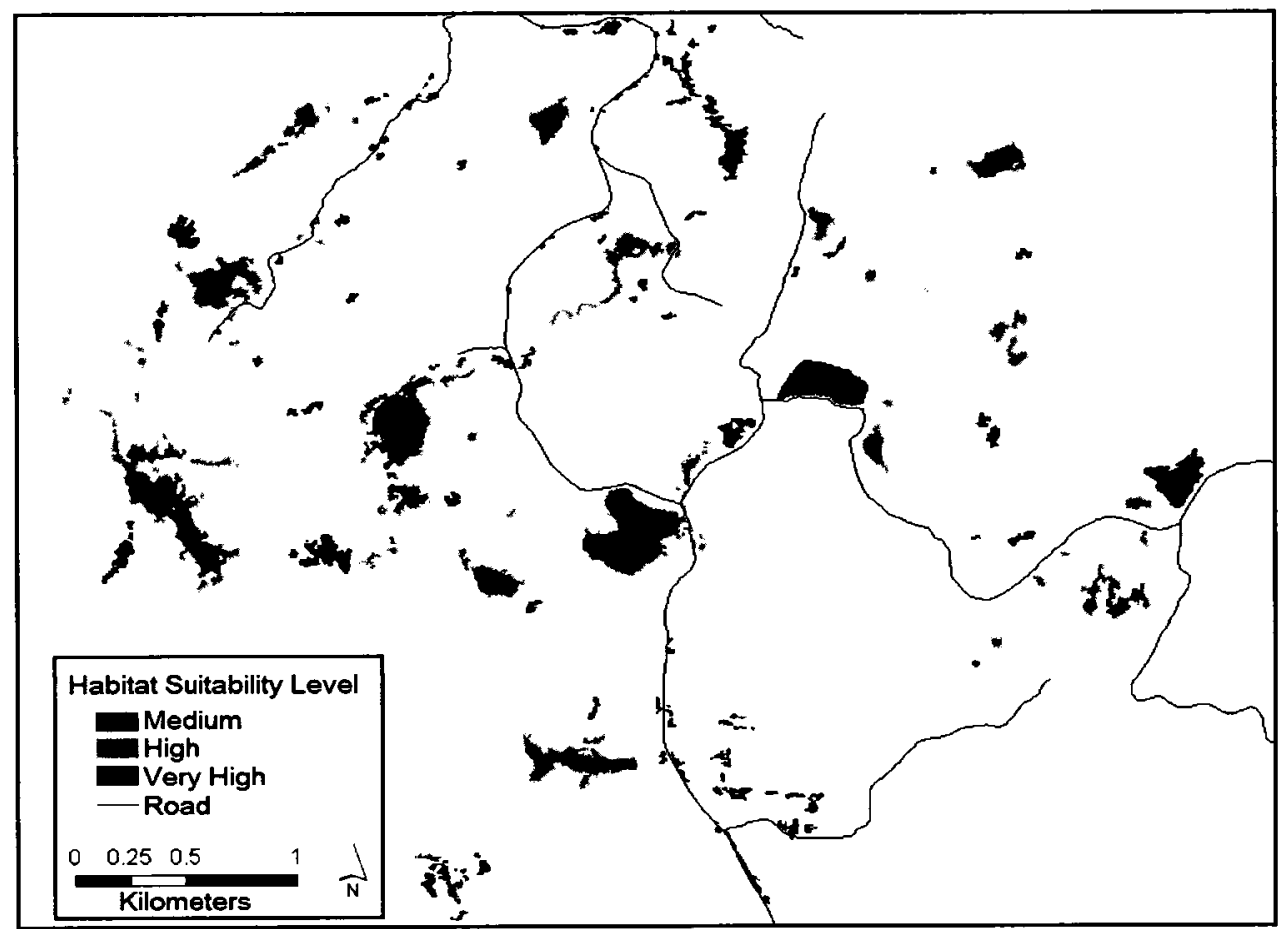

Figure 47. Habitat suitability level of wetlands within $500 \mathrm{~m}$ of Blanding's turtle observations, located near the vicinity of Eardley-Masham Road, where most observations have been documented.

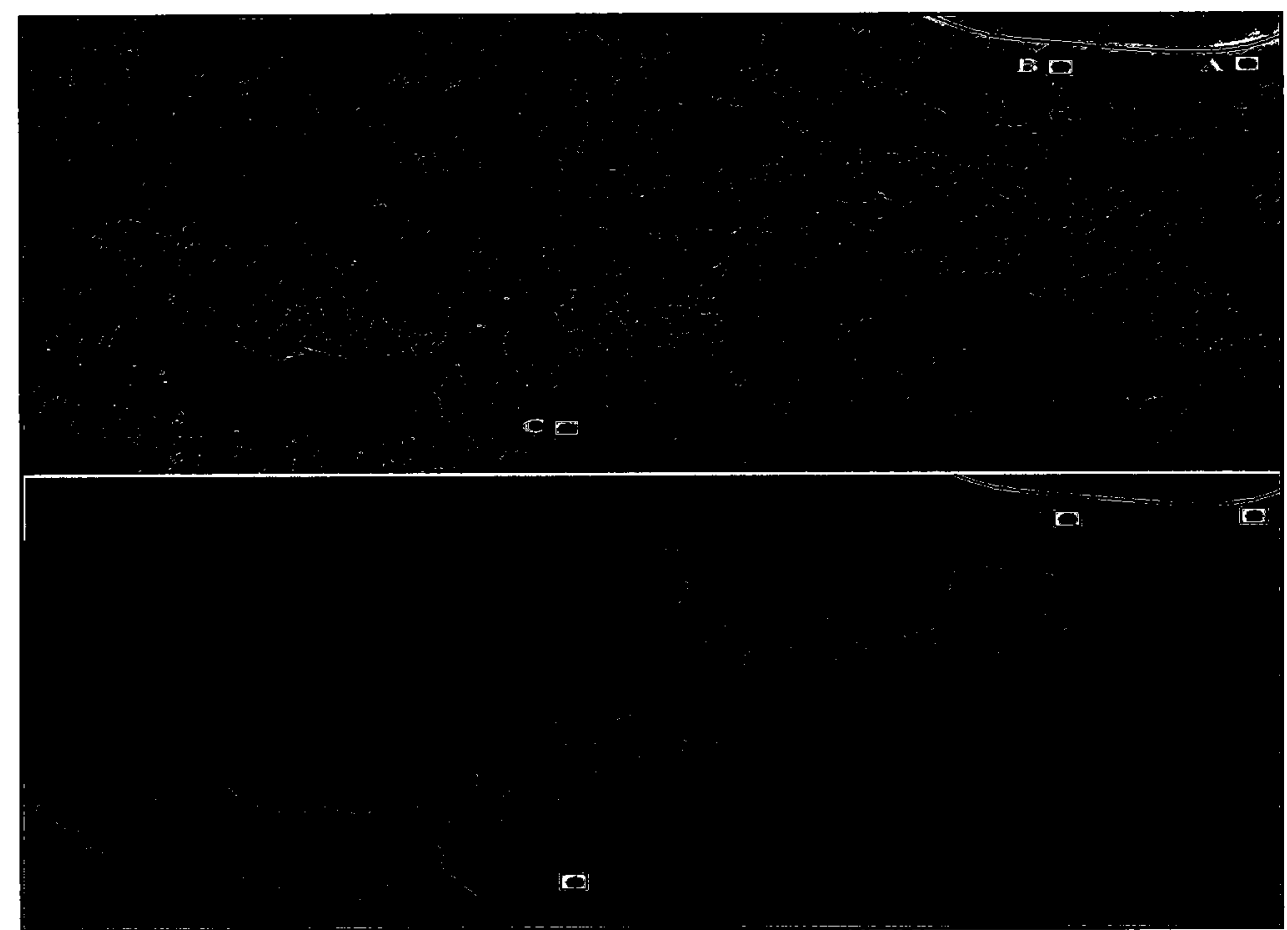

Figure 48a. Orthophoto (top) and wetland classification (bottom). The habitat suitability level was 'very high'. The wetland photos were taken from locations A, B, and C. Orthophoto source: NCC, 2007. 


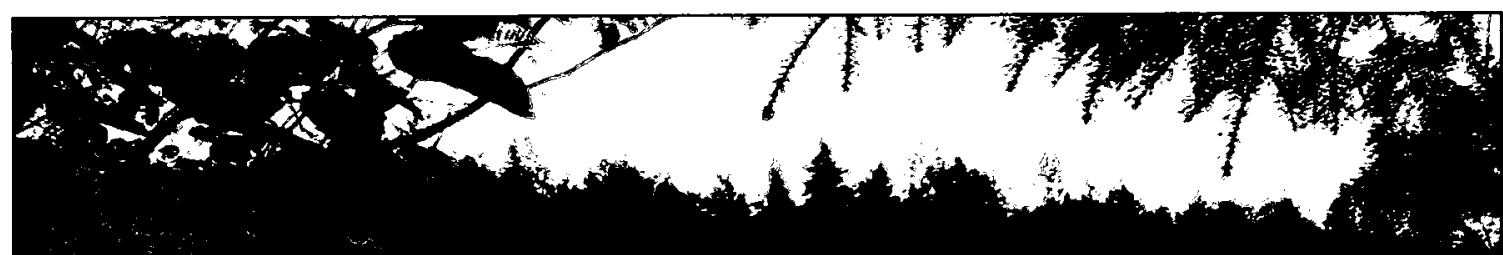

20 -

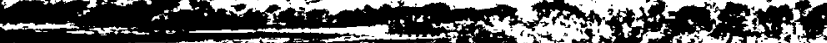

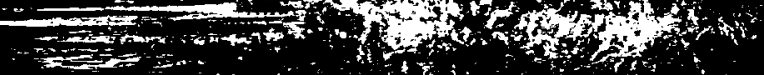

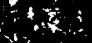

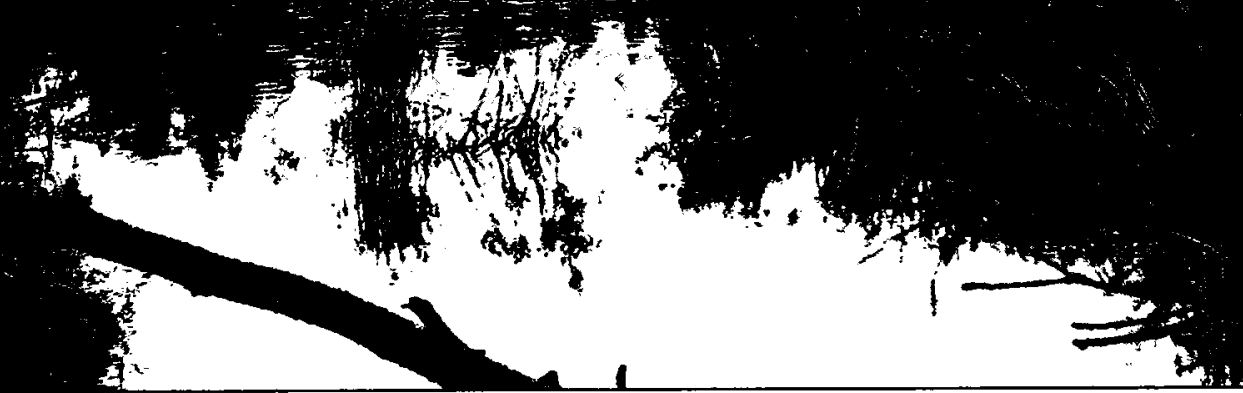

Figure 48b. Photograph of wetland taken at location B (Figure 48a) by Author (2008).

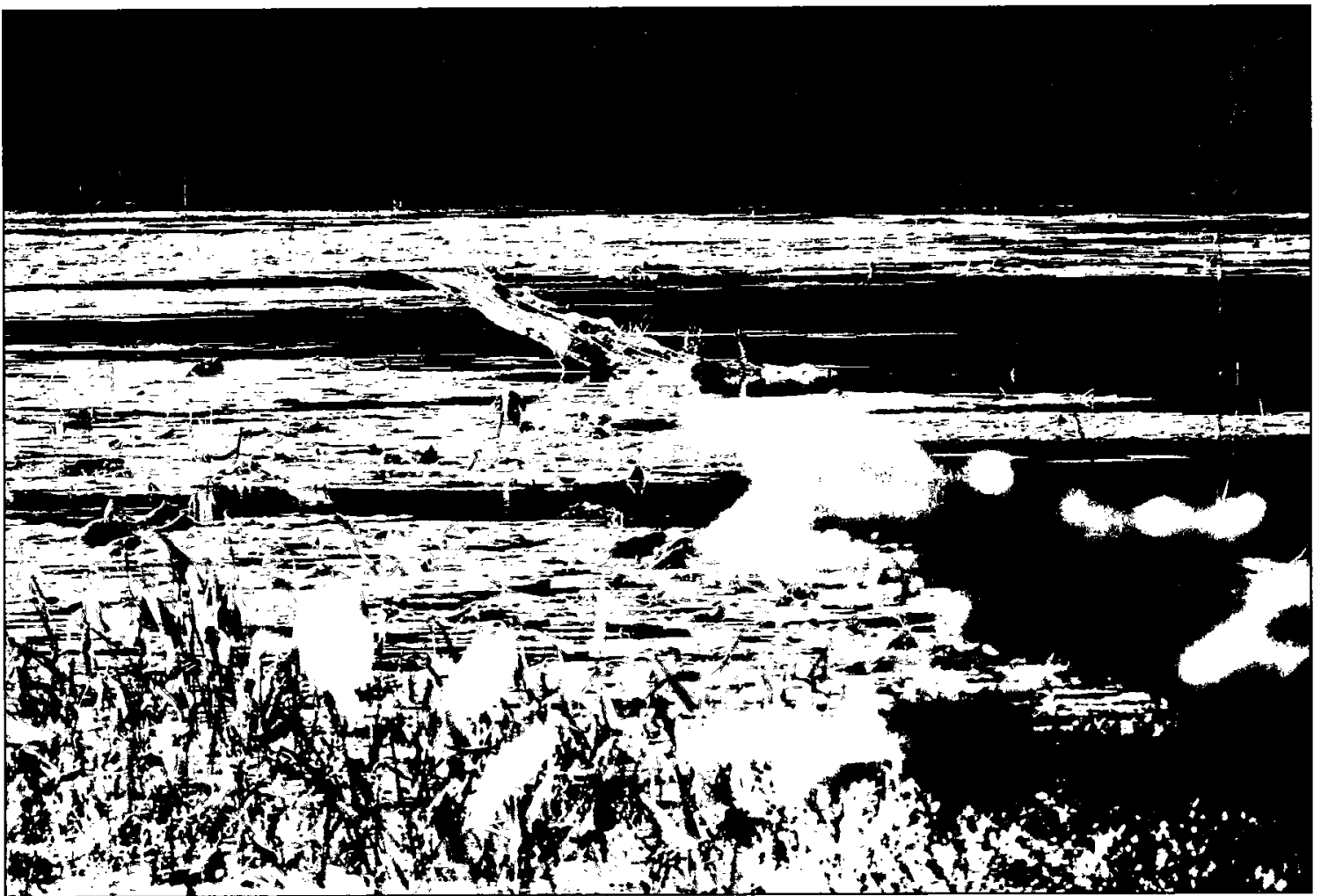

Figure 48c. Photograph of a wetland at location C (Figure 48a) and of a turtle basking on a log in the sun (arrow). Source: Author, 2008. 


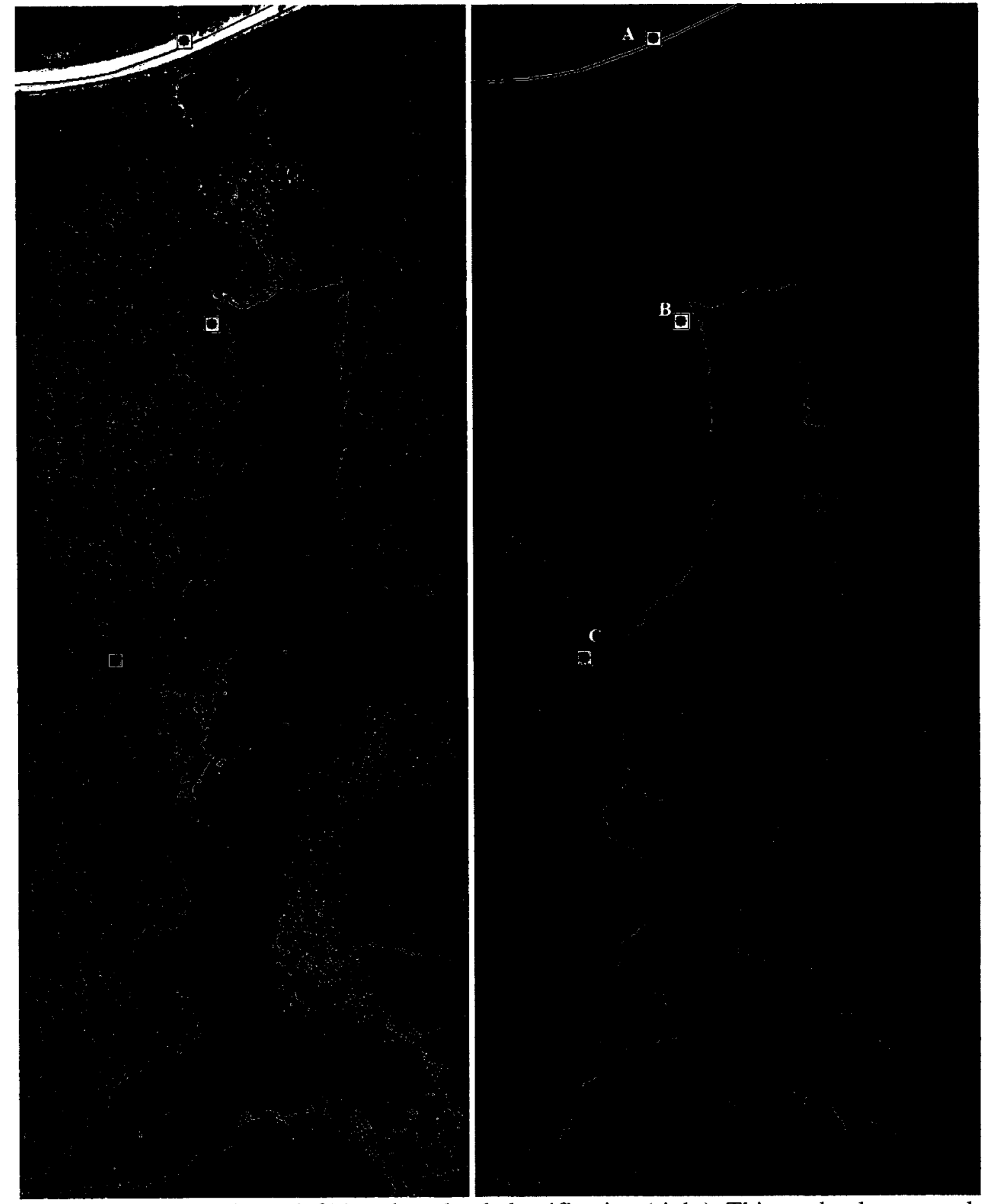

Figure 49a. Orthophoto (left)* and wetland classification (right). This wetland was rated as 'High' suitability. Photograph of wetland in Figures 48b-48d. *Source: NCC, 2007. 


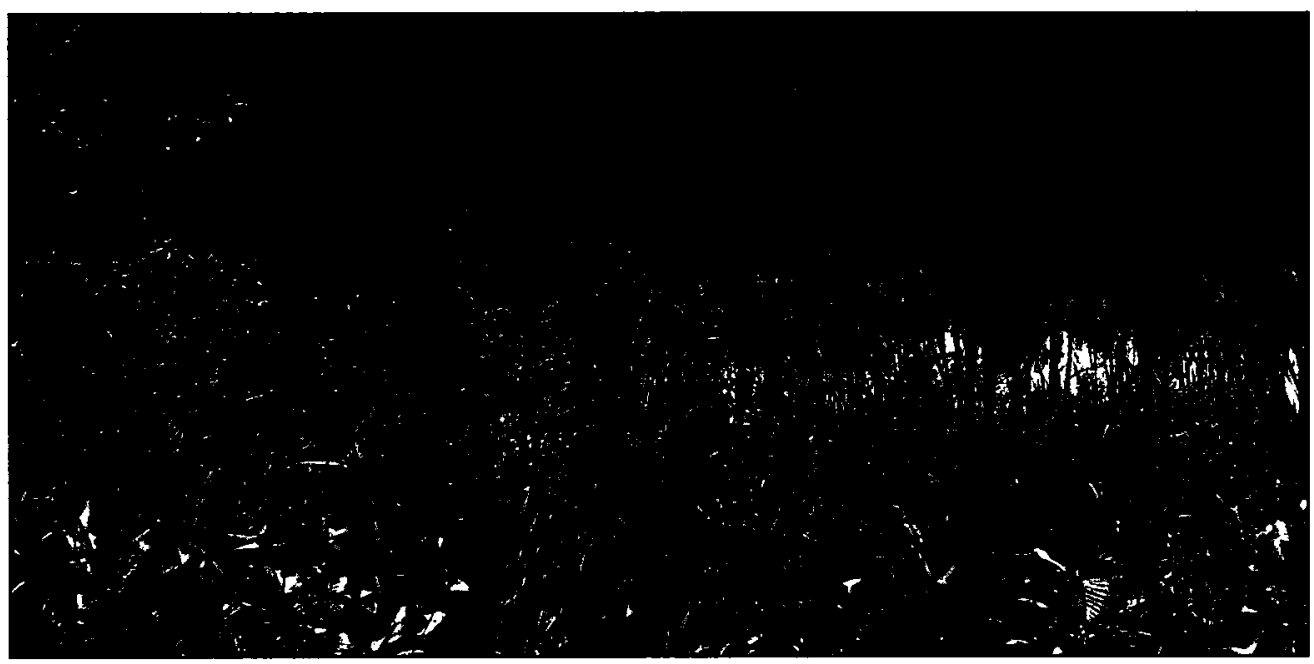

Figure 49b. Photograph of wetland at location A (Figure 49a). This area is characterized by a variety of vegetation types (including sedge tussocks). Source: Author, 2008.

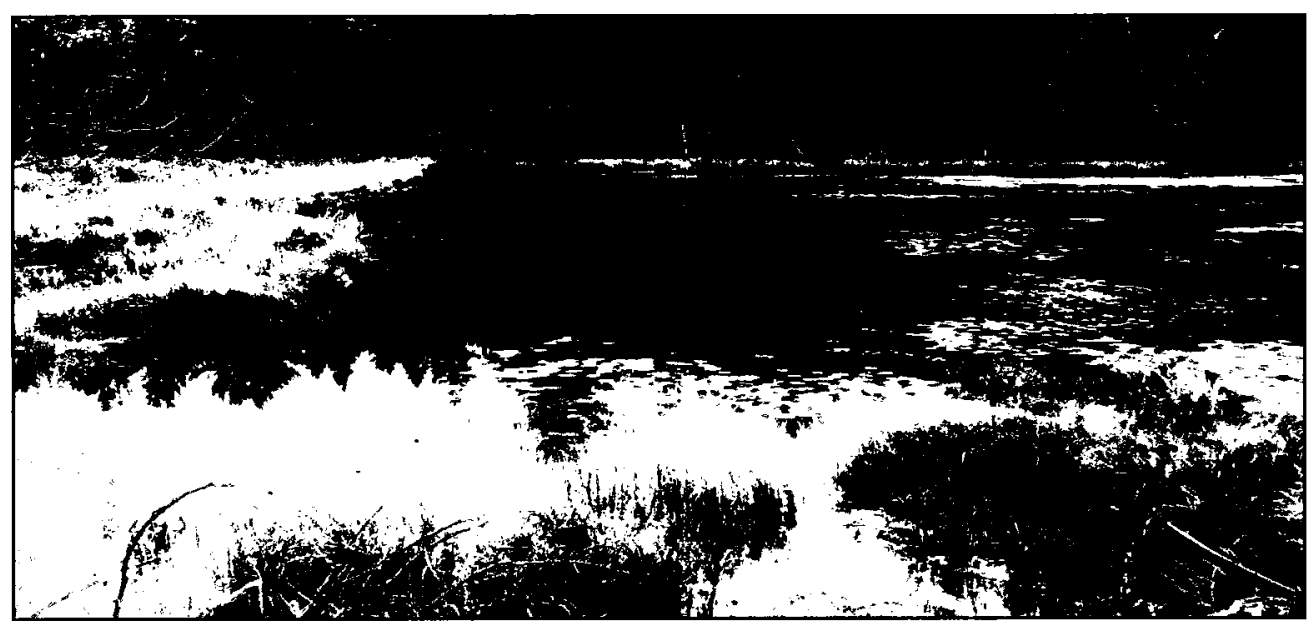

Figure 49c. Photograph of wetland at location B (Figure 49a). This area is characterized by open water, floating aquatic vegetation and bank vegetation. Source: Author, 2008.

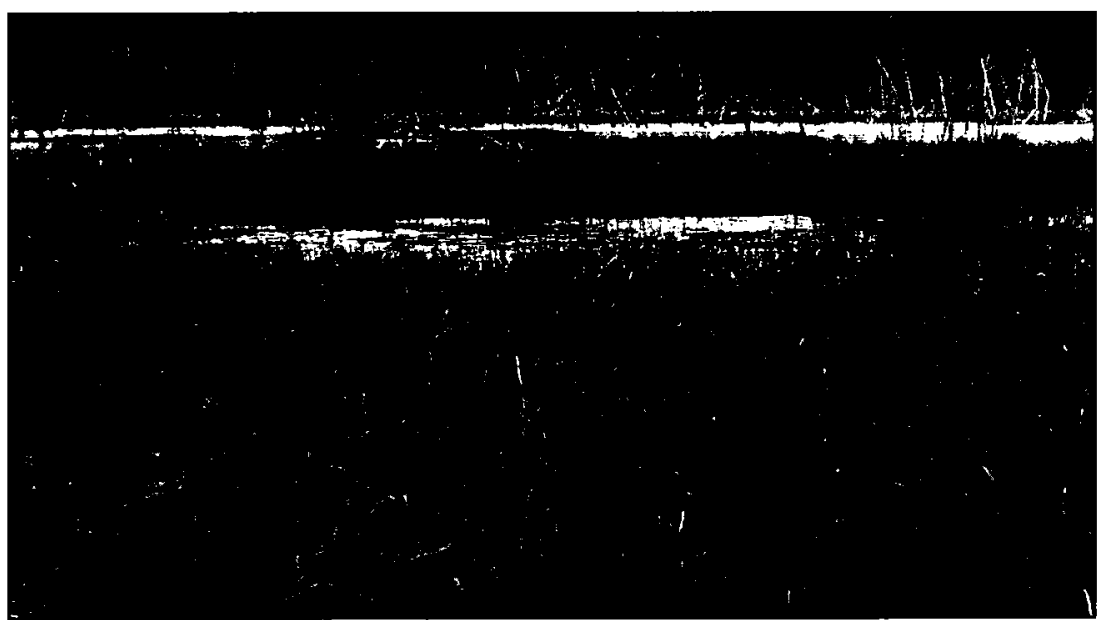

Figure 49d. Photograph of wetland at location C (Figure 49a). This area is characterized by large clusters of vegetation tussocks, trees, logs and open water. 


\section{CHAPTER FIVE}

\section{DISCUSSION}

\subsection{Significant Findings}

Taking a top-down, object-based classification approach to create a thematic map of delineated wetlands and focal attributes was an effective technique in the context of this research. Many previously unmapped wetlands were identified and well delineated in this research, including wetlands and critical habitat features that were accurately mapped using the aerial orthophotos and rule-based object segmentation and classification. The habitat suitability index, although one example of many possible formulations, was highly associated with observations and can aid targeting of future inventories and other studies related to conservation management.

Through utilization of several object characteristics besides image spectral brightness, wetlands and wetland features were effectively mapped using characteristics including: texture, shape, size and context. It is expected that it would have been difficult to map wetlands and their attributes using orthophotos in this research without an object based approach.

Very few studies in the literature employed classification of orthophotos instead of just visual interpretation for landcover mapping (2.4.2) or wetland mapping (Section 2.4.2.1) and there were no studies that classified any type of remote sensing imagery for Blanding's turtle habitat mapping or related studies besides by visual interpretation (Section 2.4.3). This was the first study to classify wetlands and critical wetland features for Blanding's turtles using orthophotos. Wetlands under the common minimum 
mapping unit (1ha) of other wetland data sources in this area were mapped in this research.

Figures 50 - 52 show several previously unmapped wetlands that were successfully mapped in this research.

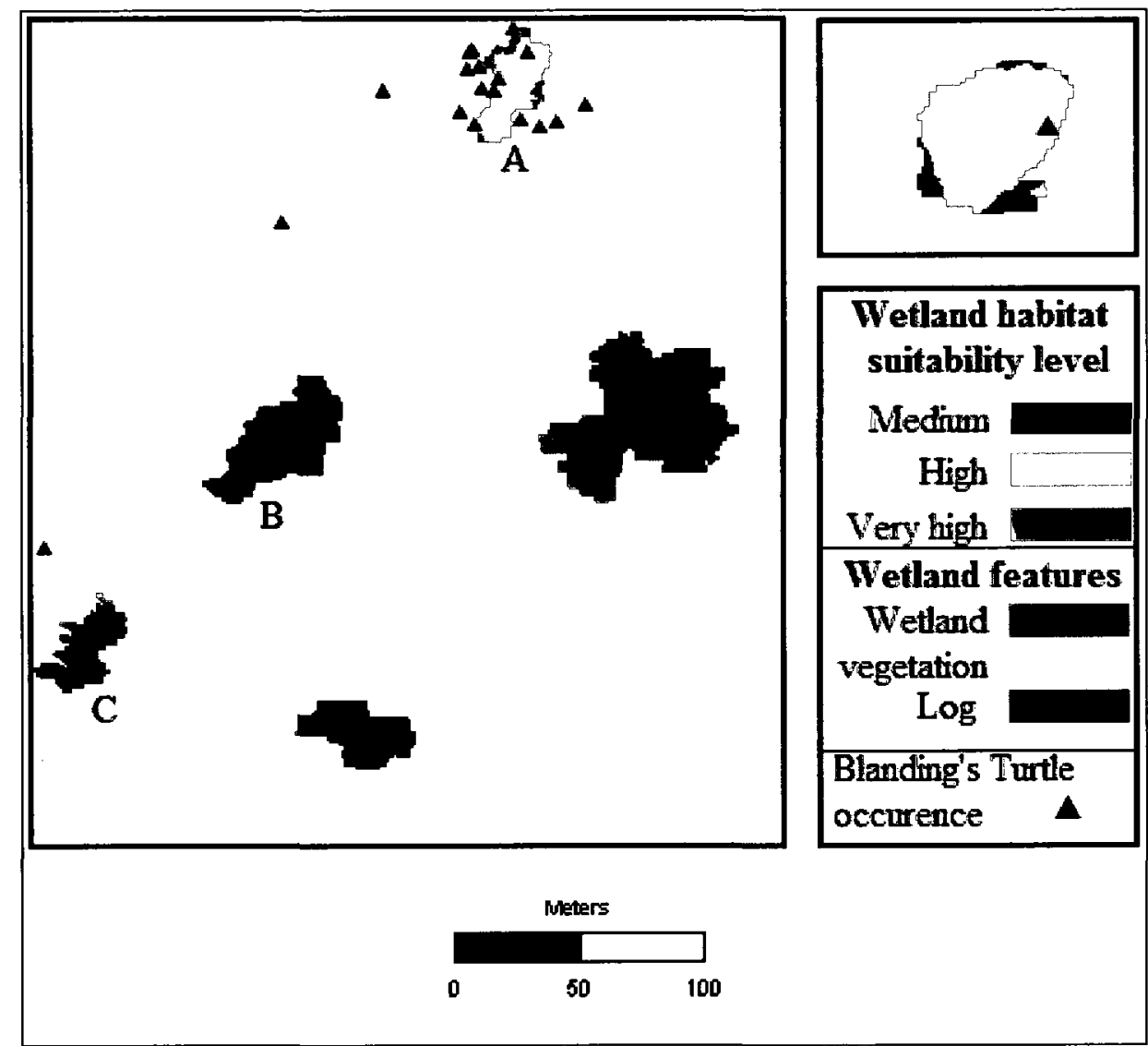

Figure 50. Example of wetlands that have not been previously mapped and have had recorded Blanding's turtle occurrences (triangles) (QMNRF, 2009; Blanding's turtle recovery team telemetry study in 2009). The wetlands labelled A, B and C are adjacent to a hydro-line. The wetland in the top right window is an isolated pool in a bog. 


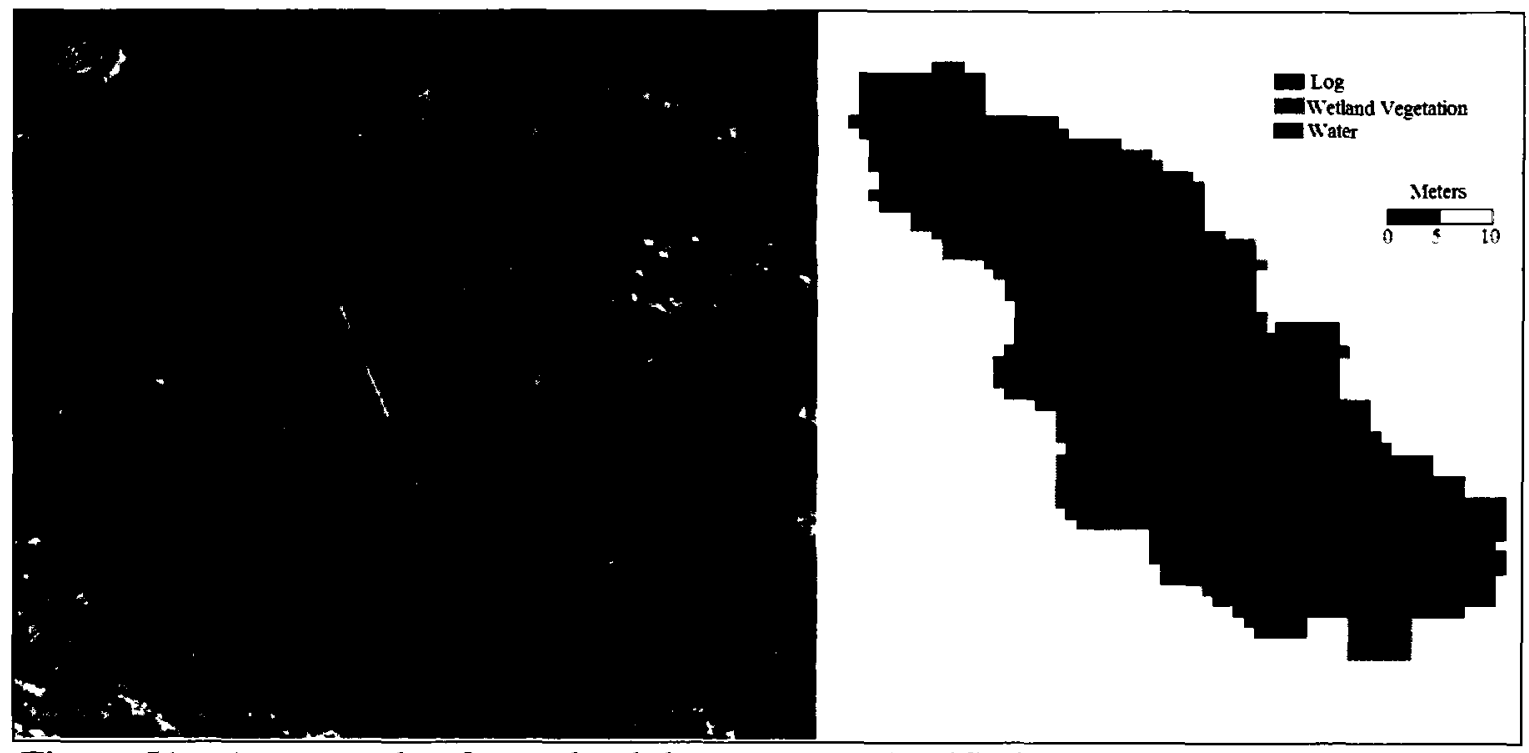

Figure 51a. An example of a wetland that was not classified before this research and also has had Blanding's turtle observations. Orthophoto source: NCC, 2007.

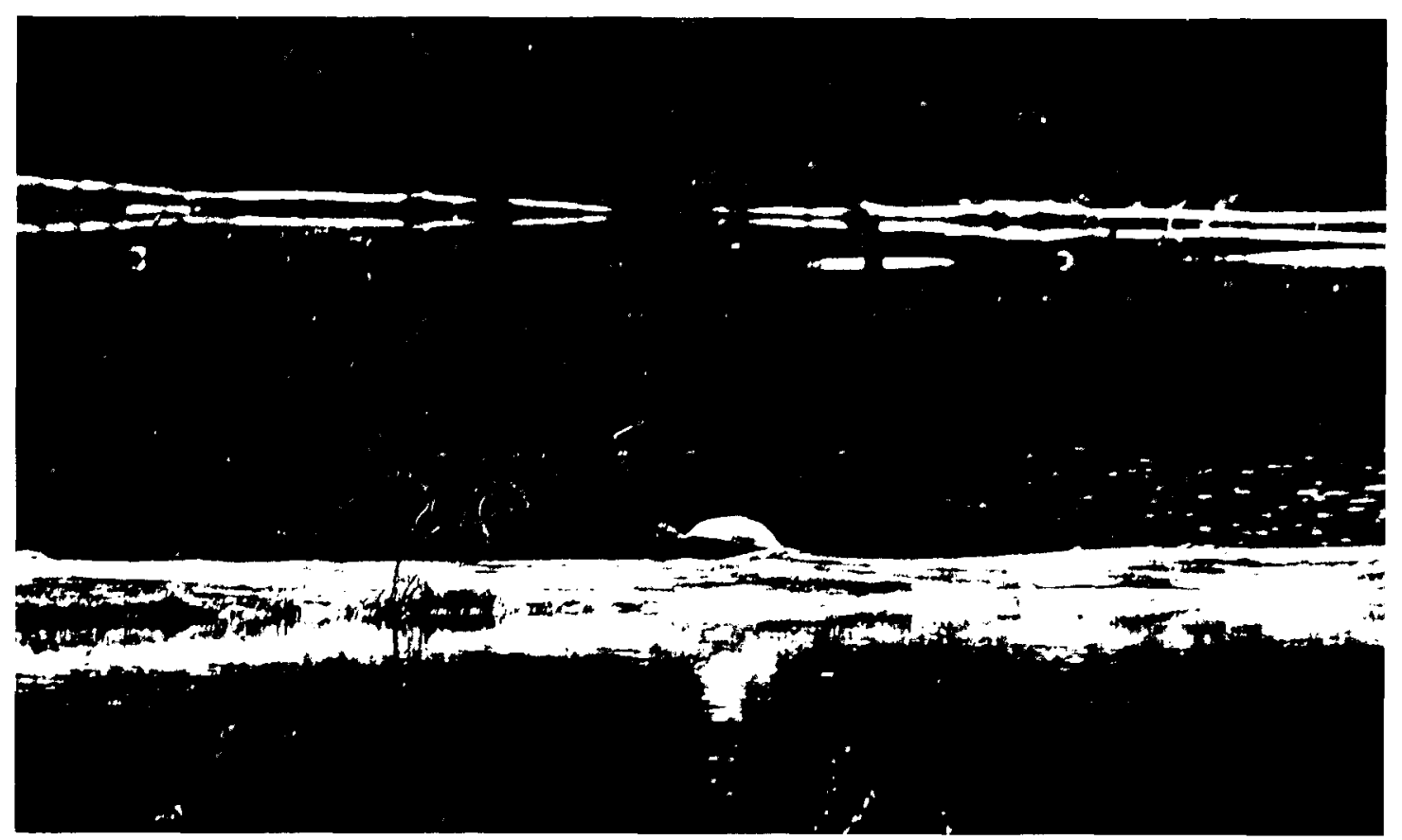

Figure 51b. Photograph of the wetland in Figure 47a. Blanding's turtle observations have been made in multiple years, including this one by the author (photo source: Author, 2008). This wetland was categorized as having high suitability. 


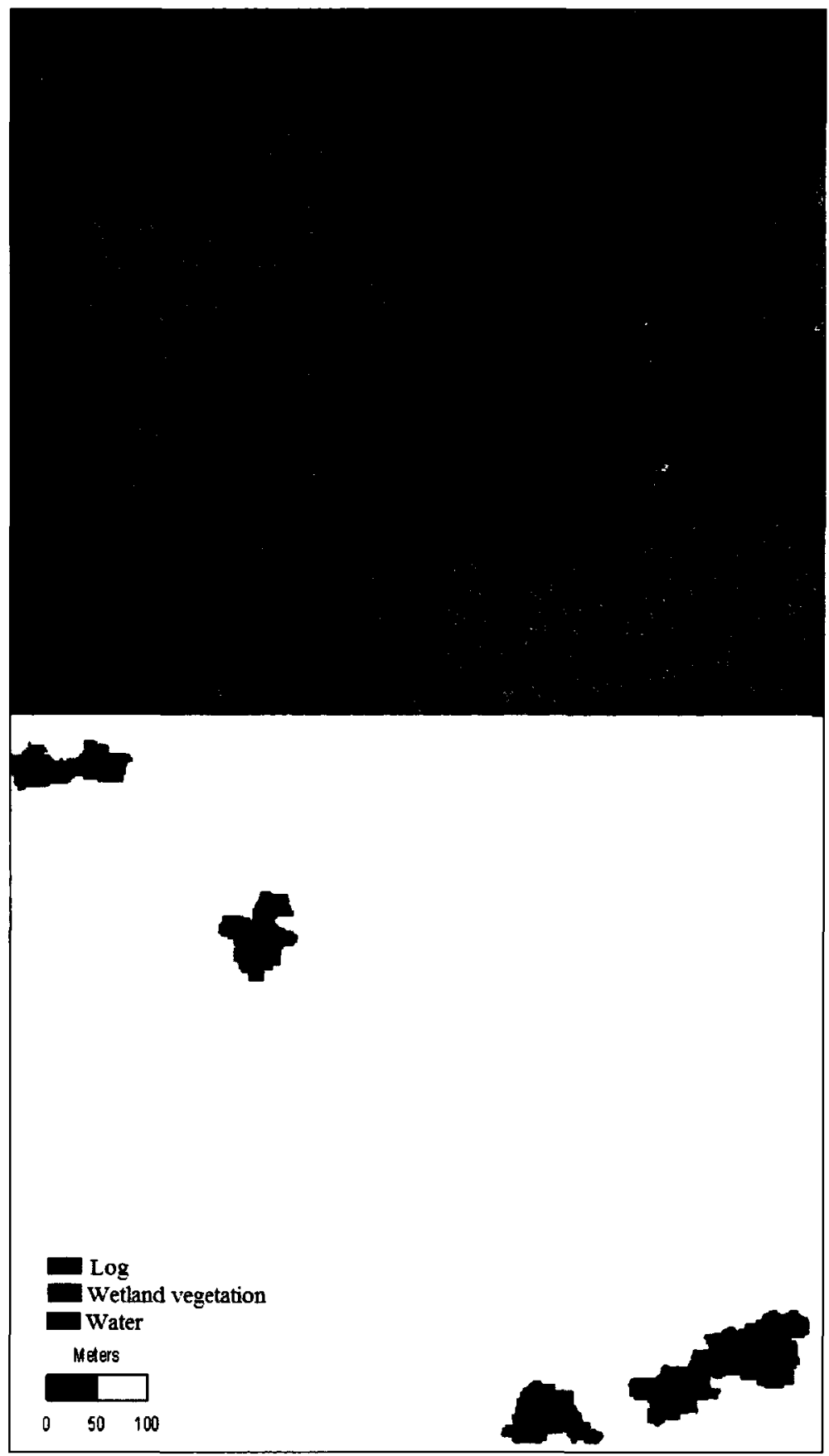

Figure 52a. Orthophoto of three wetlands (top)* and their associated classification (bottom). These wetlands have never been mapped before and the middle wetland had a Blanding's turtle observation by the author (2008) (Figure 52b). The other two wetlands were also validated in a field survey and have Blanding's turtle observations within 500 m. *Source: NCC, 2007. 


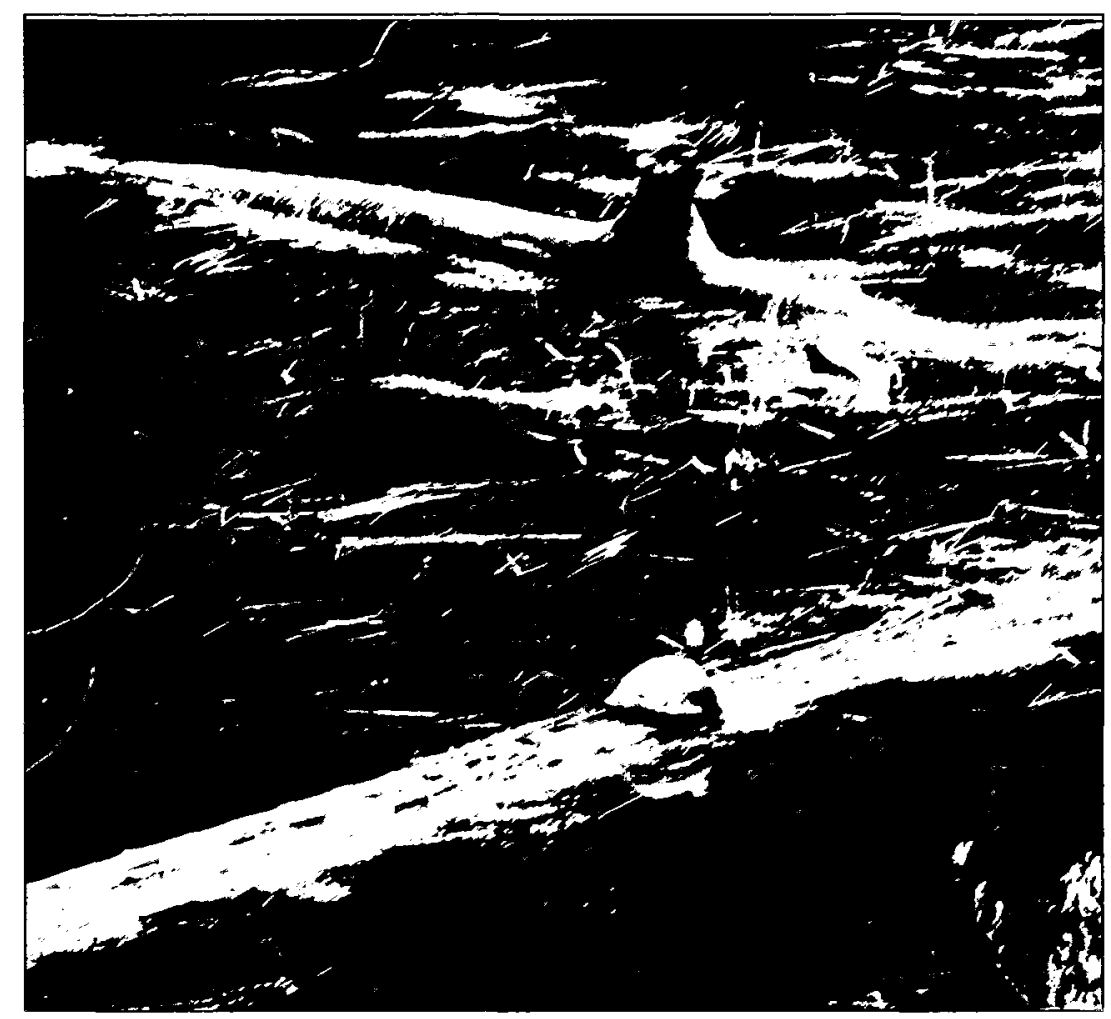

Figure 52b. Photograph of a wetland never mapped before (middle wetland in Figure 52a) and a Blanding's turtle basking in the sun on a log. Source: Author, 2008.

\subsection{Research Limitations and Recommendations}

There were several limitations in this research related to the processing that could be conducted and ultimately the objectives that could be accomplished, summarized by several defining categories : 1) the defined scope; 2) the temporal and spectral characteristics of the data; 3 ) the image processing and object-based classification methods utilized; and 4) the habitat suitability index developed.

1. The scope of the thesis

There were only 3 habitat attributes mapped, selected for several reasons. There were data limitations that influenced the ability to classify more detailed classes and the 3 classes chosen were selected as critical habitat to Blanding's turtles. There are 
other wetland attributes that have potential to be mapped with remote sensing and could be used to improve a Blanding's turtle habitat suitability map, including: 'continuous' wetland vegetation that is usually composed of large areas of grasses (e.g., sedge) or emergent vegetation (e.g., cattails) and can grow to extents far from visible open water. Grasses such as sedges are very important to Blanding's turtle habitat requirements, and they were only mapped within $20 \mathrm{~m}$ of Water in this research. It is estimated that the vegetation mapped was sufficient for rating wetland suitability, but not ideal, since some bank vegetation was not classified. Vegetation types and quantity could have been more comprehensively mapped if it were not for the data limitations, which could alter the scores of wetlands. Consequently the habitat suitability index is only a snapshot representation of potential habitat suitability. However, the habitat suitability map created is still a great improvement over what was available for the study area (Section 4.1) and could be used to assist biologists in further habitat surveying and analysis, particularly outside the park where the distribution of suitability scores may be less skewed towards high suitability.

\section{Data limitations}

To improve the accuracy of land-use and land-cover classification it is recommended to add a temporal component and additional spectral information. The addition of imagery taken during peak vegetation growing season (mid-summer) would allow classification of all wetland vegetation types that would be present in wetlands, not just the senescent wetland vegetation that is visible at high water levels in spring imagery. The inclusion of a near infrared (NIR) band in the aerial 
orthophoto acquisition, especially during summer, would provide very useful information to discriminate between wetland vegetation and other land cover types as well as between wetland vegetative species and/or forms.

There are limitations to conducting summer field work and having spring orthophotos from a different year, since vegetation cannot be comprehensively verified in the field as it appears in the orthophoto. Spring imagery doesn't show all the vegetation that will be available in summer. Classification did not fully classify all wetland vegetation and therefore underestimated wetland vegetation that could increase wetland scores associated with turtle observations. The spring imagery still had apparent wetland vegetation and in particular the vegetation structure type that is a selected habitat characteristic for Blanding's turtle, including: vegetation islands and sedge tussocks that appear as scattered or clustered vegetation mounds in the water in the spring. However, there is also the potential for tussocks and other vegetation to be submerged at high water levels in spring imagery.

There are no commercially-available satellite images that have a multispectral resolution less than $1 \mathrm{~m}$. The highest resolution imagery was not available in the summer of 2008; that satellite, GEOEYE-1 (launched Sept 2008), has a panchromatic band of $41 \mathrm{~cm}$ and a multi-spectral band pixel size of $1.65 \mathrm{~m}$ (GEOEYE, 2010). There are no satellites that could have provided as high a resolution as the orthophotos to classify small wetland features such as logs. However, satellite data could potentially be used to classify larger logs or even small logs if a sub-pixel approach was utilized. 


\section{Image processing and object-based classification}

The initial pixel-based classification conducted in order to make the wetland mask was one of the main sources of error that caused wetlands and wetland portions to not be included in the wetland mask for further classification processing. This processing phase should be further evaluated to improve the inclusion of important wetland features such as extensive wetland vegetation distant from water $(>50 \mathrm{~m})$. The processing step involving the segmentation of the MLC derived bitmap to reduce erroneous classified Water (commonly shadow between trees) could have been conducted differently by simply removing all objects below a specified size threshold.

For this research, three of the primary habitat features (wetlands, wetland vegetation, and logs) were selected for object-based classification. To accurately assign objects to the correct class, long and iterative testing was required to develop the optimal sequential rule-base. A limitation in expanding the same rules is that it would have to be re-done for a different area of different forest and wetland composition, or for different image scale or time of year (sun angle, shadow orientation, leaves, etc.). However, an advantage is that it is very interactive and can be done quickly because visual validation is easy with such high resolution imagery.

The iterative testing conducted to refine the classification and subsequent removal of deciduous objects was lengthy and could have been accomplished in a shorter duration by manual object removal instead. It is surmised that logs were more effectively mapped using the object-based approach than could have been achieved 
with a pixel-based technique. The main method used to assign objects to the Log class was based on a rule that the length: width ratio of the object must be over 2.75 . Objects assigned to the Log class also had to meet thresholds for their length, width and size, which would not be possible in a pixel-based approach.

The object-based approach was capable of producing more homogeneous class extents than would be expected for pixel-based classification. For example, in the case of wetland vegetation some pixels' brightness may be slightly lower than others but they become grouped into a larger object during initial multi-resolution segmentation (when the colour (spectral brightness) is given higher weight than shape) which makes a more continuous class than if each pixel were evaluated for its individual brightness value and likely reduces classification errors (individual pixels with lower brightness could be misclassified).

\section{Habitat Suitability Scoring System}

The scoring system applied in this research is only one example of how a Blanding's turtle suitability map can be developed using the wetland (and small waterbody) data formulated in this research. Categories were created based on an in depth literature review (Section 2.3), conversations with Blanding's turtle habitat specialists (Dubois, 2009. pers. comm.) and field experience. However, there is still inherent subjectivity in selecting discrete classes that affect scores that define wetland habitat suitability.

The categories created for wetland size, Logs and Wetland Vegetation could be devised differently and the scores distributed within each category could be changed. Wetland Vegetation could be evaluated by area instead of percent coverage. There 
could be an additional wetland size category added to discern the larger water bodies more often associated with lakes. The large open wetlands, often with very high grasses or cattails, or portions of wetland characterized by this expansive vegetation were not mapped effectively in this research, resulting in few wetlands mapped with very high Wetland Vegetation ( $>75 \%$ ) and most mapped wetlands being in the very small or small wetland size categories. For instance, in several cases where the riverine section of a wetland was mapped in this research the vast continuous vegetation extending upwards of $100 \mathrm{~m}$ (or more) was not mapped.

The Blanding's turtle population data available provide limited information to create a statistically based potential habitat map or model. The population inventories mainly occurred within relatively small areas (approx. $4 \times 6 \mathrm{~km}$ ) and were therefore expected to be spatially correlated. Many observations were static sitings, and are not representative of the larger, multi-wetland habitat range that Blanding's turtles require. Blanding's turtles are known to move $1-2 \mathrm{~km}$ a year, using multiple wetland types and traversing forest to nesting sites (Section 2.3.2). Observations were recorded across multiple years (or even within the same year) and with no knowledge on whether the same individual was observed.

The telemetry project initiated in 2009 will be continued in 2010 and is anticipated to provide more feasible data to create a statistically based habitat suitability model for Blanding's turtle in this region.

Without statistical integration of Blanding's turtle occurrences into the habitat suitability score and map, only a qualitative assessment could be conducted. The evaluation of Blanding's turtle observations related to wetlands (within $500 \mathrm{~m}$ ) 
showed that the habitat suitability scoring system and habitat suability levels were in agreement.

Once a sufficient dataset (spatially distributed sampling and enough to be statistically feasible) of Blanding's turtle occurrences is available, then several habitat suitability maps and models could be assessed. For instance, a spatial habitat suitability index could be used to associate classified landcover features (e.g., logs, different wetland vegetation types, water, different forest types and density, distance to roads) with Blanding's turtle occurrences. The telemetry data will be recorded in all activity seasons, which could be used to analyze habitat utilized in each season. The wetland map produced from this research is a snap shot of only one season and would be limited in providing characteristic information about wetlands for all seasons. A temporal wetland classification approach (classification of images from different seasons) would enhance the applicability of incorporating Blanding's turtle movements across seasons.

Additional landuse/landcover data could be incorporated in the Blanding's turtle habitat suitability map, such as distance and/or density of roads, distance to suitable nesting habitat (sandy, open areas) and the connectivity of wetlands based on topographic data (e.g., set slope threshold that turtles can not traverse). Additional data would likely change the abundance and distribution of highly suitable habitat mapped in this research. 


\section{CHAPTER SIX}

\section{THESIS SUMMARY AND CONCLUSIONS}

This research found high resolution leaf-off colour aerial orthophoto images at $20 \mathrm{~cm}$ resolution are suitable for mapping potential Blanding's turtle habitat through the mapping of wetlands and selected wetland habitat features. Object-based segmentation and classification produced accurate land cover maps and the incorporation of image texture metrics was very useful for wetland delineation in a complex forest landscape, including delineation and classification of the main Blanding's turtle habitat requirements of water, wetland vegetation and logs.

The limitations of the poor spectral information in the leaf-off colour air photos were overcome by using rule sets including aspects of shape, texture, area, and context that are possible through an object-based classification approach. The rule-sets were created through data exploration and iterative testing of different object features and thresholds followed by verification at both local and mosaic scales. The high resolution imagery allowed for accurate visual interpretation of the selected land cover types and features and made it possible to fine tune the segmentation and classification parameters. The main classification rules were applied across several mosaics with repeatable accuracy.

Given the high mapping accuracy achieved for these habitat features, the habitat suitability index that was formulated showed a strong association with known Blanding's turtle observation locations. It is anticipated that this type of imagery, classification, and habitat suitability mapping approach could be extended to other geographically similar 
areas, such as the remaining sections of Gatineau Park or the areas to the south of the study area near Bristol, Québec where there are known populations.

These maps of wetlands (including four that were previously unmapped that have had Blanding's turtle observations in the last two years), critical habitat features, and habitat suitability will be of direct benefit to Blanding's turtle recovery activities. The Blanding's turtle recovery team will use the results of this thesis and the maps produced to aid location of suitable wetlands to survey for Blanding's turtles as a part of their strategic field planning and continued telemetry studies in an effort to improve the Blanding's habitat database in the study region and our understanding of the population and habitats of this threatened species. 


\section{REFERENCES}

Arzandeh, S., \& Wang J. (2002). Texture evaluation of radarsat imagery for wetland mapping. Canadian Journal of Remote Sensing, 28, 653-666.

Attum O., Lee, Y., Roe, J., \& Kingsbury, B. (2008). Wetland complexes and uplandwetland linkages: landscape effects on the distribution of rare and common wetland reptiles. Journal of Zoology, 275, 245-254.

Baker, C., Lawrence, R., Montagne, C., \& Patten, D. (2006). Mapping wetlands and riparian areas using Landsat ETM+ imagery and decision-tree based models. Wetlands, 26, 465-74.

Becker, B. L., Lusch, D. P., \& Qi, J. (2007). A classification-based assessment of the optimal spectral and spatial resolutions for Great Lakes coastal wetland imagery. Remote Sensing of Environment, 108, 111-20.

Bechtel, R., Sanchez-Azofeifa, A., Rivard, B., Hamilton, G., Martin, J., \& Dzus, E. (2004). Associations between Woodland Caribou telemetry data and Landsat TM spectral reflectance. International Journal of Remote Sensing, 25, 4813-4827.

Belanger, L., M. Grenier. (2003). Conservation atlas of wetlands. Environment Canada and the Canadian Wildlife Service, Quebec region. Online. URL: www.qc.ec.gc.ca/faune/atlasterreshumides/html/AtlasTerresHumides_f.html

Benoit, J., Labrecque, S., Grenier, M., \& Falardeau, G. (2008). Object-based classification as an alternative approach to the traditional pixel based classification to identify potential habitat of the grasshopper sparrow. Environmental Management, 41, 20-31.

Bissonette, J. A., \& Storch, I. (2003). Landscape ecology and resource management: linking theory with practice. Island Press. Washington, DC, United States of America. p. 95. ISBN 1-55963-973-3.

Blanding's Turtle Recovery Team. (2006). Nova Scotia's Blanding's Turtles conservation and recovery. Online. URL: http://www.speciesatrisk.ca/blandings/about.htm.

Bock, M., Xofis, P., Mitchley, J., Rossner, G., \& Wissen, M. (2005). Object-oriented methods for habitat mapping at multiple scales - Case studies from Northern Germany and Wye Downs, UK. Journal of Nature Conservation, 13, 75-89.

Bourque, G. (2006). Investigating variables affecting Blanding's Turtle (Emydoidea blandingii) patch occupancy and trapping success in Nova Scotia. Acadia University, Biology Department, Nova Scotia. Masters Thesis. 79p. 
Brown, S., Buja, K., Jury, S., \& Monaco, M. (2000). Habitat suitability index models for eight fish and invertebrate species in Sasco and Sheepscot Bays, Main. North American Journal of fisheries Management, 20, 108-435.

Burnett, C., \& Blaschke, T. (2003). A multi-scale segmentation/object relationship modeling methodology for landscape analysis. Ecological Modelling, 168, 233-249.

Bury, R., \& Germano, D. (2003). Differences in habitat use by Blanding's Turtles, Emydoidea blandingii, and Painted Turtles, Chysemyspicta, in the Nebraska sandhills. American Midland Naturalist, 149, 241-244

Carroll, D. M, \& Ultsch, G. R. (2007). Emergence season and survival in the nest of hatchling turtles in southcentral New Hampshire. North Eastern Naturalist, 14, 307-310.

Carter, G., Stolen, E., \& Breininger, D. (2006). A rapid approach to modeling specieshabitat relationships. Biological Conservation, 127, 237-244.

Carver, S. (1991). Integrating multi-criteria evaluation with geographic information systems. International Journal of Geographic Information Systems, 5, 321-339.

Catarina, V., Fonseca, V., Cabral, H., \& Costa, M. J. (2006). Habitat suitability index models for the juvenile soles, Solea solea and Solea senegalensis, in the Tagus estuary: Defining variables for species management. Fisheries Research. 82, 140149.

Center for reptile and amphibian conservation management. (2008) Indiana-Purdue University. Blanding's turtle US distribution map. Online. URL: http://herpcenter.ipfw.edu/index.htm?http://herpcenter.ipfw.edu/outreach/accounts/r eptiles/turtles/Blandings_turtle/\&2.

Chen, D., Stow, D., \& Gong, P. (2004). Examining the effect of spatial resolution and texture window size on classification accuracy: an urban environment case. International Journal of Remote Sensing, 25, 2177-2192.

Chiu, W. Y., \& Couloigner, I. (2006). Modified fuzzy c-means classification technique for mapping vague wetlands using Landsat ETM+ Imagery. Hydrological Processes, 20, 3623-3634.

Congdon, J., Dunham, A., \& van LobenSels, R. (1993a). Delayed sexual maturity and demographics of Blanding's Turtles (Emydoidea blandingii): Implications for conservation and management of long-lived organisms. Conservation Biology, 7, 826-833.

Congdon, J.D., \& van LobenSels, R. C. (1993b). Relationships of reproductive traits and body size with attainment of sexual maturity and age in Blanding's turtles (Emydoidea blandingii). Journal of Evolutionary Biology, 6, 547-557 
Congdon, J.D., Nagle, R.D., Kinney, O.M., Osentoski, M., Avery, H.W., van Loben Sels, R.C., \& Tinkle, D.W. (2000). Nesting ecology and embryo mortality: Implications for hatchling success and demography of Blanding's Turtles (Emydoidea blandingii). Chelonian Conservation and Biology, 3, 569-579.

Committee on the Status of Endangered Wildlife in Canada (COSEWIC). (2005). COSEWIC assessment and update status report on the Blanding's Turtle (Emydoidea blandingii) Canada: Nova Scotia population, Great Lakes/St. Lawrence population. 40p. ISBN 0-662-40589-7.

Cronk, J. K. \& Siobhan, F. M. (2001). Wetland plants: biology and ecology. CRC Press LLC. America. ISBN 1-56670-372-7.

Davidson, N.C. \& Finlayson, C. M. (2007). Earth observation for wetland inventory, assessment and monitoring. Aquatic Conservation: Marine and Freshwater Ecosystems, 17, 219-228.

Definiens AG. (2008). Definiens developer user guide. URL: Definiens.com.

Dijak, W., Rittenhouse, C., Larson, M., Thompson, F., \& Millspaugh, J. (2007). Landscape Habitat Suitability Index Software. Journal of Wildlife Management, 71, 668-670.

Développement durable, Environnement et Parcs. (2008). Protecting threatened and vulnerable species in Québec. Online. URL:

http://www.mddep.gouv.qc.ca/biodiversite/especes/protection/index-en.htm

Dubois, Y. (2009). Distribution de la tortue mouchetée (Emys blandingii) et cartographie des aires prioritaires de conservation et des corridors écologiques à l'intérieur et en périphérie du parc de la Gatineau. Conservation de la nature Canada, pour la Commission de la capitale nationale. $56 \mathrm{pp}$.

Dubois, Y., personal communication (pers. comm.). Coordonnateur de l'Équipe de rétablissement des tortues du Québec. Québec Ministère des Ressources naturelles et de la Faune (QMNRF).

Ducks Unlimited Canada. (2008). Liste des données existantes sur les milieux humides utilisées pour générer les Plans régionaux de conservation des milieux humides de CIC (PRCMH). Online. URL : http://www.ducks.ca/fr/province/qc/outils/pdf/donnees prcmh sources mars2009.

Dwivedi, R. S., Kandrika, S., \& Ramana, K. V. (2004). Comparison of classifiers of remote-sensing data for land-use/land-cover mapping. Current science. 86, 328335 . 
Edge, C. (2008). Multiple Scale Habitat Selection by Blanding's Turtles (Emydoidea blandingii). Laurentian University, Sudbury, Canada. Masters of Science Thesis. $112 \mathrm{pp}$.

Environment Canada. (2004). Inland Waters Biodiversity. Online. URL: http://www.cbin.ec.gc.ca/enjeux-issues/eaux-waters.cfm?lang=eng.

Environment Canada. (2008). Canadian climate normals or averages 1971-2000. Luskville, Quebec. Online. URL: http://www.climate.weatheroffice.ec.gc.ca/climate_normals/index_e.html.

Foody, G. M., \& Atkinson, P. M. (2002). Uncertainty in remote sensing and GIS. John Wiley and Songs Ltd. West Sussex, England. p.68. ISBN 0-470-84408-06.

Fournier, R., Grenier, M., André, L., \& Robert, H. (2007). Towards a strategy to implement the Canadian Wetland inventory using satellite remote sensing. Canadian Journal of Remote Sensing, 33, Suppl 1, s1-S16.

Garcia, L., \& Armbruster, M. (1997). A decision support system for evaluation of wildlife habitat. Ecological modelling, 102, 287-300.

GEOEYE. (2010). Imagery Sources, Geoeye-1. Online. URL: http://www.geoeye.com/CorpSite/products/imagery-sources/Default.aspx\#geoeye1

Gibbs, J.P., \& Shriver, W.G. (2002). Estimating the effects of road mortality on turtle populations. Conservation Biology. 16, 1647-1652.

Gong, P., Marceau, D. J., \& Howarth, P.J. (1992). A comparison of spatial featureextraction algorithms for land-use classification with SPOT HRV data. Remote Sensing of Environment, 40, 137-151.

Google maps data. (2009). Gatineau Park. Online. URL: http://maps.google.ca/maps?hl=en\&tab=wl

Government of Canada. (2009). COSEWIC. Wildlife species assessment. Online. URL: http://www.cosewic.gc.ca/eng/sct0/assessment_process_e.cfm.

Grenier, M., Demers, A., Labrecque,S., Benoit, M., Fournier, R. A. \& Drolet, B. (2007). An object-based method to map wetland using RADARSAT-1 and Landsat ETM images: test case on two sites in Quebec, Canada. Canadian Journal of Remote Sensing, 33, Suppl 1, 28-45.

Grenier, M., Labrecque, S., Garneau, M., \& Tremblay, A. (2008). Object-based classification of a SPOT-4 image for mapping wetlands in the context of greenhouse gases emissions: the case of the Eastmain region, Quebec, Canada. Canadian Journal of Remote Sensing. 34, Suppl 2. Pp s398-s413. 
Grgurovic, M., \& Sievert, P. (2005). Movement patterns of Blanding's Turtles

(Emydoidea blandingii) in the suburban landscape of eastern Massachusetts. Urban Ecosystems, 8, 203-213.

Hamernick, M. G. (2001). Home ranges and habitat selection of Blanding's turtles (Emydoidea blandingii) at the Weaver Dunes, Minnesota. Thesis. St. Mary's University of Minnesota. Winona, USA. 1-18.

Haralick, R. M. (1979). Statistical and structural approaches to texture. Proceedings of the IEEE, 67, 786-804.

Henderson, F. M., \& Lewis, A. J. (2008). Radar detection of wetland ecosystems: a review. International Journal of Remote Sensing, 29, 5809-5835.

Herman, T.B., Power, T.D., \& Eaton, B.R. (1994). Status of Blanding's turtles, Emydoidea blandingii, in Nova Scotia, Canada. Canadian Field-Naturalist, 109, 182-191.

Hill, R.A., \& Foody, G. M. (1994). Separability of tropical rain-forest types in the Tambopata-Candamo reserved zone, Peru, International Journal of Remote Sensing. 15, 2687-2693.

Hirano, A., Madden, M., \& Roy, W. (2003). Hyperspectral image data for mapping wetland vegetation. Wetlands, 23, 436-448.

Innes , R. J., Babbitt, K. J., \& Kanter , J. J. (2008). Home range and movement of Blanding's turtles (Emydoidea blandingii) in New Hampshire. Northeastern naturalist, 15, 431-444.

Jensen, J.R. (2005). Introductory digital image processing: a remote sensing perspective. Edition 3. Prentice Hall. California, USA. p. 526. ISBN 0131453610.

Joyal, L., McCollough, M., \& Hunter Jr, M. (2001). Landscape ecology approaches to wetland species conservation: a case study of two turtle species in southern Maine. Conservation Biology, 15, 1755-1762

Karraker, N., Gibbs, E., \& James, P. (2009). Amphibian production in forested landscapes in relation to wetland hydroperiod: A case study of vernal pools and beaver ponds. Biological Conservation, 142, 2293-2302.

Kofron, C. P., \& Schreiber, A. A. (1985). Ecology of two endangered aquatic turtles in Missouri: Kinosternon flavescens and Emydoidea blandingii. Journal of Herpetology, 19, 27-40. 
Kroll, A., \& Haufler, J. (2006). Development and evaluation of habitat models at multiple spatial scales: A case study with the dusky flycatcher. Forest Ecology and Management, 229, 161-169.

Larson, M., Thompson III, F., Millspaugh, J., Dijak, W., \& Shifley, S. (2004). Linking population viability, habitat suitability, and landscape simulation models for conservation planning. Ecological Modelling, 180, 103-118.

Larthrop, R. G., Montesano, P., Tesauro, J., \& Zarate, B. (2005). State wide mapping and assessment of vernal pools: A New Jersey case study. Journal of Environmental Management, 76, 230-238.

Lucieer, V.L. (2008). Object-oriented classification of sidescan sonar data for mapping benthic marine habitats. International Journal of Remote Sensing, 29, 905-921.

Ludwig, D., \& Iannuzzi, T. (2006). Habitat equivalency in urban estuaries: An analytical hierarchy process for planning ecological restoration. Urban Ecosystems, 9, 265290.

Manton, M., Angelstam, P., \& Grzegorz, M. (2005). Modelling habitat suitability for deciduous forest focal species- a sensitivity analysis using different satellite land cover data. Landscape Ecology, 20, 827-839.

McDermid, G., Franklin, S., \& LeDrew, E. (2005). Remote sensing for large-area habitat mapping. Progress in Physical Geography, 29, 449-474.

McGill University. (2008). Canadian biodiversity, Canada's ecozones. Mixedwood Plain and Boreal Shield. Online. URL:

http://canadianbiodiversity.mcgill.ca/english/ecozones/ecozones.htm.

McNeil, J. A., Herman, T. B., \& Standing, L. K. (2000). Movement of hatchling Blanding's turtles (Emydoidea blandingii) in Nova Scotia in response to proximity to open water : A manipulative experiment. Chelonian Conservation and Biology, $3,611-617$.

Mladenoff, D., Sickley, T., Haight, R., \& Wydeven, A. (1995). A regional landscape analysis and prediction of favourable gray wolf habitat in the northern Great Lakes Region. Conservation Biology, 9, 279-294.

Murphy, P.N., Ogilvie, J., Connor, K., \& Paul, A.A. (2007). Mapping wetlands: A comparison of two different approaches for new Brunswick, Canada. Wetlands, 27, 846-854.

National Capital Commission (NCC). (2005). Gatineau Park Master Plan. Online. URL: http://www.capcan.ca/data/2/rec_docs/1778_Map7.pdf 
National Capital Commission (NCC). (2007). Digital aerial orthophotos (Gatineau Park, Quebec, Canada). Computer file.

The National Capital Commission. (2005). Gatineau Park, Natural Resources. Government of Canada. Online: URL: http://www.nccccn.ca/bins/ncc_web_content_page.asp?cid=16297-16299-10170-4989950069 \&lang $=1$.

National Wetland Working Group (NWWG). (1988). Wetlands of Canada. Ecological Land Classification Series, No. 24, Sustainable Development Branch, Environment Canada, Ottawa, andPolyscience Publications Inc, Montreal, Quebec. p.416.

National Wetlands Working Group. (1997). The Canadian Wetland Classification System. Second Edition. Edited by B.G. Warner and C.D.A. Rubec. Wetlands Research Centre, University of Waterloo. Waterloo, ON. 68 p.

Natural Heritage and Endangered Species Program. (2007). Massachusetts Forestry Conservation Management Practices for Blanding's Turtles. Natural Heritage and Endangered Species Program, Massachusetts Division of Fisheries and Wildlife, Westborough, Massachusetts, USA.

Natural Resources Canada (NRCan). (2003). National forest health and biodiversity database. A description of biomonitoring plots in Canada. (ARNEWS system).Online. URL:

http://www.atl.cfs.nrcan.gc.ca:8080/cfsnet/arnews/tables/index.jsp?action=descripti on

Natural Resources Canada (NRCan). (2007a). Canada's Wetlands Classification. Online. URL: http://wetlands.cfl.scf.rncan.gc.ca/classification/classification-eng.asp

Natural Resources Canada (NRCan). (2007b). National Topographic Database. Quebec boundary. Accessed through Carleton University, Online. URL: http://www.library.carleton.ca/gis/ntdb.htm.

Natural Resources Canada (NRCan). (2007c). National Topographic Database. Region Quyon. Accessed through Carleton University. Online. URL: http://www.library.carleton.ca/gis/ntdb.htm.

Natural Resources Canada. (NRCan). (2009). Atlas of Canada. Wetlands. Online. URL: http://atlas.nrcan.gc.ca/site/english/learningresources/theme modules/wetlands/inde $\underline{x . h t m l / \# f a c t s}$

NatureServe Canada, (2007). Online. URL: http://www.natureserve-canada.ca/ [Last accessed: Oct 2, 2008]. 
Neu, C.W., Byers, C.R., \& Peek, J.M. (1974). A technique for analysis of utilizationavailability data. Journal of Wildlife Management, 38, 541-545.

Ontario Ministry of Natural Resources and Ducks Unlimited Canada. (2003). Methodology development for wetland and ephemeral water mapping using remote sensing and spatial modelling techniques. Southern Ontario Land Resource Information System.

Ontario Ministry of Natural Resources. (2008). Wetland restoration. Online. URL: http://www.mnr.gov.on.ca/en/Business/Biodiversity/2ColumnSubPage/STEL02 17 $\underline{6753 . \mathrm{html}}$

Osborne, P., Olonso, J., \& Bryant, R. (2001). Modelling landscape-scale habitat use using GIS and remote sensing: a case with great bustards. Journal of Applied Ecology, $38,458-471$.

Ozesmi, S. L, \& Bauer, M. E. (2002). Satellite remote sensing of wetlands. Wetlands Ecology and Management, 10, 381-402.

Palma, L., Beja, P. \& Rodrigues, M. (1999). The use of sighting data to analyze Iberian lynx habitat and distribution. Journal of Applied Ecology, 36, 812-24.

Pappas, M. J. \& Brecke, B. J. (1992). Habitat Selection of Juvenile Blanding's Turtles, Emydoidea blandingii. Journal of Herpetology, 26, 233-234.

Parc de la Gatineau. (2007). Parc de la Gatineau Environnement, terrains et parcs de la capitale Commission de la capitale nationale. Projet d'inventaire de la tortue mouchetee (Emydoidea blandingii) au parc de la Gatineau. National Capital Commission, Ottawa, Canada.

Pasher, J., King, D., \& Lindsay, K. (2007). Modelling and mapping potential hooded warbler (Wilsonia citrina) habitat using remotely sensed imagery. Remote Sensing of the Environment, 107, 471-483.

PCI Geomatics. (1999a). Theory, Resampling. Online. URL: http://www.pcigeomatics.com/cgibin/pcihlp/GCPWORKS\%7CTheory\%7CResampling

PCI Geomatics. (1999b). Texture. Online. URL: http://www.pcigeomatics.com/cgibin/pcihlp/TEX\%7CALGORITHM

Piepgras, S.A., \& Lang, J.W. (2000). Spatial ecology of Blanding's turtle in central Minnesota. Chelonian Conservation and Biology, 3, 589-601.

Pietroniro, A., \& Leconte, R. (2000). A review of Canadian remote sensing applications in hydrology, 1995-1999. Hydrological processes, 14, 1641-1666. 
Power, T.D., Herman.T., \& Kerekes, J. (1994). Water colour as a predictor of local distribution of Blanding's Turtles, Emydoidea blandingii, in Nova Scotia. Canadian Field-naturalist, 108, 17-21.

Québec Ministère des Ressources naturelles et de la Faune (QMNRF). (2008). Base de données topographiques du Québec (BDTQ), 1999, 1:20,000

Ross, D. A., \& Anderson, R. K. (1990). Habitat Use, Movements, and Nesting of Emydoidea blandingii in Central Wisconsin. Journal of Herpetology, 24, 6-12.

Rowe, J., \& Moll, E. (1991). Radiotelemetric Study of Activity and Movements of the Blanding's Turtle (Emydoidea blandingii) in Northeastern Illinois. Journal of Herpetology, 25, 178-185.

SARA. (2003). Canada Gazette: Part 3. Canadian Government Publishing, Communication Canada, Ottawa, Canada, 25, 1-104. Online.http://www.sararegistry.gc.ca/approach/act/sara e.pdf.

SARA. (2004). Species profile: Blanding's Turtle Great Lakes / St. Lawrence population. Government of Canada.Online. URL: http://www.sararegistry.gc.ca/virtual_sara/files/statements/rs846_22_2005-8_e.pdf

SARA. (2005). Species at Risk Act Public Registry. http://www.sararegistry.gc.ca.

St-Hilaire, D. (2003). Rapport sur la situation de la tortuemouchetee (Emydoidea blandingii) au Québec. Société de la faune et des parcs du Québec, Direction de l'aménagement de la faune de l'Outaouais. 27 pages.

St-Hilaire, D., J. Caron., \& Dubois, Y. (2008). Captures, caractéristiques biologiques, déplacements, et sites fréquentés par la tortue mouchetée (Emydoidea blandingii) au sud de l'Outaouais de 1996 à 1999. Ministère des Ressources naturelles et de la Faune, Québec, Direction de l'aménagement de la faune de l'Outaouais. 56 p.

Standing, L. K., Herman, T. B., \& Morrison, I. P. (1999). Nesting ecology of Blanding's turtle (Emydoidea blandingii) in Nova Scotia, the northeastern limit of the species' range. Canadian Journal of Zoology, 77, 1609-1614.

Store, R., \& Kangas, J. (2001). Integrating spatial multi-criteria evaluation and expert knowledge for GIS-based habitat suitability modelling. Landscape and urban planning, 55, 79-93.

Store, R., \& Jokimaki, J. (2003). A GIS-based multi-scale approach to habitat suitability modeling. Ecological Modelling, 169, 1-15. 
Tiner, R. W. (1999).Wetland indicators: A guide to wetland identification, delineation, classification and mapping. CRC Press LLC. Printed in America. p. 392. ISBN 087371-892-5.

Varela Diaz, R.A., Rego, R. P., Igleseas, C. S., \& Sobrino, M. C. (2008). Automatic habitat classification methods based on satellite images: A practical assessment in the NW Iberia coastal mountains. Environmental Monitoring Assesmsment, 144, 229-250.

Verlinden, A., \& Masogo, R. (1997). Satellite remote sensing of habitat suitability for ungulates and ostrich in the Kalahari of Botswana. Journal of Arid Environments, $35,563-74$.

Warner B.G., \& Rubec C.D.A. (1997). National Wetlands Working Group. The Canadian Wetland Classification System, Second Edition. Eds.. Wetlands Research Centre, University of Waterloo, Waterloo, Ontario.68 p.

Wei, A., \& Chow-Fraser, P. (2007). Use of IKONOS Imagery to map Coastal Wetlands of Georgian Bay. Fisheries, 32, 167-773.

Whitefield Gibbons, J., Scott, D. E., Ryan T. L., Buhlmann, K. A., Tuberville, T. D., Metts, B. S., Green, J. L., Mills, T., Leiden, Y., Poppy, S. \& Winne C. T. (2000). The global decline of reptiles, Déjà vu Amphibians. Bioscience, 50, 653-666.

Wright, C., \& Gallant, A. (2007). Improved wetland remote sensing in Yellowstone National Park using classification trees to combine TM imagery and ancillary environmental data. Remote Sensing of Environment, 107, 582-605.

Yu, Q., Gong, P., Clinton, N., Biging, G., Kelly, M., \& Schirokauer, D. (2006). Objectbased detailed vegetation classification with airborne high spatial resolution resmote sensing imagery. Photogrammetric Engineering and Remote Sensing, 72, 799-811.

Zoltai , S.C., \& Vitt, D.H. (1995). Canadian wetlands: Environmental gradients and classification. Plant Ecology, 118, 131-137.

Zomer, R.J., Trabucoo, A., \& Ustin, S.L. (2009). Building spectral libraries for wetlands land cover classification and hyperspectral remote sensing. Journal of Environmental Management, 90, 2170-2177. 


\section{Appendix 1 Data Forms used during Field Surveying of Wetlands.}

Data Form 1

Date:

\begin{tabular}{|l|l|l|l|l|l|l|}
\hline site obs\# & $\begin{array}{l}\text { Location } \\
\text { (ie.rd/lk } \\
\text { close prox })\end{array}$ & Latitude & Longitude & $\begin{array}{l}\text { water } \\
\text { temp. } \\
\left({ }^{\circ} \mathrm{C}\right)\end{array}$ & $\begin{array}{l}\text { air } \\
\text { temp. } \\
\left({ }^{\circ} \mathrm{C}\right)\end{array}$ & $\begin{array}{l}\text { Water depth } \\
<.5 \mathrm{~m},>.5 \mathrm{~m} \\
\text { or }>2 \mathrm{~m}\end{array}$ \\
\hline & & & & & & \\
\hline
\end{tabular}

\begin{tabular}{|l|l|l|l|l|}
\hline $\begin{array}{l}\text { Turtle obs Or egg } \\
\text { shells (TS) \& Where } \\
\text { (log,rd etc) }\end{array}$ & $\begin{array}{l}\text { Expected sun } \\
\text { exposure } \\
\text { closed =cl, fair } \\
\text { Blanding's=B, Painted } \\
\text { =P, Snagh=hi } \\
\text { unknown (U). }\end{array}$ & $\begin{array}{l}\text { Reduced sun } \\
\text { exposure from: trees, } \\
\text { size (sm/g), shape } \\
\text { (narrow) or topo } \\
\text { (side nsew) } \\
\text { \% by 20x }\end{array}$ & $\begin{array}{l}\text { Wetland } \\
\text { type marsh } \\
\text { (ma), swamp } \\
\text { (sw), pond } \\
(\mathrm{p}), \\
\text { ephemeral } \\
\text { (eph), small } \\
\text { lake (slk) }\end{array}$ & comments \\
\hline & & & & \\
& & & & \\
\hline
\end{tabular}

Data Form 2

Date:

\begin{tabular}{|c|c|c|c|c|c|}
\hline Site obs \# & $\begin{array}{l}\text { Deadwood } \\
\text { wetland } \\
\text { none, }<5 \\
\text { (sm), } 5-10 \\
\text { (med), 10+ } \\
\text { (ab) }\end{array}$ & $\begin{array}{l}\text { Tranpsortation } \\
\text { lines (hwy), } \\
\text { (Rd), (rec), } \\
\text { (ski), (thru or } \\
\text { btwn) }\end{array}$ & $\begin{array}{l}\text { Geol for nest } \\
\text { Sandy in prox } \\
\text { or n/a. If } Y \text { : } \\
<20 \mathrm{~m} \text { (near), } \\
>20 \mathrm{~m} \text { (present } \\
\text { ) }\end{array}$ & $\begin{array}{l}\text { Size of } \\
\text { wetland } \\
\text { Distance } \\
\text { (m) }\end{array}$ & $\begin{array}{l}\text { Wetland Veg Type: } \\
\text { shrub (sh), sedge } \\
\text { tussocks (vm), } \\
\text { continuous gram } \\
\text { (cgram), dead trees } \\
\text { (dtre), live (ltre), } \\
\text { emergent (em or } \\
\text { gramem) Floating } \\
\text { aquatic (fla) }\end{array}$ \\
\hline & & & & & \\
\hline
\end{tabular}

\begin{tabular}{|l|l|}
\hline $\begin{array}{l}\text { \% veg cover in order of type: } \\
10 \% \mathrm{x}\end{array}$ & Sketch of wetland and comments \\
\hline & \\
& \\
\hline
\end{tabular}




\section{Appendix 2 Field Survey Records}

Example field survey records from wetlands evaluated in qualitative accuracy assessment (Section 3.5.3). Wetland Vegetation is in 10\% increments.

Abbreviations for wetland vegetation: fla=floating acquatic; cgram=continuous grasses with roots; gramem=emergent grasses; $\mathrm{dtr}=$ dead tree; $\mathrm{ltr}=$ live tree; vm=sedge tusscok (bank, dispersed, clustered); sh=shrubs

\begin{tabular}{|c|c|c|c|}
\hline $\begin{array}{l}\text { Wetland } \\
\text { ID }\end{array}$ & $\begin{array}{l}\text { Wetland Vegetation } \\
\text { Type and Percent } \\
\text { Cover }\end{array}$ & Comments & Logs \\
\hline 211 & $\begin{array}{l}\text { fla }(<5) \text {, gramem }(<5) \text {, } \\
\operatorname{sh}(<5)\end{array}$ & $\begin{array}{l}\text { lots of open water, like pond or } \\
\text { small lake. Good for overwintering }\end{array}$ & $\mathrm{sm}<5$ \\
\hline 230 & $\begin{array}{l}\text { gramem }(50), \text { afl }(10), \\
\operatorname{dtr}(<5)\end{array}$ & large pond with dtr & $\begin{array}{l}\text { abundant } \\
(10+)\end{array}$ \\
\hline 257 & $\begin{array}{l}\text { dtr }(300+), \text { vm }(10), \\
\text { gramem }(<5), \text { cgram } \\
(10)\end{array}$ & $\begin{array}{l}\text { pond with dtr, em, vm. Beaver } \\
\text { huts. }\end{array}$ & $\begin{array}{l}\text { very } \\
\text { abundant } \\
(10+)\end{array}$ \\
\hline 403 & $\begin{array}{l}\text { em (70), cgram } \\
(10), \operatorname{dtr}(<5)\end{array}$ & $\begin{array}{l}\text { long/narrow. Lots of wetland } \\
\text { vegetation. Some dead standing } \\
\text { trees, floating logs, no mounds or } \\
\text { shrubs. }\end{array}$ & \begin{tabular}{|l} 
very \\
abundant $+>$ \\
10 \\
\end{tabular} \\
\hline 423 & $\begin{array}{l}\operatorname{vm}(10), \operatorname{sh}(<5), \\
\text { dtr(20), afl }(<5), \\
\text { cgram }(20)\end{array}$ & $\begin{array}{l}\text { very open pond. }+60 \text { dead trees, } \\
+20 \text { fallen trees, few beaver dams }\end{array}$ & $\mathrm{sm}<5$ \\
\hline 478 & $\begin{array}{l}\text { sh(10), emgram }(10), \\
\text { fla(10), } \operatorname{ltr}(10), \text { dtr } \\
(<5), \text { cgram }(30)\end{array}$ & $\begin{array}{l}100+\text { ltr and dtr. Deep enough for } \\
\text { overwintering }\end{array}$ & $\mathrm{sm}<5$ \\
\hline 488 & $\begin{array}{l}\text { dispersed vm }(<5)+ \\
\text { clustered vm }(<5), \\
\text { gramem }(<5), \mathrm{dtr} \\
(100+;<5)\end{array}$ & $60+$ logs. Pond/swamp. & $\begin{array}{l}\text { very } \\
\text { Abundant } \\
>10 \\
\end{array}$ \\
\hline 531 & gram em (30), dtr $(<5)$ & more like wet meadow. & $\mathrm{sm}<5$ \\
\hline 565 & $\begin{array}{l}\text { gram em }(<5), \\
\text { clustered vm }(10)+ \\
\text { scattered vm }(<5), \mathrm{dtr} \\
(200+; 10) \\
\end{array}$ & good for spring with dtr and logs. & $\begin{array}{l}\text { very ab } \\
(10++)\end{array}$ \\
\hline 590 & $\begin{array}{l}\text { cgram }(60), \operatorname{sh}(<5), \\
\text { dtr }(<5), \text { fla }(<5), \\
\text { graem }(<5)\end{array}$ & $\begin{array}{l}\text { creek/marsh. Windy creek with veg } \\
\text { on sides }\end{array}$ & med $(5-10)$ \\
\hline
\end{tabular}

